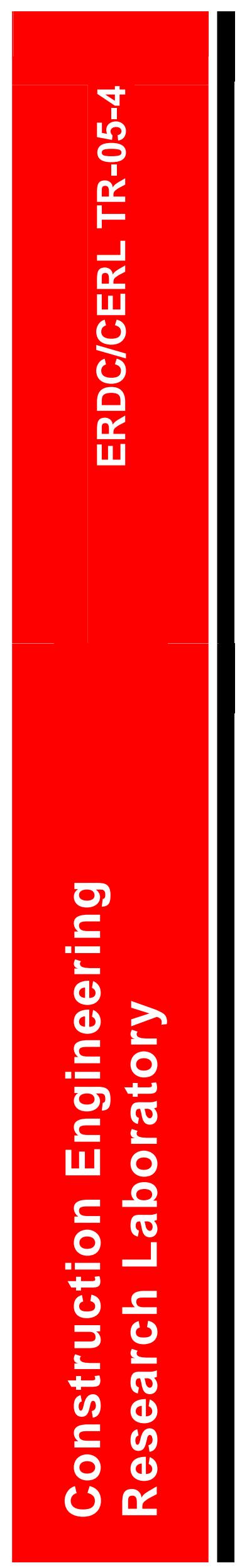

Ecological Risk Assessment of the Effects of Military Fog Oil Obscurant Smoke on the Red-cockaded Woodpecker

Thomas Smith, Matthew G. Hohmann, and Robert H. Melton January 2005 



\section{Ecological Risk Assessment of the Effects of Military Fog Oil Obscurant Smoke on the Red- cockaded Woodpecker}

Thomas Smith, Matthew G. Hohmann, and Robert H. Melton

Construction Engineering Research Laboratory

PO Box 9005

Champaign, IL 61826-9005

Final Report

Approved for public release; distribution is unlimited.

Prepared for Strategic Environmental Research and Development Program Arlington, VA 2220-1821 
ABSTRACT: To satisfy its mission of wartime readiness, the U.S. Army relies on extensive troop training at military installations. These installations must comply with the mandates of Congressional directives and other regulations, including the Endangered Species Act (16 USC 1531-1544). Because the military is required to protect State and Federally listed threatened and endangered species on its lands, the Army and other military services must evaluate any activities that are potentially harmful to threatened and endangered species and their habitats. Toward that end, the Army has initiated studies to evaluate any potential impacts and effects of certain military-specific soldier training actions and activities on threatened and endangered species. Considerable study and management effort have been devoted to the redcockaded woodpecker (Picoides borealis), in part because of its relatively widespread occurrence on installations. This report provides an assessment of the ecological risks that fog oil obscurant smoke training may pose to individual redcockaded woodpeckers, red-cockaded woodpecker populations, and red-cockaded woodpecker habitat. The risks from military fog oil obscurants do not appear to be significant in field use.

DISCLAIMER: The contents of this report are not to be used for advertising, publication, or promotional purposes.

Citation of trade names does not constitute an official endorsement or approval of the use of such commercial products.

All product names and trademarks cited are the property of their respective owners. The findings of this report are not to be construed as an official Department of the Army position unless so designated by other authorized documents.

DESTROY THIS REPORT WHEN IT IS NO LONGER NEEDED. DO NOT RETURN IT TO THE ORIGINATOR. 


\section{Contents}

List of Figures and Tables ................................................................................................. v

Conversion Factors ......................................................................................................... vi

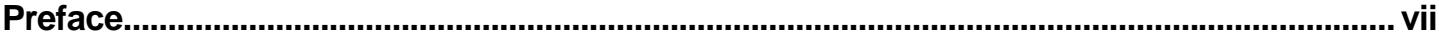

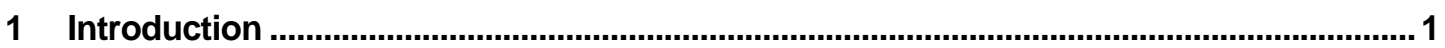







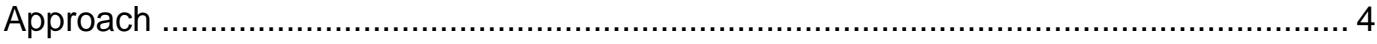

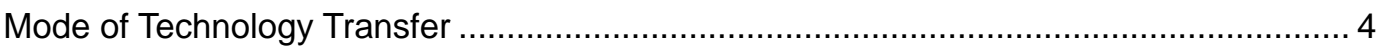



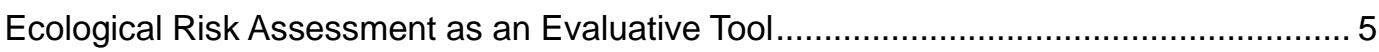

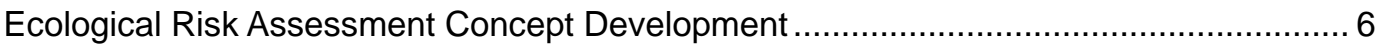

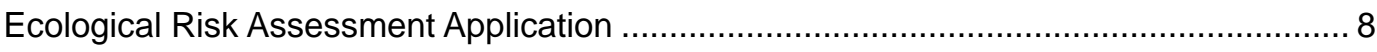

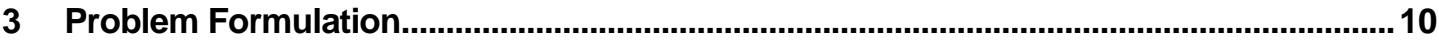



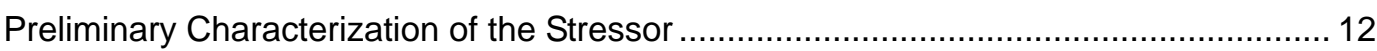





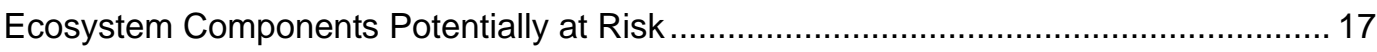



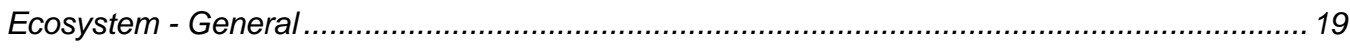

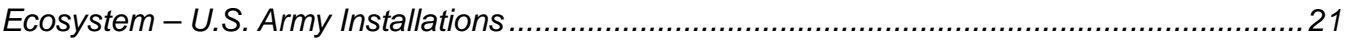



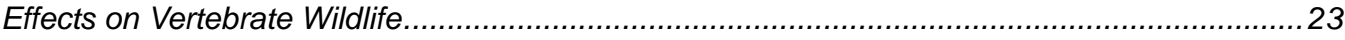

Effects of Fog Oil Smoke on Avian Species.......................................................... 24

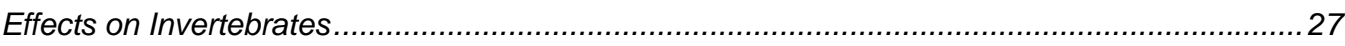

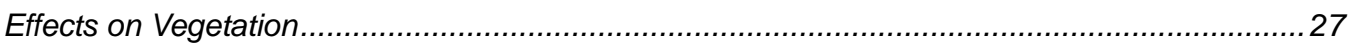

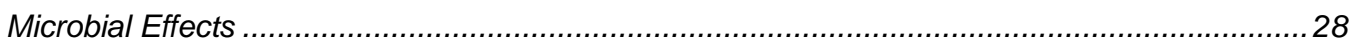

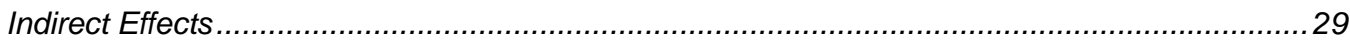

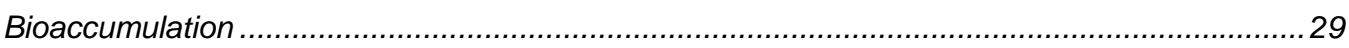

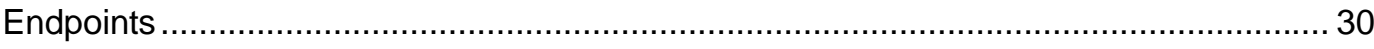

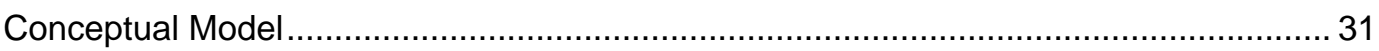




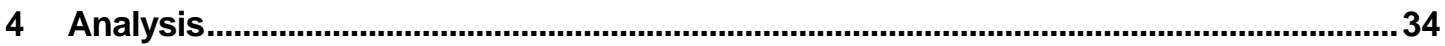



Exposure Characterization ......................................................................... 34

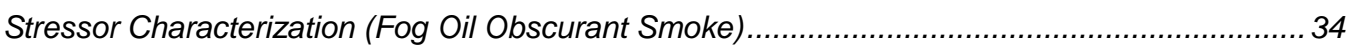

Fog Oil Smoke Environmental Concentrations ................................................................. 36

Deposition of Fog Oil Obscurant Smoke in the Environment.................................................. 37

Depuration of Fog Oil Obscurant Smoke Residues........................................................ 38

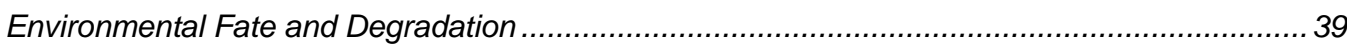

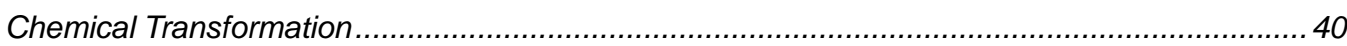



Reproduction: Cooperative Behavior/Nesting Cavities .................................................... 40

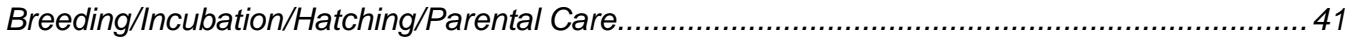

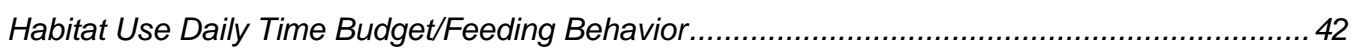

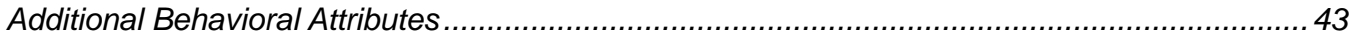



Role of the Ecosystem in Affecting Stressor Fate and Distribution .......................................... 44

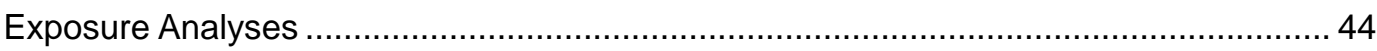

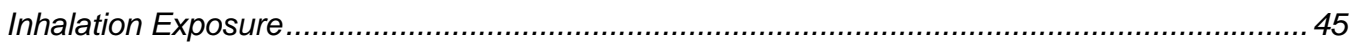

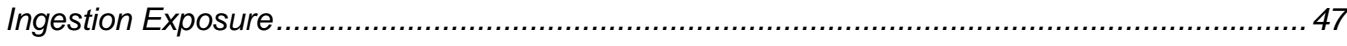

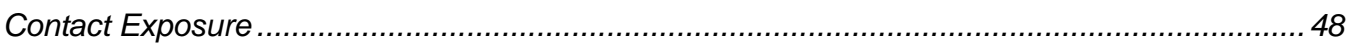

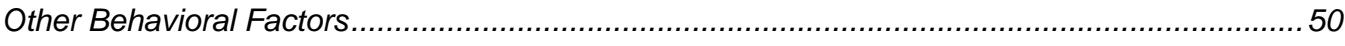

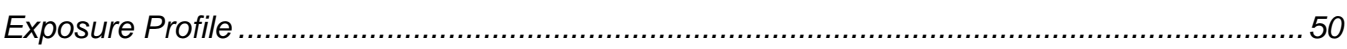

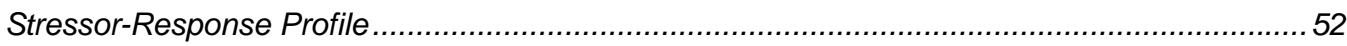



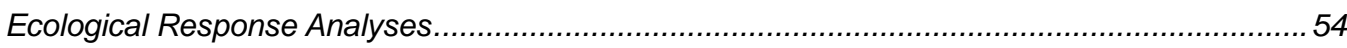

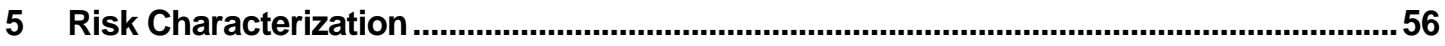

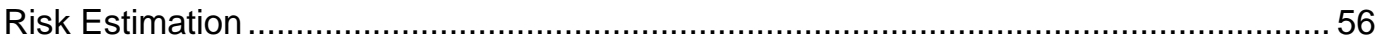



Integration of Exposure and Ecological Characterizations and Exposure-Stressor

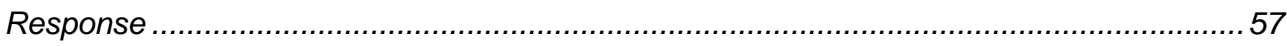

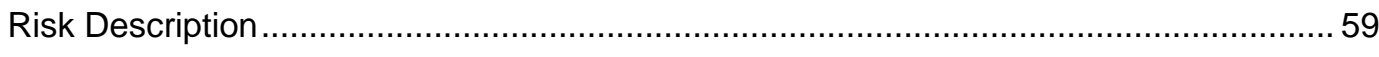

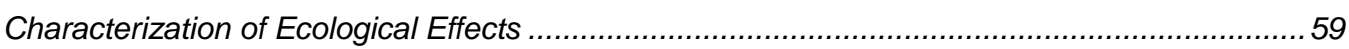

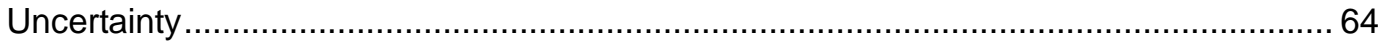



Red-cockaded Woodpecker and Fog Oil Obscurant Smoke Interaction Uncertainty.................. 65



6 Summary



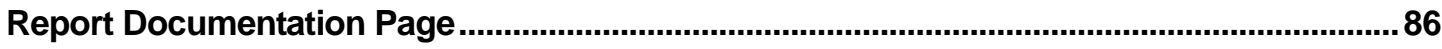




\section{List of Figures and Tables}

\section{Figures}

1. Framework for ecological risk assessment (modified from USEPA 1992). ................. 2

2. Components of screening and baseline ecological risk assessment (ERA)



3. Red-cockaded woodpecker range based on county occurrences (adapted from

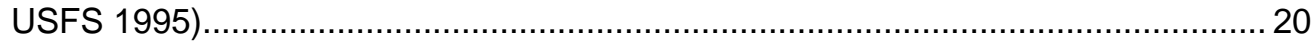

4. Hypothetical higher-level conceptual model for release of military obscurant smokes (from Suter et al. 2001).

5. Hypothetical lower-level conceptual model for release of military obscurant smokes.

6. Annual cycle of breeding and molt for the red-cockaded woodpecker.

\section{Tables}

1. Number of active red-cockaded woodpecker clusters on Army properties.

2. Physical and chemical properties of fog oil (derived from NRC 1997, MILSPEC 1998).

3. Fog oil composition before and after generation (from Driver et al. 2002b).

4. Estimates of fog oil concentrations resulting from typical smoke screening operations at given distances from the source (from Getz et al. 1996).

5. Estimated airborne concentrations of polycyclic aromatic hydrocarbons in fog oil aerosols (from Driver et al. 2002a).

6. Sources of habitat information for the red-cockaded woodpecker.

7. Summary of toxicological and other effects of exposure to fog oil obscurant smoke in red-cockaded woodpecker surrogates.

8. Fog oil smoke aerosol exposure profile.

9. Response levels of red-cockaded woodpeckers and red-cockaded woodpecker surrogates to exposure to fog oil or fog oil smoke aerosol. ....

10. Calculated lowest adverse effect levels of fog oil smoke aerosol on the redcockaded woodpecker (derived from Table 9).

11. Hatching and fledging success of House Sparrow clutches exposed to fog oil aerosols (from Driver et al. 2002b).

12. Summary of weight of evidence analysis for exposure of red-cockaded woodpeckers and their habitat to military fog oil smoke obscurant. 


\section{Conversion Factors}

Non-SI* units of measurement used in this report can be converted to SI units as follows:

\begin{tabular}{|c|c|c|}
\hline Multiply & By & To Obtain \\
\hline acres & $4,046.873$ & square meters \\
\hline cubic feet & 0.02831685 & cubic meters \\
\hline cubic inches & 0.00001638706 & cubic meters \\
\hline degrees (angle) & 0.01745329 & radians \\
\hline degrees Fahrenheit & $(5 / 9) \times\left({ }^{\circ} \mathrm{F}-32\right)$ & degrees Celsius \\
\hline degrees Fahrenheit & $(5 / 9) \times\left({ }^{\circ} \mathrm{F}-32\right)+273.15$ & kelvins \\
\hline feet & 0.3048 & meters \\
\hline gallons (U.S. liquid) & 0.003785412 & cubic meters \\
\hline horsepower (550 ft-lb force per second) & 745.6999 & watts \\
\hline inches & 0.0254 & meters \\
\hline kips per square foot & 47.88026 & kilopascals \\
\hline kips per square inch & 6.894757 & megapascals \\
\hline miles (U.S. statute) & 1.609347 & kilometers \\
\hline pounds (force) & 4.448222 & newtons \\
\hline pounds (force) per square inch & 0.006894757 & megapascals \\
\hline pounds (mass) & 0.4535924 & kilograms \\
\hline square feet & 0.09290304 & square meters \\
\hline square miles & $2,589,998$ & square meters \\
\hline tons (force) & $8,896.443$ & newtons \\
\hline tons (2,000 pounds, mass) & 907.1847 & kilograms \\
\hline yards & 0.9144 & meters \\
\hline
\end{tabular}

\footnotetext{
*Système International d'Unités ("International System of Measurement"), commonly known as the "metric system."
} 


\section{Preface}

This study was conducted for the Department of Defense's Strategic Environmental Research and Development Program (SERDP) under project CS-766, "Identification, Assessment, and Mitigation of Impacts of Military Related Chemicals and Pollutants on TES" and project CS-507, "Threatened, Endangered, and Sensitive Resources: Impact of Smokes and Obscurants on TES." Congress established SERDP through Public Law 101-150 on 5 November 1990 (10 USC 2901-2904). SERDP is a joint multi-agency (Department of Defense, Department of Energy, and Environmental Protection Agency) effort to support environmental quality research, development, demonstration, and applications programs. The technical monitor at the beginning of this work was Dr. Femi A. Ayorinde, SERDP Cleanup and Conservation Program Manager, followed by Dr. Robert W. Holst, SERDP Compliance and Conservation Program Manager. The Executive Director of SERDP is Mr. Bradley Smith.

The work was performed by the Ecological Processes Branch (CN-N) of the Installations Division (CN), Construction Engineering Research Laboratory (CERL). The CERL Principal Investigator was Thomas S. Smith (CN-N). Ms. Patricia M. Kirby coordinated preparation of this report. Dr. Harold E. Balbach (CN-N) was the Threatened and Endangered Species Research Project Leader. Steve Hodapp is Chief, CEERD-CN-N, and Dr. John T. Bandy is Chief, CEERD-CN. The associated Technical Director is Dr. William D. Severinghaus CEERD-CV-T. The Director of CERL is Dr. Alan W. Moore.

CERL is an element of the U.S. Army Engineer Research and Development Center (ERDC), U.S. Army Corps of Engineers. The Commander and Executive Director of ERDC is COL James R. Rowan, and the Director of ERDC is Dr. James R. Houston. 



\section{Introduction}

\section{Overview}

To satisfy its mission of wartime readiness, the U.S. Army relies on extensive troop training at military installations throughout the United States and in allied nations. However, it is also important that military installations comply with the mandates of Congressional directives and other regulations, including the Endangered Species Act (16 USC 1531-1544). Because the military is required to protect State and Federally listed threatened and endangered species on its lands, the Army and other military services must evaluate any activities that are potentially harmful to threatened and endangered species and their habitats. Toward that end, the Army has initiated studies to evaluate any potential impacts and effects of certain military-specific soldier training actions and activities on threatened and endangered species. Considerable study and management effort has been devoted to the red-cockaded woodpecker (Picoides borealis), in part because of its relatively widespread occurrence on important Army and other military installations, Previous investigations have addressed military noise (e.g., weapons systems, Delaney et al. 2002) and large-scale military maneuver activities (Hayden et al. 2002) on that species. This report (and the pertinent and related studies referenced herein) addresses the impact and effects of training and testing use of military fog oil obscurant smoke on the red-cockaded woodpecker and its habitat. More specifically, following the U. S. Environmental Protection Agency (USEPA) framework and the subsequently derived Military Ecological Risk Assessment Framework (MERAF), this report provides an assessment of the ecological risks that fog oil obscurant smoke training may have upon the health of individual red-cockaded woodpeckers, the stability of red-cockaded woodpecker populations, and on red-cockaded woodpecker habitat.

\section{Ecological Risk Assessment Background}

Ecological risk assessment is not a product. Rather, it is a process for estimating the likelihood of adverse ecological effects resulting from exposure to environmental stressors. An ecological risk assessment process may provide a practical method of identifying and communicating risks about potentially harmful agents or activities to threatened and endangered and other species at risk. To ensure comparable and 
effective communication of ecological risks, the U.S. Environmental Protection Agency (USEPA) has developed a framework for conducting ecological risk assessments (USEPA 1998, 63 FR 26845-26924). Among other things, this framework proposes the use of consistent methodology and terminology in risk assessment. Application of the USEPA framework may also focus efforts and help to establish goals, characterize exposure and effects, and provide an accurate representation of the risk based on available information. In the USEPA framework, and other subsequently derived ecological risk assessment guides (e.g., Suter et al. 2001), the three primary phases in developing an ecological risk assessment include: (1) problem formulation, (2) analysis, including exposure and effects assessment, and (3) risk characterization (Figure 1). During problem formulation, risk assessors identify the problem, set the goal and select the endpoint, and consider and formulate assessment approaches. In the analysis phase, risk assessors evaluate the exposure of the environmental or ecological subject to the stimulus or stressor and the relationships between the subject and stressor. In the characterization phase, risk assessors estimate risk to the ecological subject through integration of relevant information and evidence of the effects of the stressor on the subject.

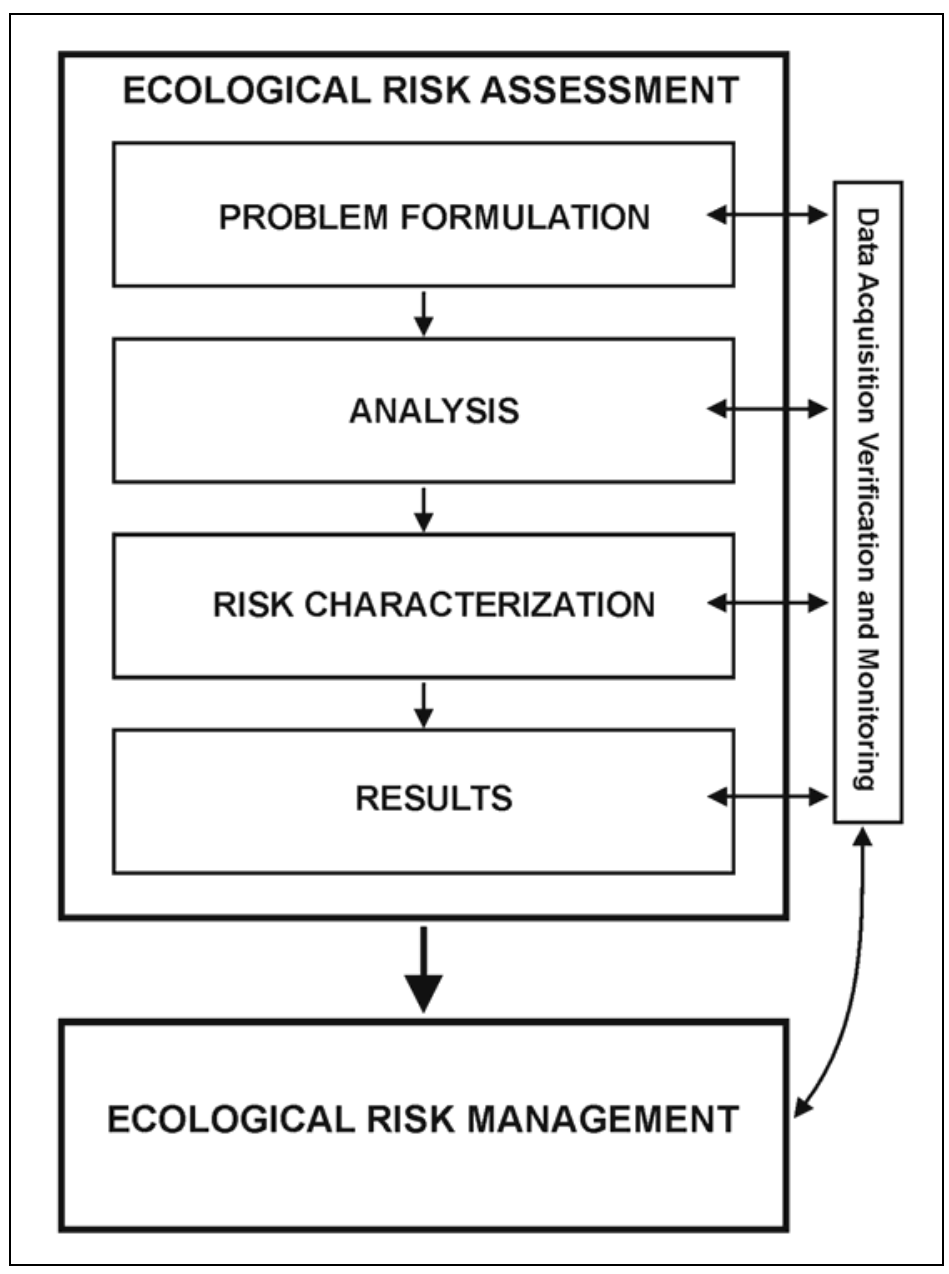

Figure 1. Framework for ecological risk assessment (modified from USEPA 1992). 
More recently the Department of Defense (DoD) has pursued development, based in part on refinement of the USEPA ecological risk assessment guidelines, of a framework or guide for ecological risk assessment on military lands and related ecosystems. This Military Ecological Risk Assessment Framework (MERAF), while integrating the USEPA guidelines, is intended to make ecological risk assessment of increased utility to military natural resources managers, biologists, and training and testing personnel. Additionally, this framework can be adapted to a site or location as well as to broader programmatic approaches (i.e., same or similar activity at multiple locations). Although ecological risk assessment processes may prove to be valuable tools for risk assessment and risk management related to wildlife and fisheries resources, they have not been widely adopted or used by the Army or other agencies with threatened and endangered species management responsibilities.

\section{Objective}

The purpose of the ecological risk assessment presented here is to help predict the likelihood of adverse effects of the use of fog oil smoke obscurant in military training and testing applications and protocols with respect to the endangered red-cockaded woodpecker. This ecological risk assessment examines the potential impacts of fog oil obscurant smoke on the red-cockaded woodpecker. More specifically, the assessment focuses on the potential toxicity of fog oil obscurant smoke on the red-cockaded woodpecker and its habitat. In that sense, this ecological risk assessment focuses primarily on potential direct effects. However, in some instances it is difficult to separate direct effects from indirect effects, in part because of the potentially large number of incompletely understood ecological interactions. This report also integrates indirect effect as appropriate.

It is intended that this ecological risk assessment also serve as a model and stimulus for potential application of this and other risk assessment methodologies and processes on military lands, and that it will stimulate a broader consideration and use of effective approaches to risk analysis involving land use and other actions on biological systems and individual species. Concurrently, and more importantly, it is intended that this risk assessment help provide a basis for risk managers, and other inter- and intra-agency personnel with a responsibility and interest in red-cockaded woodpecker management and recovery, to make informed decisions regarding the use and implementation of military smoke and obscurant during training and testing and other programs. 


\section{Approach}

In developing this ecological risk assessment, the research team gave substantial consideration to previously developed USEPA and MERAF approaches and frameworks. Using the foundation of those works, problem formulation was approached from the standpoint of what is known and understood, from published and unpublished literature or otherwise, about red-cockaded woodpecker biology and ecology as well as the physical, chemical, biological, geographic, and other parameters of fog oil and fog oil obscurant smoke utilization. Based on that information and the research team's interpretation of it, potential effects of military fog oil obscurant use on the species were analyzed, and potential ecological risks were characterized.

\section{Mode of Technology Transfer}

The information in this document will be made available to environmental researchers through the Strategic Environmental Research and Development Program (SERDP) office. Additionally, this report will be made accessible through the World Wide Web (WWW) at URL: http://www.cecer.army.mil 


\section{Supplemental Information}

\section{Ecological Risk Assessment as an Evaluative Tool}

Ecological risk assessment ideally "evaluates the likelihood that adverse ecological effects may occur or are occurring as a result of exposure to one or more stressors" (USEPA 1992). Ecological risk assessment provides a technique that uses available toxicological and ecological data and information to estimate the probability that an adverse ecological effect will occur. Thus, an ecological risk assessment process is a tool or methodology that can help evaluate the likelihood that an activity resulting in the release or exposure of an environmental stressor (e.g., military training employing fog oil smoke obscurant) will result in negative effects on a designated ecological component or receptor (e.g., red-cockaded woodpecker). It is implicit that risk does not exist unless the stressor has an inherent ability to cause negative effects and the stressor comes into contact with or is otherwise exposed to the designated ecological component or receptor. This contact or exposure must be of sufficient time and/or intensity to cause or result in an identifiable adverse effect. Although it has been clear that the stressor could come into contact with the redcockaded woodpecker and its habitat, the effects of fog oil obscurant smoke on the species were unknown prior to recent Army-sponsored research that focused on this topic.

In its traditional application, an ecological risk assessment process can provide risk managers with an approach for organizing and structuring scientific information when selecting a course of action. Although extremely valuable, this scientific information does not stand alone and needs to be considered in conjunction with other factors (e.g., legal, social, political, economic, etc.; USEPA 1998). Ecological risk assessment can provide a valuable support element for ecological and/or "environmental" decisionmaking. Similar to the environmental impact assessment process as called for under the National Environmental Policy Act (NEPA) and supporting agency-specific regulations (e.g., Environmental Effects of Army Actions, Army Regulation 200-2; U.S. Army 1988), the MERAF template (Suter et al. 2001) allows for tiering of ecological risk assessments when appropriate. In that sense it is explicit that this ecological risk assessment, with additional investigation and refinement as necessary, can serve as input into future and next tier ecological risk assessments (Figure 2). 


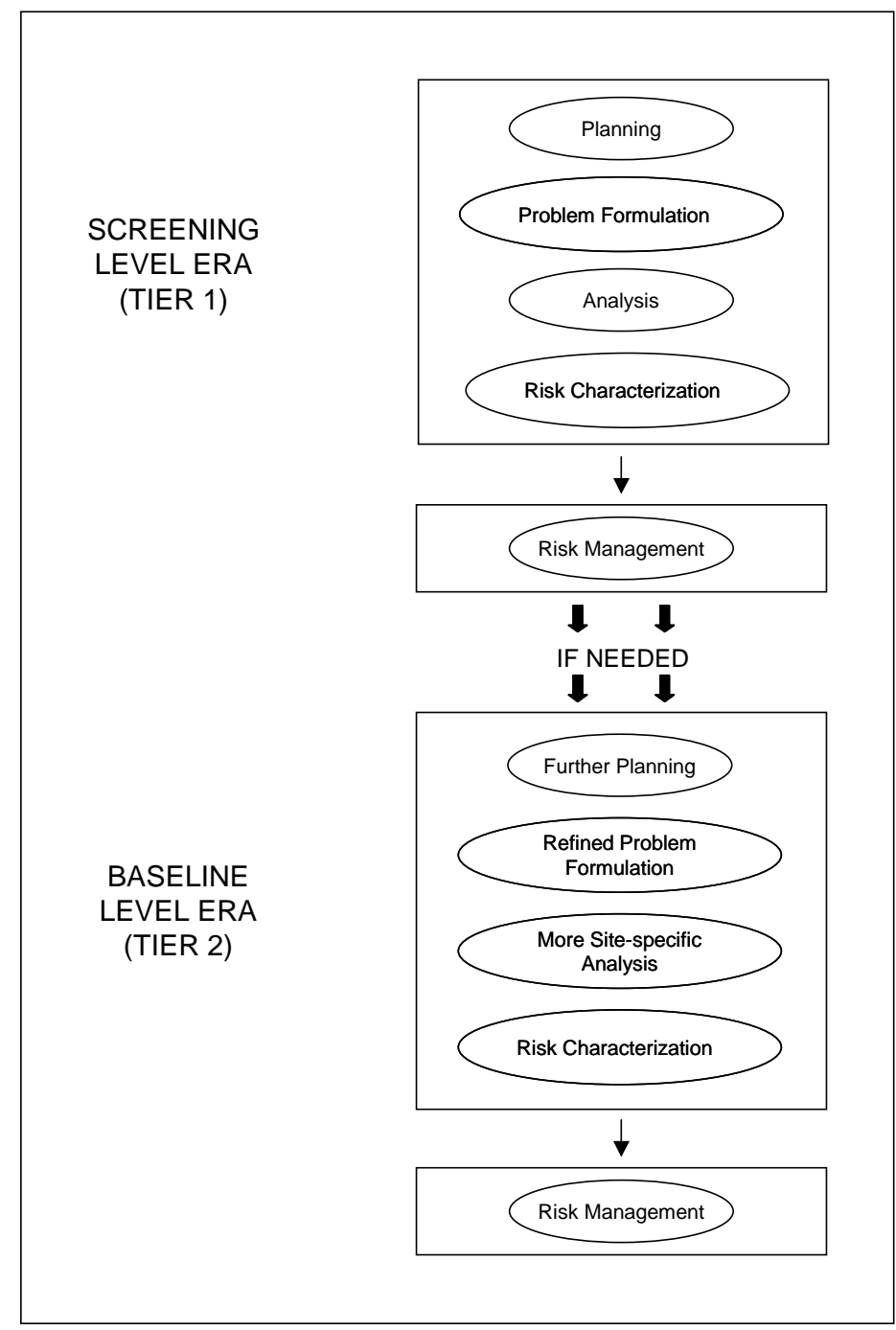

Figure 2. Components of screening and baseline ecological risk assessment (ERA) process (from Simini et al. 2000).

\section{Ecological Risk Assessment Concept Development}

The concept of ecological risk assessment has evolved relatively recently; indeed, the field of ecological risk assessment is in its early development (Calabrese and Baldwin 1993). Nevertheless, ecological risk assessment is slowly emerging as a discipline that is responding to the need for ecologically and toxicologically defensible schemes to evaluate the effects of ecological contaminants (Calabrese and Baldwin 1993, USEPA 1998, Suter et al. 2001).

In simplest terms, an ecological assessment problem can be approached simply as a comparison of alternatives. NEPA, the most comprehensive and far-reaching of national environmental laws, can be characterized as a Federal environmental fulldisclosure law (Anderson and Daniels 1973) that requires identification and consid- 
eration of alternatives, but makes no reference to risk or risk assessment per se. The need for ecological risk assessment approaches appears to have been stimulated by language in other legislation, such as the Federal Insecticide, Fungicide, and Rodenticide Act (7 USC 136-136y) and the Toxic Substances Control Act (15 USC 26012654) that speak of protection from "unreasonable risks."

Somewhat more recently, the Comprehensive Environmental Response, Compensation and Liability Act (CERCLA; 42 USC 9601-9675), as amended by the Superfund Amendments and Reauthorization Act of 1986, refers to the protection of health and the parts of the environment as a whole. In applying and implementing CERCLA, environmental pollution or contaminants at specific sites or locations as well as human health and ecological risks are critically evaluated (USEPA 1997a, 1999). Thus, ecological risk assessments have typically been most often applied to "cleanup" investigations and strategies at chemically contaminated sites where multiple jurisdictions and entities (e.g., Federal, State, industry) are involved. At other similar sites (e.g., DoD hazardous waste sites) ecological risk assessment approaches are becoming more widely utilized (Wentsel et al. 1994, LaPoint et al. 1995, Simini et al. 2000).

The Endangered Species Act prohibits the taking of threatened or endangered species, to include harassing, harming, or killing (16 USC 1532). The Endangered Species Act also states that it is to be the policy of Congress that all Federal departments and agencies shall seek to conserve endangered species and threatened species and shall use their authorities in furtherance of the purpose of the Act (16 USC 1531c). Thus, there is both a prohibition against harming individual members of threatened or endangered species and an affirmative obligation to conserve those species, including the preclusion of toxic environmental effects. While there is no specific requirement in the Endangered Species Act for ecological or other risk assessment for threatened and endangered species, the Act is a Federal "applicable or relevant and appropriate requirement" (42 USC 9605) with which CERCLA remedial actions must comply. ${ }^{*}$ It follows then that in concept at least, ecological risk assessments conducted to support and help satisfy CERCLA or "CERCLA like" requirements or actions, could be used to support more direct Endangered Species Act

\footnotetext{
* The Migratory Bird Treaty Act (16 USC 703 et seq.) is also a Federal "applicable or relevant and appropriate requirement" with which CERCLA remedial actions must comply.
} 
requirement actions such as listing-delisting, critical habitat designation, ${ }^{*}$ consultation, permit, management, and recovery for threatened or endangered species. Applying ecological risk assessment methodologies to threatened and endangered species not impacted by designated CERCLA or comparable sites appears to be practical and of developing interest. With continued thought and refinement, the utility and application of ecological risk assessment processes to range-wide or programmatic threatened and endangered species issues may prove beneficial.

The concept and application, at least to the extent outlined in the USEPA framework (USEPA 1998) and with limited exception, of ecological risk assessment has not typically been extended to programmatic activities (the use of military fog oil obscurant), widespread or large geographic area (military red-cockaded woodpecker range), continuing forward into time (release at regularly occurring training events), or single species (red-cockaded woodpecker). With the development of MERAF and this assessment, applying ecological risk assessment approaches to natural resources issues may gain impetus and acceptance and provide additional support for informed decisionmaking.

\section{Ecological Risk Assessment Application}

One of the difficulties with applying and using ecological risk assessment for wildlife can be the uncertainty in the quantitative assessment of abundance and production as well as mortality and other abundance-related factors (Ralph and Scott 1981, Verner 1985, Efroymson and Suter 2001). Other difficulties may include the transient nature of some wildlife species, difficulties and uncertainty in quantifying exposure, difficulties and uncertainty in quantifying effects, and the general interconnected complexities of ecosystems. While guidelines and frameworks for performing ecological risk assessments specific for remediation and clean-up of contaminated sites at Army installations (Wentsel et al. 1994, Simini et al. 2000) and for Army training and testing activities (Sample et al. 1997, Efroymson et al. 2000, Suter et al. 2001) have been proposed, developed, and applied, their overall applicability and acceptance have not been widely recognized for biological or species management purposes (Efroymson et al. 2001, Efroymson and Suter 2001).

\footnotetext{
* The National Contingency Plan (42 USC 9605) prepared under CERCLA, specifies that evaluations shall be performed to assess threats to the environment, especially sensitive habitats and critical habitats of species protected under the Endangered Species Act (emphasis added). Similarly, USEPA regulations for "State and Local Assistance" (40 CFR Part 35, Appendix A to subpart $\mathrm{H}$ ) require that project proposals determine whether there would be significant adverse effects on critical habitat of endangered species.
} 
Nonetheless, it seems intuitive that ecological risk assessment methodologies and approaches can be used to affect and support endangered species conservation and recovery not only on a site- or property-specific basis, but also in addressing impacts and effects of programs or activities on threatened and endangered species.

That being said, the ecological risk assessment provided in this report is intended to help predict the likelihood of future adverse effects due to exposure to a single stressor, that being military fog oil smoke obscurant, on the red-cockaded woodpecker. In that sense this ecological risk assessment is prospective in that it can be used to assist in predicting the likelihood of adverse effects of future exposures. This is in contrast to other ecological risk assessments, which can be considered retrospective in that they can assist in evaluating adverse effects attributable to past exposures.

This ecological risk assessment may contain more explanatory information than assessments in other documents. The primary audience includes Army "risk managers" (e.g., installation natural resources managers, wildlife biologists, and military training managers; military training and doctrine planners; military commanders), U.S. Fish and Wildlife Service risk managers (e.g., ecological services personnel; species recovery team leaders and members, and agency experts; agency decisionmakers), appropriate State wildlife agency risk managers (e.g., State agency wildlife biologists; agency decisionmakers), and others with species or other expertise (e.g., academia and private conservation support groups such as The Nature Conservancy). This ecological risk assessment is intended to aid regulatory decisions and other considerations relating to the red-cockaded woodpecker, in support of both the Endangered Species Act and Army and DoD environmental security and other mission actions and requirements. 


\section{Problem Formulation}

In the problem formulation phase of an ecological risk assessment, preliminary data are identified and reviewed so that an informed evaluation of risk can be made. The steps in this phase can include: (1) summarizing available data on the stressors, ecological effects, and ecosystem at risk, (2) determining assessment and measurement endpoints, and (3) identifying causal pathways in the form of a conceptual model (Barnthouse and Brown 1994, USEPA 1998, Suter et al. 2001).

\section{Background}

The Army and other military services use smokes and other obscurants as an important tactic during training. Large obscurant smoke screens are generated to visually mask the movements of soldiers and mechanized equipment, confuse enemy sensors, reduce exposure to enemy fire, and reduce enemy command and control capabilities (Palmer 1990). Because it is important to simulate the conditions likely to be encountered under live combat situations, the use of smokes and obscurants is an important element of tactical training. Although numerous obscurants have been developed, obscurant "smoke" derived from fog oil currently is the most widely used in training exercises. The term "fog oil smoke," as used in this report, is intended to be a generic description applied to the form of the chemical compound during its exposure to the environment. Although the whitish-colored clouds emitted from the generators have the appearance of and are commonly called "smoke," they are more accurately defined as "fog," as they are composed of small liquid droplets not unlike water droplets in commonly recognized atmospheric fog. The chemical composition of fog oil smoke is similar but not necessarily identical to that of fog oil (Driver et al. 1993, 2002a, 2002b, 2004). While fog oil and its derivatives as used in military training appear to pose only a minimal risk of negative health effects in humans, their impacts and effects on wildlife were largely unidentified (Driver et al. 1993, National Research Council [NRC] 1997), prior to a recent series of Army-sponsored studies (Driver et al. 2002a, 2002b, 2004). Consequently, it is appropriate that the ecological risks associated with the use of fog oil smoke obscurant in Army training be evaluated, specifically as they relate to threatened and endangered species. 
The red-cockaded woodpecker is an endangered species found on or near 16 military bases in the southeastern United States* (U. S. Fish and Wildlife Service [USFWS] 2003). All of the military services have installations with red-cockaded woodpecker populations. However, the bulk of the red-cockaded woodpeckers found on military lands are found on Army installations. Of the nine Army and Army Reserve installations where red-cockaded woodpecker clusters are present (Table 1) most routinely use fog oil obscurant during training exercises (see Hayden 1997a). Sunny Point Military Ocean Terminal, NC, supports the deployment of armed forces by providing terminal facilities and staging areas for forces and materials. No fog oil obscurant smoke exercises are conducted there.

Table 1. Number of active red-cockaded woodpecker clusters on Army properties.

\begin{tabular}{|l|l|l|l|l|}
\hline \multirow{2}{*}{ Property Name $^{\text {A }}$} & \multicolumn{4}{|l|}{ Active Red-cockaded Woodpecker Clusters } \\
\cline { 2 - 5 } & $\mathbf{1 9 9 8}$ & $\mathbf{1 9 9 9}$ & $\mathbf{2 0 0 0}$ & Goal $^{\text {B }}$ \\
\hline Camp Mackall, NC & 9 & 11 & 11 & 11 \\
\hline Fort Benning, GA & 187 & 186 & 219 & 450 \\
\hline Fort Bragg, NC & 309 & 350 & 350 & 436 \\
\hline Fort Gordon, GA & 2 & 3 & 5 & 25 \\
\hline Fort Jackson, SC & 13 & 21 & 24 & 126 \\
\hline Fort Polk, LA & 45 & 44 & 46 & 179 \\
\hline Fort Stewart, GA & 189 & 198 & 212 & 500 \\
\hline $\begin{array}{l}\text { Military Ocean Terminal } \\
\text { Sunny Point, NC }\end{array}$ & 6 & 6 & 9 & 17 \\
\hline $\begin{array}{l}\text { Peason Ridge, LA } \\
\text { Total }\end{array}$ & 25 & 25 & 23 & 120 \\
\hline $\begin{array}{l}\text { A Many of the identified installations have been in existence and involved in training soldiers } \\
\text { for a century or more. }\end{array}$ & $\mathbf{7 8 5}$ & $\mathbf{8 9 9}$ \\
\hline $\begin{array}{l}\text { The goal is based on habitat designated for red-cockaded woodpeckers in site-specific } \\
\text { management plans (derived from USFWS 2003). }\end{array}$ \\
\hline
\end{tabular}

Because the military services are responsible for maintaining and managing existing red-cockaded woodpecker populations on lands under their control, it is important that military activities do not cause any harmful effects to the species. Because of the nature of its mission, the Army conducts the great majority of the military training that uses obscurant smoke. Consequently, it is incumbent on the Army to examine any potential threats to the red-cockaded woodpecker resulting from these training exercises.

\footnotetext{
* This includes Florida Department of Military Affairs Camp Blanding which is used by the Florida National Guard.
} 


\section{Preliminary Characterization of the Stressor}

\section{General}

In ecological risk assessment, any physical, chemical, or biological entity that can induce an adverse response in the species or ecosystem of concern is a stressor (Norton et al. 1993, Suter et al. 1993). Therefore, in a broad sense, any ecological disturbance associated with or resulting from military training exercises is a potential stressor. Stressors may be harmful only during particularly vulnerable periods of a species' life cycle. For example, a chemical stressor may have a significant negative effect only on the young of a species, or during periods of physiological stress. Stressors are typically most detrimental when acting in conjunction with other impinging factors, which may be either natural or anthropogenic. Stressors can also have more than one mode of transmission. For example, fog oil obscurant smoke exposure might occur via inhalation of aerosols or ingestion of residues. The degree to which stressors impact the ecological component(s) of concern depends on the duration, scale, frequency, mode of exposure, intensity, and timing of the stressor (Wentsel et al. 1994, Barnthouse and Brown 1994, Suter et al. 2001). The chemical and physical information available on fog oil and fog oil obscurant smoke is summarized in the following paragraphs.

\section{Fog Oil and Fog Oil Obscurant Smoke}

Fog oil, which is also known as 100 pale oil or Standard Grade Fuel (SGF), is a light-duty lubricating oil equivalent to an SAE 20-grade motor oil (Shinn et al. 1985, Driver et al. 1993). It typically has two standard grades: SGF No. 1 and SGF No. 2. SGF No. 1 has a higher viscosity and is intended for use when the atmospheric temperature is $4.4^{\circ} \mathrm{C}\left(40^{\circ} \mathrm{F}\right)$ or above. SGF-2 is designed for use when the temperature is between $-27^{\circ} \mathrm{C}\left(-15^{\circ} \mathrm{F}\right)$ and $4.4^{\circ} \mathrm{C}\left(40^{\circ} \mathrm{F}\right)$. Below $-27^{\circ} \mathrm{C}$, a mixture of SGF No. 2 and wax-free kerosene may be used. Historically, only SGF No. 2 has been used during military training exercises (Muhly 1983).

Fog oil is produced by hydrogenation of a naphthalenic petroleum stock (the multiple bonds between carbon atoms are saturated by addition of hydrogen), followed by extraction of the aromatic and polycyclic aromatic hydrocarbons (PAHs; Brubaker et al. 1992). The chemical components remaining after this processing mainly include alkanes and aliphatic hydrocarbons (Katz et al. 1980). The number of carbon atoms in the alkane molecules can range from 12 to 40, and may form linear structures (nalkanes), branched structures (isoalkanes), or nonaromatic rings (cyclic alkanes; Brubaker et al. 1992). 
Because fog oil is defined by physical characteristics (Table 2) its exact chemical composition can vary. Much of this variation can be attributed to the fact that crude oils often have different chemical compositions depending on their source (Driver et al. 1993). Prior to Military Specification Amendments Mil-F-12070C, and Mil-F12070D (29 April 1986), manufacturers were not required to remove carcinogens, which, in the context of fog oil, primarily include aromatic hydrocarbons (i.e., PAHs; Brubaker et al. 1992, Driver et al. 1993, 3D/International Inc. [3D/I] 1997). PAHs can be categorized by the number of aromatic (i.e., benzene) rings in their structure as well as their carcinogenicity as demonstrated in laboratory animals (Cura et al. 1999). Examples of 2- and 3-ringed PAHs (those with a low molecular weight) include naphthalene and fluorine, respectively. Examples of 4- and >4-ringed PAHs (those with a high molecular weight) include crysene and benzo(g,h,i)perylene (see Table 3). As a gross generalization, based on studies of laboratory animals, high molecular weight PAHs tend to be more toxic or carcinogenic (Cura et al. 1999). The current Military Specification Amendment (MIL-F-12070E) requires that fog oil "...shall be of overhead petroleum fraction(s) and shall contain no additives" and "shall not demonstrate any toxic effect or carcinogenic or potentially carcinogenic effect" (MILSPEC 1998). Certainly, the highly refined fog oil that is produced and used currently (i.e., types C, D, and E after respective Military Specification Amendments) should not contain detectable quantities of many aromatic hydrocarbons (3D/I 1997). Furthermore, as defined under the Hazard Communication Standard (29 CFR 1910.1200), manufacturers must certify that no carcinogenic or potentially carcinogenic constituents are present.

When liquid fog oil is injected into a heated chamber (i.e., a smoke generator), it vaporizes and is released into the air. Upon contact with the cooler surrounding air, the gas rapidly condenses, forming an aerosol of very small oil droplets between 0.5 and 3.0 micrometers $(\mu \mathrm{m})$ in diameter (Shinn et al. 1985, Driver et al. 1993). The typical aerodynamic size distribution of fog oil aerosols ranges from 0.9 to $1.9 \mu \mathrm{m}$. Particles of this size are estimated to have settling velocities of approximately 0.001 to $0.03 \mathrm{~cm} / \mathrm{s}$ (Driver et al. 1993).

Table 2. Physical and chemical properties of fog oil (derived from NRC 1997, MILSPEC 1998).

\begin{tabular}{|l|l|}
\hline Characteristic & Value \\
\hline Composition: & $\begin{array}{l}\text { Mineral oil; overhead petroleum fractions, no } \\
\text { carcinogenic or potential carcinogenic constituents }\end{array}$ \\
\hline Minimum flash point: & $160^{\circ} \mathrm{C}$ \\
\hline Viscosity, kinematic: & 3.40 to 4.17 at $100^{\circ} \mathrm{C}$ \\
\hline Pour point, ${ }^{\circ} \mathrm{C}$ minimum: & $-40^{\circ} \mathrm{C}$ \\
\hline Boiling point: & 300 to $600^{\circ} \mathrm{C}$ \\
\hline Neutralization number, maximum: & 0.1 \\
\hline Ramsbottom carbon, \% vol. maximum: & 0.2 \\
\hline Water and sediment, \% vol. maximum: & 0.06 \\
\hline
\end{tabular}


During smoke generation, there are apparently few demonstrable changes in the chemistry and, by inference, the toxicity of fog oil, because the process most simply involves a phase transformation (i.e., vaporization; Katz et al. 1980, Poston et al. 1986, Driver et al. 2002a). Known changes in composition include a 97\% decrease in naphthalene concentration and a slight increase in the number and concentration of higher molecular weight PAHs (Table 3). Studies of fog oil smoke samples generally show a shift in molecular weight of the unspeciated hydrocarbons when compared to the parent oil; after release, heavier compounds $\left(\mathrm{C}^{10}\right.$ to $\left.\mathrm{C}^{50}\right)$ increase while lighter hydrocarbons $\left(<\mathrm{C}^{10}\right)$ decrease. These same studies show that generated fog oil smoke contained $>99.2 \%$ parent fog oil, with no aromatic, volatile, or semivolatile organic compounds detected at concentrations larger than $0.8 \%$ (3D/I 1996).

Table 3. Fog oil composition before and after generation (from Driver et al. 2002b).

\begin{tabular}{|c|c|c|}
\hline \multirow[b]{2}{*}{ Constituent } & \multicolumn{2}{|c|}{ Concentration ( $\mu \mathrm{g} / \mathrm{g}$ Fog Oil) } \\
\hline & Before Generation & After Generation $^{A}$ \\
\hline \multicolumn{3}{|c|}{ Lower Molecular Weight PAHs: } \\
\hline Naphthalene & 78.5 & 1.8 \\
\hline 1-methyl naphthalene & 98.3 & $<\mathrm{MDL}^{\mathrm{B}}$ \\
\hline Biphenyl & 22.2 & $<\mathrm{MDL}$ \\
\hline 2,6 dimethyl naphthalene & 110.0 & $<\mathrm{MDL}$ \\
\hline Acenaphthylene & 2.4 & 2.5 \\
\hline Acenaphthene & 3.5 & 3.2 \\
\hline $2,3,5$ trimethyl naphthalene & 70.7 & $<\mathrm{MDL}$ \\
\hline Fluorene & 19.1 & 21.5 \\
\hline Dibenzothiophene & 63.9 & 264.0 \\
\hline Phenanthrene & 40.8 & 162.0 \\
\hline Anthracene & 3.6 & 15.2 \\
\hline 1 methyl phenanthrene & 49.2 & $<\mathrm{MDL}$ \\
\hline Fluoranthene & 2.2 & 27.2 \\
\hline \multicolumn{3}{|c|}{ Higher Molecular Weight PAHs: } \\
\hline Pyrene & 14.7 & 40.2 \\
\hline Benzo(a)anthracene & 1.8 & 14.5 \\
\hline Chrysene & 9.3 & 57.2 \\
\hline Benzo(b)fluoranthene & 2.5 & MDL \\
\hline Benz(k)fluoranthene & $<\mathrm{MDL}$ & $<\mathrm{MDL}$ \\
\hline Benzo(e)pyrene & 2.2 & $<\mathrm{MDL}$ \\
\hline Benzo(a)pyrene & 0.5 & $<\mathrm{MDL}$ \\
\hline Perylene & 1.1 & $<\mathrm{MDL}$ \\
\hline Indeno(123-cd)pyrene & $<\mathrm{MDL}$ & $<\mathrm{MDL}$ \\
\hline Dibenzo(a,h)anthrancene & $<\mathrm{MDL}$ & $<\mathrm{MDL}$ \\
\hline Benzo(g,h,i)perylene & 0.6 & $<\mathrm{MDL}$ \\
\hline \multicolumn{3}{|c|}{$\begin{array}{l}{ }^{A} \text { No PAHs were observed in the generated aerosol during the exposure sampling. Post-generation values from a } \\
\text { previous study (Driver et al. 2002a) in which 2- and 3-hour collections were made are reported. } \\
{ }^{B} \text { Less than the minimum detection limit. }\end{array}$} \\
\hline
\end{tabular}


The concentration of fog oil aerosols and rates of deposition are dynamic and highly dependent on local conditions such as the length of the military training exercise, distance from the source (i.e., generator), wind currents, temperature, humidity, local terrain, and precipitation. Many estimates of airborne and deposition concentrations are available (e.g., Liss-Suter and Villaume 1978, Muhly 1983, Shinn et al. 1985). However, the models of Driver et al. (1993) incorporate the complex atmospheric conditions that affect fog oil smoke dispersion and deposition. Using these models, Getz et al. (1996) have estimated the maximum airborne and deposition concentrations of fog oil expected during training exercises (Table 4). The airborne concentrations of PAHs in fog oil aerosols have been estimated by Driver et al. (2002a; Table 5).

Table 4. Estimates of fog oil concentrations resulting from typical smoke screening operations at given distances from the source (from Getz et al. 1996). ${ }^{A}$

\begin{tabular}{|c|c|c|c|}
\hline Air Concentration $^{\mathrm{B}}$ & Distance (meters) & Average $\left(\mathrm{mg} / \mathrm{m}^{3}\right)$ & Range $\left(\mathrm{mg} / \mathrm{m}^{3}\right)$ \\
\hline & 100 & 64 & $25-102$ \\
\hline & 200 & 56 & $8-105$ \\
\hline & 500 & 46 & $1.3-90$ \\
\hline & 1000 & 13 & $0.8-25$ \\
\hline \multirow[t]{5}{*}{ Aquatic Concentrations $^{c}$} & Distance (meters) & Average $\left(\mathrm{mg} / \mathrm{m}^{3}\right)$ & Range $\left(\mathrm{mg} / \mathrm{m}^{3}\right)$ \\
\hline & 100 & 3080 & $160-6000$ \\
\hline & 200 & 1030 & $960-2000$ \\
\hline & 500 & 243 & $6-480$ \\
\hline & 1000 & 101 & $2.4-200$ \\
\hline Surface Deposition $^{\mathrm{D}}$ & Distance (meters) & Average $\left(\mathrm{mg} / \mathrm{m}^{2}\right)$ & Range(mg/m²) \\
\hline \multirow[t]{4}{*}{ At the end of the smoking period } & 100 & 3080 & $160-6000$ \\
\hline & 200 & 1030 & $960-2000$ \\
\hline & 500 & 243 & $6-480$ \\
\hline & 1000 & 101 & $2.4-200$ \\
\hline \multirow[t]{4}{*}{1 hour after stopping the smoking } & 100 & 2000 & $104-3900$ \\
\hline & 200 & 670 & $40-1300$ \\
\hline & 500 & 158 & $3.9-312$ \\
\hline & 1000 & 66 & $1.6-130$ \\
\hline \multirow[t]{4}{*}{1 week after stopping the smoking } & 100 & 462 & $24-900$ \\
\hline & 200 & 154 & $9-300$ \\
\hline & 500 & 36.5 & $0.9-72$ \\
\hline & 1000 & 15 & $0.4-30$ \\
\hline \multicolumn{4}{|c|}{$\begin{array}{l}\text { The values represent midpoints (average) of the lowest and highest (range) estimated concentrations predicted from models based } \\
\text { on the six sets of environmental conditions in Driver et al. 1993. The models are based on a 2-hour release at a rate of } 80 \text { gal } \\
\text { (302L) per hour. }\end{array}$} \\
\hline \multicolumn{4}{|c|}{$\begin{array}{l}{ }^{\mathrm{C}} \text { Based on the assumption that all the fog oil released deposits on the surface deposits of the water and becomes incorporated in } \\
\text { the water column; pools are assumed to be } 1 \mathrm{~m} \text { deep. Thus surface deposition in } \mathrm{mg} / \mathrm{m}^{2} \text { translates to total concentration in } \mathrm{mg} / \mathrm{m}^{3} \\
\text { However, in reality, oils do not mix with water. The contrary assumption is made to facilitate calculation of theoretical total } \\
\text { concentration. }\end{array}$} \\
\hline
\end{tabular}


Table 5. Estimated airborne concentrations of polycyclic aromatic hydrocarbons in fog oil aerosols (from Driver et al. 2002a).

\begin{tabular}{|l|l|}
\hline Constituent & $\begin{array}{l}\text { Mean Concentration } \\
\left(\boldsymbol{\mu g} / \mathrm{m}^{3}\right)^{\mathbf{A}}\end{array}$ \\
\hline Low Molecular Weight PAHs: & \\
\hline Naphthalene & 0.5 \\
\hline Acenaphthylene & 1.1 \\
\hline Acenaphthene & 1.3 \\
\hline Fluorene & 8.1 \\
\hline Dibenzothiophene & 99.2 \\
\hline Phenanthrene & 60.9 \\
\hline Anthracene & 5.9 \\
\hline Fluoranthene & 10.2 \\
\hline & \\
\hline High Molecular Weight PAHs: & \\
\hline Pyrene & 15.4 \\
\hline Benzo(a)anthracene & 5.6 \\
\hline Chrysene & 21.5 \\
\hline Benzo(g,h,i)perylene & 1.0 \\
\hline $\begin{array}{l}\text { A Airborne concentration of individual constituent at generation of the } \\
\text { 400 mg/m }{ }^{3} \text { aerosols estimated from deposition composition. }\end{array}$ \\
\hline
\end{tabular}

Fog oil smoke clouds vary in size and configuration, depending on the area to be obscured, the wind speed, and fluctuations in wind direction. Fog oil smoke plumes often include areas \pm 45 degrees from the mean vector of the plume (Driver et al. 1993). Aerosol smoke clouds as large as 1500 x 3000 m can result. However, under most conditions smaller clouds are generated. Therefore, a reasonable estimate of the area for a typical release is 1000 by $1000 \mathrm{~m}$ (Getz et al. 1996). The vertical or elevational extent of fog oil smoke clouds is also variable and likewise depends on local meteorological conditions. Fog oil smoke concentrations within the cloud tend to be greatest close to the ground (i.e., $<5 \mathrm{~m}$ ) and decrease rapidly with increasing height.

Local meteorological conditions, site geography, and surface terrain affect fog oil smoke dispersion, making airborne concentrations highly variable (Driver et al. 1993). However, concentrations are almost always highest near the generator and rapidly decline as distance increases (Driver et al. 1993). Exposure to fog oil smoke aerosols is possibly of a shorter duration than is exposure to possible fog oil obscurant smoke residues.

Fog oil smoke is a mist composed of liquid particles (Driver et al 1993). Fog oil droplets can remain airborne for long periods of time, but ultimately evaporate or deposit onto environmental surfaces, such as soils, vegetation, and organisms. 
Deposition rates are determined in part by local meteorological conditions, site geography, and surface morphology. Deposition rates decline with distance from the source (Donald Cropek, Chemist, U.S. Army Engineer Research and Development Center-Construction Engineering Research Laboratory, Professional Communication) and are probably insignificant at distances greater than 20 to $25 \mathrm{~m}$ (Policastro 1989, Liljegren et al. 1988, Liljegren et al. 1989). Due to a lack of fog oil smoke aerosol deposition on both vertical and horizontal surfaces under field release conditions, detection of deposited fog oil smoke can be problematic (Liljegren et al. 1988). Deposition increases as wind speed increases beyond $6 \mathrm{mph}$ ( $10 \mathrm{kph}$ ) (Cataldo et al. 1989). Elevated deposition rates are also likely during temperature inversions and precipitation (Getz et al. 1996).

Fog oil smoke residues evaporate at relatively rapid rates, suggesting little potential for long-term accumulation in the environment. At 0 to $40^{\circ} \mathrm{C}$ approximately $30 \%$ to $40 \%$ of fog oil residues will evaporate within 1 hour; within 1 week, about $80 \%$ to $90 \%$ of the fog oil will evaporate (Driver et al. 1993). Initial evaporation rates decline over time, as the remaining constituents have lower vaporization rates. Once deposited, resuspension and redeposition of fog oil residues is unlikely due to the natural adhesive properties of fog oil. However, there may be some potential for redistribution if deposition occurs on soils prone to wind or water erosion (Driver et al. 1993).

Fog oil smoke residues degrade over time via natural biotic and abiotic mechanisms including chemical, photochemical, photolytic, and microbial action (Poston et al. 1988, Driver et al. 1993). Degradation rates are dependent on local environmental conditions such as temperature, relative humidity, moisture level, and surface texture. Because certain chemical constituents may bioaccumulate in the environment, it is difficult to establish or estimate the period over which fog oil obscurant smoke is biologically available (Driver et al. 1993). The fog oil currently in use meets a specification different from that manufactured prior to 1986. Fog oil of this more recent manufacture should not bioaccumulate, but studies have still not determined the period for which it is biologically available (3D/I 1996).

\section{Ecosystem Components Potentially at Risk}

The second task in the problem formulation stage is identification of the ecological component, ecosystem, or ecosystem properties that are at risk. 


\section{Red-cockaded Woodpecker}

The natural history and ecology of the red-cockaded woodpecker has received considerable attention from wildlife and other endangered species biologists (Thompson 1971, Wood 1983, Jackson 1994, Kulhavy et al. 1995, Conner et al. 2001). In addition, a recovery plan as called for under the Endangered Species Act has been prepared (Jackson et al. 1979, Lennartz and Henry 1985), and is now in its second revision (USFWS 2003). Red-cockaded woodpecker biology has been summarized by Jackson (1994) and others (USFWS 2003).

The red-cockaded woodpecker is a year-round resident bird* endemic to open mature pine forests of the southeastern United States. Loss of habitat, fragmentation of populations, and reduction in population size led to Federal listing of the redcockaded woodpecker as an endangered species in 1970 [35 Federal Register 16047]. In addition to protection of populations, endangered species status also mandates the protection of habitat, and to a degree generally not found in other Federal statutes dealing with wildlife, the protection of individuals. Undoubtedly, maintenance of overall ecosystem function is critical for ensuring the long-term viability of redcockaded woodpecker populations and the integrity of the species' habitat. This will require that key components of the open southern pine ecosystem are preserved and maintained. Consequently, in this assessment we identify components of the ecosystem - soils, vegetation, and fauna hypothesized to be integral for maintenance of red-cockaded woodpecker habitats and populations.

The overriding threat to red-cockaded woodpecker abundance is lack of suitable habitat (USFWS 2003). Table 6 lists some specific habitat factors and related research sources.

Other factors, including those as yet unidentified and others for which the importance has not been determined, may pose a threat to red-cockaded woodpeckers. These threats may include exotic species (e.g., melaleuca, Melaleuca quinquenervia; red imported fire ants, Solenopsis invicta) and environmental contaminants (USFWS 2003). In a broad sense, fog oil obscurant smoke can be considered a potential environmental contaminant.

\footnotetext{
* Although nonmigratory in behavior and a year-round resident in areas of its occurrence, the species is nonetheless considered to be migratory for purposes of the Migratory Bird Treaty Act and is afforded protection in accordance with that authority (see 50 CFR 10.13; Executive Order 13186).
} 
Table 6. Sources of habitat information for the red-cockaded woodpecker.

\begin{tabular}{|c|c|}
\hline Factor & Source \\
\hline Scarcity of open, mature pine woods & $\begin{array}{l}\text { Lennartz et al. 1983a, 1983b, Frost 1993, Simberloff } \\
\text { 1993, Ware et al. } 1993\end{array}$ \\
\hline $\begin{array}{l}\text { Degradation due to hardwood } \\
\text { midstory encroachment }\end{array}$ & Hooper et al. 1980, Conner and Rudolph 1989 \\
\hline $\begin{array}{l}\text { Fire suppression and } \\
\text { silviculture practices }\end{array}$ & $\begin{array}{l}\text { Ligon et al. 1986, 1991, Baker 1995, Cely and Ferral } \\
\text { 1995, Masters et al. 1995, Conner et al. } 2001\end{array}$ \\
\hline Shortage of suitable nesting cavity trees & $\begin{array}{l}\text { Costa and Escano 1989, James 1995, Hardesty et } \\
\text { al. 1995, Conner } 1995\end{array}$ \\
\hline Loss and fragmentation of habitat & Conner and Rudolph 1991 \\
\hline Scarcity of adequate foraging habitat & $\begin{array}{l}\text { Conner and Rudolph 1991, Walters et al. 2000a, } \\
2000 \text { b, James et al. } 2001\end{array}$ \\
\hline $\begin{array}{l}\text { Demographic isolation and risks inherent } \\
\text { with small populations }\end{array}$ & $\begin{array}{l}\text { Schaffer 1981, 1987, Walters et al. 1988a, Walters } \\
\text { 1991, Connor and Rudolph 1991, Hooper and } \\
\text { Lennartz } 1995\end{array}$ \\
\hline
\end{tabular}

\section{Ecosystem - General}

The current range of the red-cockaded woodpecker is discontinuous and fragmented, with localized populations occurring in the few remaining stands of extensive, mature (i.e., 80 to 100 years old) pine forest (Lennartz et al. 1983a; Figure 3). Historically, the forest type most commonly inhabited by the red-cockaded woodpecker was longleaf pine (Pinus palustris; Conner et al. 2001), but within its geographic range the red-cockaded woodpecker also utilizes other pine species including loblolly $(P$. serotina), shortleaf (P. echinata), slash ( $P$. elliottii), and Virginia pines ( $P$. virginiana; Hovis and Labisky 1985, Jackson 1994). Longleaf forests once ranged over much of the southeastern United States (Ware et al. 1993) and may have covered over 59 million acres before European settlement (Hanula et al. 2000a). Due in large part to widespread timber harvesting and replacement by slash and loblolly pine monocultures, these forests are now reduced to comparatively small and isolated parcels totaling perhaps 3 million acres (Outcalt and Sheffield 1996). It is estimated that only $2 \%$ to $3 \%$ of the original longleaf forests now remain (Frost 1993, Ware et al. 1993). Current slash and loblolly pine plantations are typically comprised solely of even-aged trees and the most popular management regime calls for short rotation times (e.g., less than 30 years; Means and Grow 1985, Hermann 1993). 




Figure 3. Red-cockaded woodpecker range based on county occurrences (adapted from USFS 1995).

The longleaf pine forest of the southeastern United States is a pyroclimax community - part of an ecosystem maintained by regular fire events (Platt et al. 1988a, 1988b). Under the natural fire regime, frequent (i.e., every 3 to 5 years) spring and early-summer fires prevent most tree species, except longleaf, from becoming established (Robbins and Myers 1992). Longleaf trees are widely spaced, creating a sparse canopy that permits development of diverse shrub and graminaceous (grass) groundcover layers (Platt et al. 1988a, 1988b). But when fires are suppressed, hardwood species (e.g., sweet gum, Liquidambar styraciflua and oaks Quercus spp.) quickly form a dense midstory and shade out native groundcover species. Although fire suppression on public and private lands has degraded much of the red-cockaded woodpecker habitat, periodic fires resulting from military training activities have contributed to the maintenance of large areas of suitable red-cockaded woodpecker habitat on military lands. Military installations also generally conduct extensive forest management, including tree thinning and prescribed burning specifically to promote suitable red-cockaded woodpecker habitat (Hayden 1997b). Because of the combination of fortuitous fire events and management efforts, the resulting redcockaded woodpecker habitat and populations on military lands play an increasingly important role in the recovery of the species (USFWS 2003).

As cavity availability has been shown to limit population abundance, loss of nesting cavities to kleptoparasites is also likely to impact population size (Conner 1995). Both avian (e.g., red-bellied woodpecker, Melanerpes carolinus; eastern bluebird 
Sialia sialis; northern flicker, Colaptes auratus; red-headed woodpecker, Melanerpes erythrocephalus; great crested flycatcher, Myiarchus crinitus) and mammalian species (e.g., southern flying squirrel, Glaucomys volans) are known to usurp redcockaded woodpecker cavities (Harlow and Lennartz 1983). Kleptoparasitism often leads to reproductive failure for the breeding season. Therefore, any changes in the abundance of kleptoparasitic species may indirectly influence the red-cockaded woodpecker.

A variety of reptilian, avian, and mammalian predators are known to prey on the red-cockaded woodpecker (Martin and Boyce 1993). Corn snakes (Elaphe gutatta) and rat snakes (Elaphe obsolete) prey on nestlings, eggs, and possibly adults. Avian predators include the eastern screech owl (Otus asio) and American kestrel (Falco sparverius). Southern flying squirrels may eat eggs and small nestlings (Jackson 1994). However, the mechanisms that limit red-cockaded woodpecker populations are not dominantly related to predation, but instead are associated with resource (i.e., habitat) availability (James et al. 1997, USFWS 2003).

\section{Ecosystem - U.S. Army Installations}

The natural history and ecology of the red-cockaded woodpecker on Army and other military installations does not materially differ from that at other sites within its range (Conner et al. 2001, USFWS 2003). Physiographic and habitat features relative to the red-cockaded woodpecker on Army installations with important redcockaded woodpecker populations (Table 1, page 11) have been described by Hayden (1997a). The ecological characteristics of established red-cockaded woodpecker recovery units (USFWS 2003), as part landscape-scale ecoregions, have been described by Austin (1965) and Bailey (1995, 1998).

Fort Benning, GA; Fort Bragg, NC; and Fort Stewart, GA; all of which have primary core populations ${ }^{*}$ of red-cockaded woodpeckers, have forest lands dominated by pine and mixed pine-hardwoods, as does Camp Mackall, NC. Fort Polk, LA, which also contains part of a primary core population of red-cockaded woodpeckers, has an upland vegetation component composed primarily of and dominated by pine. Other

\footnotetext{
* A primary core population, as identified in the recovery criteria, contains at least 350 potential breeding groups at the time of and after delisting. Populations are defined by biological boundaries (USFWS 2003). A group is considered the social unit in red-cockaded woodpeckers and consists of a breeding pair with one or more helpers, a breeding pair without helpers, or a solitary male (USFWS 2003).
} 
Army installations with smaller, but nonetheless significant, support populations* of red-cockaded woodpeckers, including Fort Gordon, GA; Fort Jackson, SC; and Military Ocean Terminal, Sunny Point, NC, have forest vegetation communities composed primarily of pine and pine-hardwood complexes. The vegetation communities found on Army and other military installations with red-cockaded woodpecker populations are representative of the region. Concurrently, Army lands contain some of the best remaining red-cockaded woodpecker habitat, in part because of past land and resource stewardship actions.

\section{Ecological Effects}

In an ecological risk assessment, the available information on the stressor(s) and the ecological component(s) of concern is examined to determine any potential direct and/or indirect effects. For example, a species may experience negative health effects after being exposed to a chemical via prey consumption. Alternately, a species may suffer declines in food availability if the chemical affects important prey species (Barnthouse and Brown 1994).

Maintenance of viable red-cockaded woodpecker populations is dependent on the maintenance and protection of suitable habitat. Long-term habitat protection requires maintenance of the integrity of ecosystem properties, including basic processes such as primary productivity, but also including ecosystem structure. In addition to the possibility of direct toxicity effects to the red-cockaded woodpecker, indirect and harmful effects on the species' habitat may also be important. In this step of the risk assessment process, the available information on the toxicological effects of fog oil obscurant on wildlife and the critical components of red-cockaded woodpecker habitat are summarized and evaluated.

Unfortunately, the majority of the available toxicity data on fog oil are based on laboratory experiments using old fog oil ${ }^{\dagger}$, which may have substantially different toxicity than fog oil as it is currently produced (Driver et al. 1993, Getz et al. 1996,

\footnotetext{
* All known populations not designated as a primary or secondary core population (USFWS 2003).

† Fog oil produced prior to 1986, termed "old" fog oil, is no longer used. This significant modification is important in evaluating toxicity, since "new" fog oil (i.e., produced after 1986) is presumably much less toxic than old fog oil. Henceforth, the use of the terms "fog oil" and "fog oil smoke" refer to fog oil produced after 1986; the term "old fog oil" will be used in reference to fog oil produced prior to 1986. Also note the time frame for published studies on fog oil effects, since they may have taken place before this reformulation or they may have used the older formulation without specifically stating it.
} 
Driver et al. 2002a). Additionally, most studies are also based on unrealistically high doses (i.e., concentrations or exposure times much greater than that predicted to occur in the field); thus, actual impacts are likely to be less due to lower exposure rates. Also, any toxicity of fog oil is not necessarily representative of or comparable to toxicity of fog oil smoke. The heat used in generating fog oil smoke, along with other factors including vaporization, photolytic processes, and climactic or meteorological conditions, may all serve to affect toxic characteristics. Furthermore, there is little information available on the chronic toxicity of fog oil or fog oil smoke. Findings published prior to 1986 are almost certainly based on old fog oil, and those published after 1986 don't necessarily refer to the newer, currently manufactured fog oil unless so stated.

\section{Effects on Vertebrate Wildlife}

Data and information on the effects and impacts of fog oil on wildlife species are sparse. Yanders et al. (1985) indicate that fog oil is weakly mutagenic to rodents exposed in the wild. Although data on the toxicity and carcinogenicity of fog oil on wildlife are limited, the effects of inhalation, ingestion, and dermal exposure of laboratory mammals to various petroleum products have been investigated (Bingham et al. 1965; Costa and Amdur 1979; Grose et al. 1985, 1986; Jepsen et al. 1977; Lushbaugh 1950; Mayhew et al. 1985; Selgrade et al. 1987, 1990; Wagner et al. 1964). In lab mammals, oil aerosols are known to have only moderate and largely reversible respiratory effects, such as the development of oil-filled macrophages (Shoshkes et al. 1950). Similarly, no data on the effects and impacts of inhaled fog oil aerosols are available for any avian species prior to the recent Army-sponsored research (Driver et al. 2002a, 2002b, 2004).

Extrapolating findings from lab mammals to avian species is problematic because they have considerably different body size, behavior, physiology, metabolism, and sensitivity. This caveat is particularly true when extrapolating findings on inhalation effects from mammals to birds, because the respiratory rate of birds is much greater than that of mammals of equivalent body size (Phalen 1984). Higher respiratory rates are likely to result in greater inhalation exposure. Morphological differences in avian and mammalian respiratory systems could also lead to very different exposure rates and/or health effects. Certain chemical constituents of fuel and crude oils are known to be particularly toxic to birds. For example, some lower molecular weight ( $<4$ benzene rings) PAHs, such as naphthalene, are known to be particularly toxic to birds (Peakall et al. 1981, 1982).

Little is known about the effects of fog oil ingested by wildlife. However, the toxicity of lubricating oils is generally low, and chronic oral uptake of highly refined oils is not tumorgenic in laboratory animals (Roush et al. 1980). Similarly, daily oral doses 
of crude oil or SFG No. 2 fuel oil has not been shown to cause body or organ weight changes in waterfowl (Holmes and Cronshaw 1977). Yet, ingestion of fuel oils has been shown to affect avian fecundity; symptoms include interruption of egg production and anomalies in yolk deposition (Grau et al. 1977). In addition, small amounts of crude and refined (e.g., diesel) oils are known to affect embryonic development, if applied to the surface of avian eggs (Kopischke 1972, Albers 1977, White et al. 1979, Trivelpiece at al. 1984, Macko and King 1980). Applying petroleum compounds to eggs or otherwise exposing eggs to petroleum compounds is also known to cause embryo mortality (Hoffman 1990). If eggs are excessively exposed, or if petroleum or vegetable oils are applied freely to egg surfaces, embryo mortality will occur due to interference with normal respiratory atmospheric exchanges through the shell. Note however, that this route of exposure is not characteristic of military fog oil use.

Standard grade fuel oils are considered moderate skin irritants (Mayhew et al. 1985). In mammals, symptoms resulting from dermal exposure are largely reversible and limited to erythema, edema, and desquamation (Mayhew et al. 1985). Although petroleum products are known to cause eye damage in mammals, fog oil aerosols are not considered eye or skin irritants (Geraci and Smith 1977, Mayhew et al. 1985). In cases of oil coating, reduced thermoregulatory ability, especially in avian species, is another potentially harmful effect (Hartung 1967, McEwan et al. 1974). Data on the effects of dermal exposure to newer manufactured fog oil are not available for birds and relatively little is known about the effect of fog oil or fog oil smoke on avian endocrine, reproductive, immune, physiological, or nervous systems.

\section{Effects of Fog Oil Smoke on Avian Species}

Due to the paucity of relevant data on fog oil smoke and the limitations of extrapolation from petroleum oil information, several fog oil obscurant smoke toxicity studies have been initiated to provide information on the effects of fog oil smoke on the red-cockaded woodpecker and its habitat (Driver et al. 2002a, 2002b, 2004).

Driver et al. (2002a, 2000b, 2004) found no toxicological effects in the red-winged blackbird (Agelaius phoeniceus), house sparrow (Passer domesticus), and northern bobwhite (Colinus virginianus) after exposures at up to twice the concentrations expected under usual field conditions during military fog oil smoke training for any of the suite of biological parameters examined (Table 7). The red-winged blackbird was chosen as a suitable surrogate species based on similar physical size (20 to 23 cm for red-winged blackbirds and red-cockaded woodpeckers), and body mass (average $47 \mathrm{~g}$ to $74 \mathrm{~g}$ for females and $40 \mathrm{~g}$ to $55 \mathrm{~g}$ for males; $42 \mathrm{~g}$ to $45 \mathrm{~g}$ for fledgling redcockaded woodpeckers; Ligon 1970, Beletsky 1996, Jackson 1994, Conner et al. 2001). These similarities are likely to result in similar weight-specific doses via inhalation and ingestion. In addition, the red-winged blackbird has a known sensitiv- 
ity to pollutants (Shafer 1972, Schafer et al. 1973, Schafer et al. 1983). The exposure rates applied in that study were based on maximum estimated field exposures (i.e. $400 \mathrm{mg} / \mathrm{m}^{3}$, for up to 4 hours, corresponding to a close proximity to fog generator for extended periods). Ingestion of fog oil, from preening activities of fog oil potentially deposited on feathers during smoke generation exercises, was calculated to be at rates of 10 to 20 times lower than the rates of exposure to unrefined oils that have been shown to cause adverse effects in other avian species (Hartung and Hunt 1966).

Similarly, Driver et al. (2002b) found no adverse effects attributable to fog oil smoke aerosol exposure on the hatchability of eggs, fledgling success, or the survivability of house sparrow young. In that study, eggs and nestlings were exposed for $30 \mathrm{~min}$ utes at fog oil smoke aerosol concentrations of up to $450 \mathrm{mg} / \mathrm{m}^{3}$. The house sparrow was used as a surrogate because it typically nests in cavities of similar dimension to those of the red-cockaded woodpecker and, like the red-cockaded woodpecker, is altricial, with the hatchlings being naked and with a potentially greater opportunity for dermal fog oil aerosol exposure. In addition, because of its relatively small size, the species has weight-specific respiration that results in a relatively high inhalation rate of atmospheric constituents (Phalen 1984). The house sparrow also has a known relative sensitivity to environmental pollutants (Schafer 1972, Schafer et al. 1973, Schafer et al. 1983).

In another related study, Driver et al. (2004) reported on further exposures of redwinged blackbirds and house sparrows to fog oil smoke aerosol concentrations of up to $450 \mathrm{mg} / \mathrm{m}^{3}$ and averaging $300 \mathrm{mg} / \mathrm{m}^{3}$ and $430 \mathrm{mg} / \mathrm{m}^{3}$ for each species, respectively. While studies involving waterfowl (e.g.,mallard, Anas platyrhynchos) have shown that ingestion of petrochemicals reduced resistance (i.e., ability of leucocytes to phagocytize bacterial disease (such as avian cholera; Rocke et al. 1984), no immunosuppression (i.e., lack of leukocyte depression or hemolytic anemia) was observed in red-winged blackbirds challenged with viral avian pox. Similarly, no immunosuppression was observed in house sparrows challenged with sheep erythrocytes. Additionally, no mortality, chemical signs of toxicity, long term organ dysfunction, or significant histopathology was observed in either species. While the liver mass of fog oil smoke aerosol exposed red-winged blackbirds was reduced, the reason for this was unclear and the end point metabolite levels in peripheral blood indicated that the functional integrity of major organ systems was intact.

In a related study (3D/I 1997), no chronic inhalation, ingestion, or dermal absorption effects were determined for eggs, sub-adult, or adult American robins (Turdus migratorius) subject to fog oil smoke exposure from Army fog oil smoke testing and training events. 
Table 7. Summary of toxicological and other effects of exposure to fog oil obscurant smoke in red-cockaded woodpecker surrogates. ${ }^{A, B}$

\begin{tabular}{|c|c|}
\hline Parameter & Effect \\
\hline Dermal deposition & $\begin{array}{l}\text { Greatly below acute dose resulting in drop in } \\
\text { body temperature }\end{array}$ \\
\hline Dermal absorption & No chronic effects observed \\
\hline Body temperature & No behavioral indications of body heat loss \\
\hline Food consumption & $\begin{array}{l}\text { No behavioral indications of increased feeding } \\
\text { activity }\end{array}$ \\
\hline Ingestion & No chronic effects observed \\
\hline Weight loss & Not observed \\
\hline $\begin{array}{l}\text { Diminished carcass condition } \\
\text { (wasted fat and muscle tissue) }\end{array}$ & Not observed \\
\hline Behavior & No changes observed \\
\hline $\begin{array}{l}\text { Indications of stress } \\
\text { (fluffed feathers, gaping, lowered posture) }\end{array}$ & None observed \\
\hline Muscular atrophy & Not observed \\
\hline Depleted body fat & Not observed \\
\hline Plumage characteristics & No changes observed \\
\hline Diarrhea, vent staining & None observed \\
\hline Exudates from eyes or nares & None observed \\
\hline Air sacs & Clear \\
\hline $\begin{array}{l}\text { Gross lesions } \\
\quad \text { (ileum, spleen, bill) }\end{array}$ & None attributable to exposure \\
\hline $\begin{array}{l}\text { Histopathological lesions } \\
\text { (lung, liver, proventriculus) }\end{array}$ & None attributable to exposure \\
\hline $\begin{array}{l}\text { Parasites, enteric } \\
\quad \text { (protozoa, helminthes) }\end{array}$ & No differences attributable to exposure \\
\hline Body weight, male and female & No differences attributable to exposure \\
\hline Liver weight & No differences attributable to exposure \\
\hline $\begin{array}{l}\text { Respiratory function } \\
\text { (frequency, minute ventilation) }\end{array}$ & No changes observed \\
\hline Inhalation & No chronic effects observed \\
\hline Deposition on eggs & Not detectable in $92 \%$ of exposures \\
\hline Hatching success & No differences attributable to exposure \\
\hline $\begin{array}{l}\text { Fledgling success } \\
\quad \text { (survival to } 140 \text { days) }\end{array}$ & No differences attributable to exposure \\
\hline Immune response & No changes observed \\
\hline White blood cell count & No differences attributable to exposure \\
\hline Hemolytic anemia & None observed \\
\hline Hematocrit & No changes observed \\
\hline Peripheral blood metabolites & No differences attributable to exposure \\
\hline Bioaccumulation & No differences attributable to exposure \\
\hline \multicolumn{2}{|c|}{$\begin{array}{l}\text { A Summarized from Driver et al. 2002a, 2002b, 2004; 3D/I 1996, } 1997 . \\
\text { B Surrogate species include red-winged blackbird, house sparrow, northern bobwhite, and Americar } \\
\text { robin. }\end{array}$} \\
\hline
\end{tabular}




\section{Effects on Invertebrates}

The effects of fog oil or fog oil obscurant smoke on invertebrates are not well documented. Invertebrates (e.g., termites, ants, and earthworms) play an important role in the physical and biological breakdown of organic matter in terrestrial ecosystems, thereby promoting microbial decay and nutrient cycling. In soils, earthworms are particularly important for maintaining soil aeration, increasing water infiltration, and facilitating decomposition. At surface deposition rates of up to $800 \mu \mathrm{g} / \mathrm{cm}^{2}$, fog oil does not cause adverse effects in earthworm cocoon hatch, or survival of young and adults (Cataldo et al. 1989). Furthermore, at concentrations 28 times higher than maximum field deposition rates (equivalent to aerial deposition of 3,600

$\mu \mathrm{g} / \mathrm{cm}^{2}$ ) earthworm survival was $100 \%$ (Cataldo et al. 1989).

At sites where long-term (i.e., 10 years or more) exposure to fog oil smoke aerosols has taken place (such as the former site of the U. S Army Chemical Training School at Fort McClellan, AL), there were no statistically significant differences in concentrations of fog oil hydrocarbons in insect tissue between exposure and reference sites (3D/I 1996). This study looked at active training areas so concentrations were at true field levels. Further, use of field fog oil obscurant smoke at the chemical school was almost certainly more frequent and of higher intensity or concentration than any use for general soldier training. This examination tends to support the hypothesis that long-term fog oil smoke exposure at field sites does not increase concentration of fog oil hydrocarbon constituents in site insects.

Effects of fog oil smoke exposure to the pine forest arthropod community may be important to the red-cockaded woodpecker in part because of the species' reliance on arthropods, primarily insects, as a food source (Hanula and Franzeb 1998, Hanula et al. 2000a). Wood roaches (Blatellidae) in particular compose a major portion of the red-cockaded woodpecker diet (Hanula and Franzreb 1995, Hanula et al. 2000b). Wood roaches appear to be extremely resistant to any observable effects of high laboratory exposures of fog oil smoke (Dennis Strenge, Pacific Northwest National Laboratory, Richland, WA, professional communication).

\section{Effects on Vegetation}

There are few data describing the effects of fog oil or fog oil smoke on vegetation and soils. On leaf surfaces, fog oil deposits can cause moderate toxicity responses, including chlorosis, leaf burn, and necrotic spotting (Cataldo et al. 1989). These symptoms are probably caused by the aliphatic hydrocarbon constituents of fog oil, which can damage cell membrane permeability (Driver et al. 1993). Other investigations have discovered no observable harmful effects on vegetation, and have 
shown that fog oil constituents are not present at levels higher than control sites in soil and vegetation samples (3D/I 1996). Woody species seem to be less susceptible than perennial grasses, which can suffer reductions in biomass production. Apparently, grasses transfer and accumulate fog oil constituents to below-ground plant tissues (Cataldo et al. 1989).

Although acute exposure to fog oil may have no lethal effects on vegetation, local primary productivity could possibly decline over longer time periods (i.e., chronic exposures), especially if vegetation is subject to exposures during the growing season (Cataldo et al. 1989). Though indirect, such long-term impacts to local habitats would certainly have a detrimental effect on the red-cockaded woodpecker. James et al. (1997) provide evidence of the subtle but important role that effects on habitat can have on a species' biology. They recently demonstrated that the red-cockaded woodpecker have greater reproductive productivity one season after their territories have been burned. Up to $25 \%$ of the variation in group size can be accounted for by variation in ground-cover composition; red-cockaded woodpecker group size increases with the percent of wiregrass (Aristida stricta) in the groundcover. Maintenance of wiregrass groundcover is highly dependent on the local fire regime (i.e., frequency and seasonality). Based on these findings, James et al. (1997) hypothesize that fire is important in mobilizing nutrients within the ecosystem.

Deposition and accumulation of fog oil residues on soil surfaces does not appear to affect seed germination or soil nutrient levels (Cataldo et al. 1989). However, residues on soils can have indirect effects on plant growth (e.g., reduced biomass in perennial grasses), and are believed to be related to water transport (Cataldo et al. 1989). Yet, it is also possible that any observed reductions in biomass are caused by a disruption of the symbiotic fungal endophyte associations that many perennial grasses support. Unfortunately, no data are available on the effects of fog oil on soil fungi.

\section{Microbial Effects}

From a taxonomic and apparently distributional point of view, degradation (formation of smaller molecules), transformation (chemical alteration), or mineralization (conversion to inorganic material) of petroleum-based products among microorganisms is widespread and well documented (Bausum and Taylor 1986). Though few studies have investigated the effects of fog oil smoke residues on soil or microbial activity, no negative effects are known. For example, Cataldo et al. (1989) reported no deleterious effects of fog oil residues on soil microbe activity and found that even at relatively high exposures (e.g., 1,100 $\mu \mathrm{g}$ fog oil $/ \mathrm{cm}^{2}$ ), soil respiration was not af- 
fected and nitrobacter activity increased only slightly. Light oils (e.g., fog oil) are generally attributed with high rates of mineralization (Bausum and Taylor 1986).

\section{Indirect Effects}

Links between trophic levels can lead to indirect effects on other components of the ecosystem, which may ultimately affect the red-cockaded woodpecker and/or its habitat. For example, deposits of airborne chemicals might lead to reduced rates of nutrient cycling in soils, which can cause a decline in primary productivity, thereby indirectly affecting wildlife. However, given the numerous and often unknown interdependencies that exist in ecosystems, a comprehensive analysis of potential indirect effects on all ecosystem components is nearly impossible. Consequently, this assessment will focus on those ecosystem components hypothesized to be integral to the persistence and growth of red-cockaded woodpecker populations and to key aspects of the species' habitat (i.e., known habitat requirements).

One indirect effect that is appropriate to mention is general disturbance that may be associated with fog oil obscurant smoke training. This disturbance generally can be described as anthropogenic and related to soldiers and associated vehicles and weapons that are part of training exercises. The possible effects of fog oil obscurant smoke on the red-cockaded woodpecker or its habitat may be masked or over-ridden by potential effects from other concurrent military training activity. However, in this regard it has been established that noise disturbance typical of military training operations (e.g., small- and large-caliber live fire, vehicles, aircraft) did not produce significant differences in nesting success or productivity (Delaney et al. 2002). In addition, typical training operations have been shown not to have impacts on redcockaded woodpecker reproductive success (Hayden et al. 2002). Furthermore, demographic factors, such as group size and prior reproductive success, apparently have more effect on red-cockaded woodpecker reproductive success than disturbance from human activities (Hayden et al. 2002).

\section{Bioaccumulation}

Lubricating oils similar to SGF No. 2 have been shown to bioaccumulate in aquatic food chains (Smith et al. 1987). However, investigations on fog oil obscurant smoke have not demonstrated bioaccumulation in tissues or in soil, water, sediment, or vegetation (3D/I 1996). Further, no statistical significance between chemical concentrations of fog oil obscurant smoke at the control site and at the testing sites has been observed (3D/I 1996). 


\section{Endpoints}

Any characteristic (e.g., reproductive success, primary productivity) of the ecological component of concern (e.g., species, ecosystem) that may be affected by exposure to a stressor is an endpoint (Suter 1990, Norton et al. 1993). An assessment endpoint should be an explicit expression of the environmental value that is to be protected. However, because assessment endpoints often cannot be directly evaluated, measurement endpoints are identified. Measurement endpoints are measurable responses to a stressor that are related to the characteristic chosen as the assessment endpoint (Norton et al. 1993). Typically, a set of measurement endpoints is examined when determining whether or not a stressor is likely to have a significant effect on the assessment endpoint. The ecological or organizational scale of the assessment endpoint may be different than that of the measurement endpoints (Norton et al. 1993, Barnthouse and Brown 1994). For example, measurement endpoints at the individual or organism level (e.g., individual mortality, reproduction, and growth) can be used to evaluate effects on a population level assessment endpoint (e.g., red-cockaded woodpecker population viability or stability).

The assessment endpoints of this ecological risk assessment are the survival and reproduction of red-cockaded woodpecker individuals and populations, and the maintenance of suitable red-cockaded woodpecker habitat. Risks to red-cockaded woodpecker survival from exposure to fog oil smoke will be evaluated with measurement endpoints to include: (1) exposure rates (aerosol and residue concentrations) based on model, laboratory, and field data; (2) the toxicity of fog oil aerosols (inhalation, ingestion, and dermal exposures) in surrogate avian species, and (3) acute effects on behavior, reproductive success, and observable physiological processes (e.g., thermoregulation, immune response) in surrogate avian species. Measurement endpoints applied to red-cockaded woodpecker reproduction include laboratory studies of: (1) aerosol exposures in nesting cavities, (2) egg hatchability, and (3) nestling and fledgling survival. Risks to the maintenance of red-cockaded woodpecker habitat will be ascertained with measurement endpoints that address (1) the potential for biological accumulation of fog oil obscurant smoke, and (2) the toxicity of fog oil to vegetation, arthropod prey, and soil microbe communities. Although chronic effects of exposure to stressors can also be a major concern in assessing risks to populations and habitats, the limits of long-term data on fog oil obscurant smoke accumulation and transformation makes detailed assessment of these effects impractical at this time. 


\section{Conceptual Model}

The problem formulation phase can culminate in the development of the conceptual model that describes how the stressor(s) might affect important components of the environment (Norton et al. 1993).

The conceptual model describing environmental exposure to fog oil smoke is portrayed in Figure 4. For the red-cockaded woodpecker, direct and indirect exposure to fog oil aerosols and residues is possible through inhalation, ingestion, and absorption (Figure 5). Red-cockaded woodpeckers may inhale fog oil smoke aerosols if training exercises are conducted within their territories and the birds encounter the fog oil smoke plume. During foraging or preening, birds may ingest residues that have deposited on arthropod prey, water, and feathers. Dermal exposure is possible through direct deposition of fog oil smoke or fog oil smoke residues on skin or eyes, as well as through contact with residues on environmental surfaces (e.g., tree trunks, limbs, or other vegetation). In addition, indirect ingestion exposure is possible if fog oil smoke constituents bioaccumulate and move through food chains. Exposure to fog oil residues and bioaccumulated constituents is possible over larger temporal and spatial scales than is the relatively brief and small scale event or site exposure to fog oil aerosols. However, amounts and rates of deposition, degradation, and bioaccumulation of fog oil obscurant smoke under field conditions are generally unknown.



Figure 4. Hypothetical higher-level conceptual model for release of military obscurant smokes (from Suter et al. 2001). 
Important components of the red-cockaded woodpecker's habitat such as soils, vegetation, and food resources may also be exposed to fog oil aerosols and deposits. Degradation of these ecological component resources by fog oil smoke may indirectly affect red-cockaded woodpecker populations (Figure 5). For example, potential adverse effects on red-cockaded woodpecker habitat are possible through impacts to soils, vegetation, and arthropod prey. Soil processes such as nutrient cycling might be either impeded or arrested. Concurrently, a reduction in primary productivity might cause reductions in prey abundance or in habitat quality. Vegetation may suffer increased mortality, reduced productivity, declines in reproduction, and increased susceptibility to insect damage or parasitic infection. Habitat quality and quantity may be altered if some plant species are susceptible to fog oil aerosol damage. Arthropod prey species, which are important red-cockaded woodpecker food resources, might be affected by exposure to fog oil smoke or smoke residues. Reductions in the prey base might reduce red-cockaded woodpecker productivity. These types of habitat changes would most likely be long term, developing over a period of years or even decades and consequently impossible to identify in the short term and document or relate to fog oil smoke exposure events.

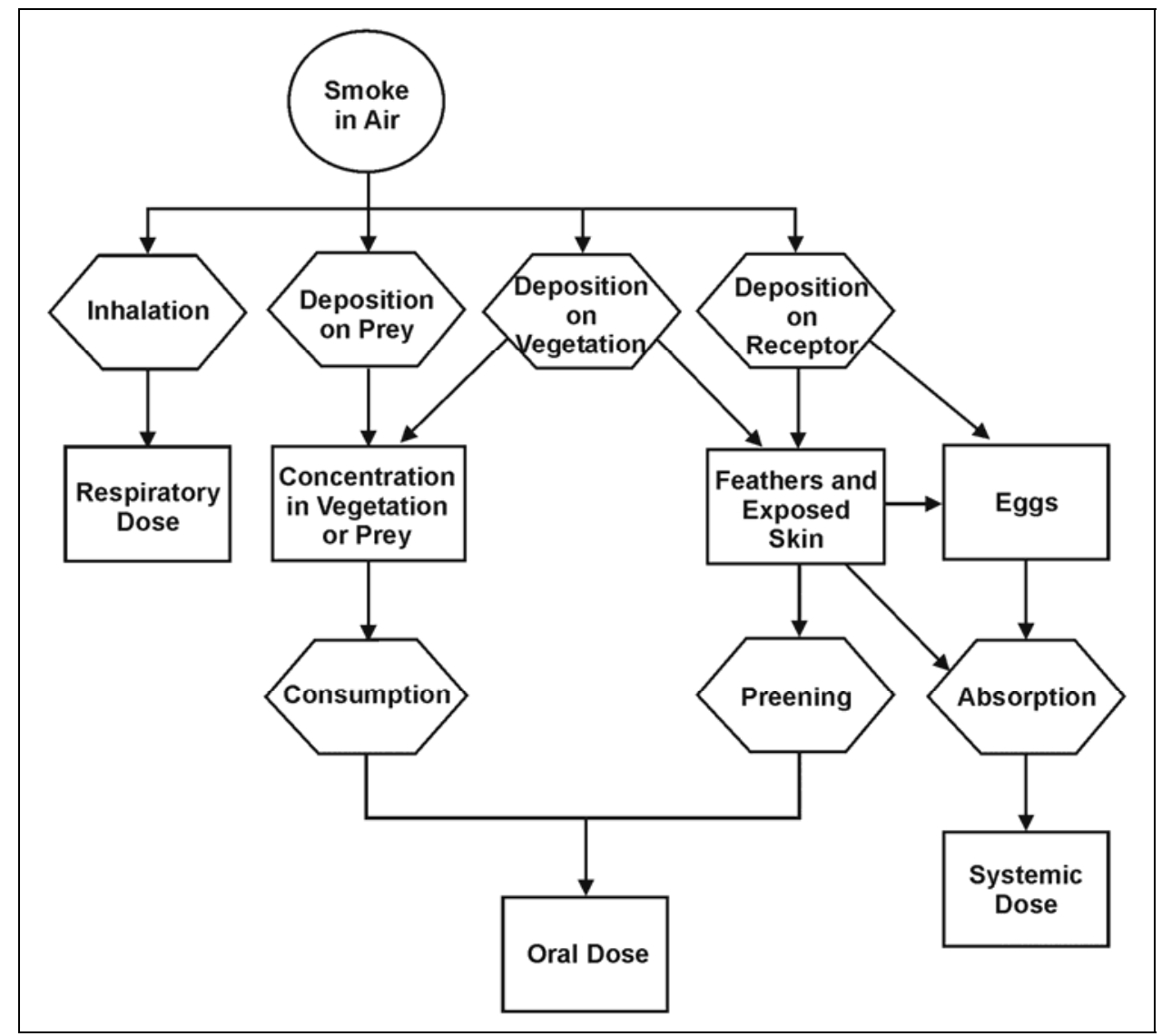

Figure 5. Hypothetical lower-level conceptual model for release of military obscurant smokes. 
Red-cockaded woodpecker populations might decline if fog oil obscurant smoke exposure reduces individual survivorship or reproduction. Mortality may not be a direct consequence of exposure; instead birds might suffer negative health effects that indirectly increase susceptibility to parasites, predators, or extreme weather. Declines in avian reproduction may be expressed in numerous ways including, fewer eggs, reduced egg hatchability, increased hatchling mortality, skewed sex ratios, and/or delayed sexual maturity. However, these population declines could be difficult to identify much less to attribute them to fog oil smoke exposure events, in part because of the possibility of ingress from expanding and/or otherwise non-exposed populations or population segments and other factors (Hayden et al. 2002).

The likelihood of exposure and potential for subsequent harmful effects depends on numerous factors such as the red-cockaded woodpecker life stage affected, period of the annual cycle, local environmental conditions, mode of exposure, and location and frequency of the aerosol plume relative to active cavity trees and other locations frequented by the birds. 


\section{Analysis}

In the analysis phase of an ecological risk assessment, data on the potential effects and exposure of the stressor are evaluated (Norton et al. 1993, USEPA 1998, Suter et al. 2001). Summary profiles resulting from characterization of the potential exposure and ecological effects are then used in risk characterization.

\section{Background}

The objective of the exposure characterization is to examine the spatial and temporal co-occurrence of the stressor and the ecological components of concern in order to evaluate potential exposure. Because fog oil smoke can be a chemical stressor, this characterization will focus on the quantities of fog oil that are biologically available. A chemical is said to be biologically available if it can come in contact with the organism and it is in a state capable of being absorbed and able to interact with the metabolic processes of an organism (Suter et al. 1993). Depending on the nature of the receptor and the stressor, the potential for both lessened or increased effects and/or exposure may be enhanced by the exposed organism's activity and behavior patterns. This analysis will examine exposures and effects of fog oil obscurant smoke exposure at individual stages of the red-cockaded woodpecker life cycle (e.g., eggs, young, and adults), and at different periods of the species' annual cycle (e.g., breeding, molting). For example, in avian species a chemical stressor may have a significant effect only on young during the brood rearing period, since early life stages are generally more sensitive to stressors than adults. Similarly, due to physiological stress, adults may be more susceptible to negative effects during breeding season or migration.

\section{Exposure Characterization}

\section{Stressor Characterization (Fog Oil Obscurant Smoke)}

On a given installation, fog oil smoke training exercises are conducted erratically throughout the year (Getz et al. 1996), with approximately six to eight 1-week long training sessions per year. During training exercises, fog oil smoke is released about four times (Getz et al. 1996). Although some permanent training sites have been established (e.g., U.S. Army Chemical Training School, Fort Leonard Wood, 
MO; Getz et al. 1996), training sites are generally not used more than once during a training session. Fog oil obscurant smoke training exercises are typically limited to daylight hours and typically last 30 to 90 minutes (U.S. Army 1996a).

Fog oil smoke dissipates within 5 to 30 minutes after generation efforts cease with the longer estimate usually occurring under temperature inversion conditions (Getz et al. 1996). With the possible exception of some chemical school training, the maximum expected duration of a smoke cloud is approximately 2 hours. The size of smoke clouds varies depending on the area to be obscured and meteorological conditions, but a general estimate of cloud size, at higher concentrations that result in obscurity, is approximately $1000 \mathrm{~m}$ by $1000 \mathrm{~m}$ (Getz et al. 1996).

The dispersion, dissipation, and concentration of fog oil smoke clouds are determined in part by local environmental conditions, such as local terrain and weather. Eventually, clouds dissipate; aerosols will evaporate, settle, photolyze, or diffuse into the atmosphere. The fate of the fog oil particles that do settle on environmental surfaces is determined by the relative rates of mass transport, phase transformation, and chemical, photochemical, and biological degradation.

Typical fog oil smoke generation and fog oil utilization rates range between 24 and $100 \mathrm{gal} / \mathrm{hr}$. The M157, which is a common smoke generating device used during training exercises, releases $50 \mathrm{gal} / \mathrm{hr}$ (Getz et al. 1996). This smoke generator can be operated for up to 2 hours on a full load of fuel. The other common smoke generating device, the newer M56, which is typically mounted on the M1113 utility truck (a.k.a. Highly Mobile Multipurpose Utility Vehicle [HMMUV]), has one or more fog oil tanks with a total capacity of up to 100 gallons per tank and can operate up to approximately 1.5 hours depending on the amount of oil released to the heated manifold (i.e., 60 to 80 gal/hr). One or more generators may be used during a fog oil smoke generation event. Up to 200 gal of fog oil have been used daily for smoke generation at a single location (Brubaker et al. 1992). Fog oil obscurant smoke generation and deployment during training events is most often 1 hour or less. In 1985, the Army used 10,000 55-gallon barrels of fog oil in training exercises (Poston et al. 1986). Therefore, based on a release rate of approximately $50 \mathrm{gal} / \mathrm{hr}$ over a 1hour training event, and daily training events totaling 4 hours (i.e., 200 gal), approximately 2,750 fog oil smoke training or testing events are conducted annually at Army installations. These training or testing events also can be considered location events since on a given installation training or testing may be conducted at multiple and specific locations. For risk assessment purposes, at the U.S. Army Chemical Training School, fog oil usage has been calculated at $0.66 \mathrm{gal} / \mathrm{min}$ and a maximum of $1,200 \mathrm{gal} /$ day (3D/I 1997). 
Not all fog oil smoke training is conducted at Army installations where red-cockaded woodpeckers are present. The installations where red-cockaded woodpeckers are present (Table 1, page 11), are considered or categorized as maneuver installations (i.e., major Army power projection locations that provide facilities and resources to house, maintain, train, and deploy major combat forces), training installations (i.e., entry, general, specialized, combat, and other), or major and / or reserve component training installations (i.e., facilities to conduct large-scale unit training for active and reserve military components). In these categories there are also approximately 46 Army installations where red-cockaded woodpeckers are not present. These categories include those installations that, by Army mission requirements and other factors, would be expected to employ and utilize fog oil obscurant smoke as part of their training and testing programs and protocols. Also, in addition to the U.S. Army Chemical Training School, there are at least three Army proving grounds where fog oil obscurant smoke is potentially utilized and tested (e.g., Dugway Proving Ground, UT; Liljegren et al. 1988). Similarly, an unknown number of fog oil smoke training and testing exercises are conducted in other countries (e.g., Germany; Brubaker et al. 1992) as part of routine military mission related training and testing exercises. At the U.S. Army Chemical Training School, a "worst case" (for environmentally preferred training methods) fog oil usage of 49,500 gal/yr has been estimated (3D/I 1997).

Thus, considering available usage data (Posten et al.1986, 3D/I 1997), 550,000 gallons of fog oil is used in 2,750 training or testing events on more than 57 Army installations annually. This averages to 9,650 gal of fog oil used in 48 training or testing events per installation annually (i.e., four per month per installation). This estimate of average installation use may be high in part because of the uncertainty of the amounts used outside of the United States, and because of the potentially large amount used at installations outside of red-cockaded woodpecker range.

\section{Fog Oil Smoke Environmental Concentrations}

The atmospheric concentration of fog oil aerosols will vary, depending on the length of generation time, generation rate, distance from generator, site terrain, and meteorological conditions (Driver et al. 1993). Also, fog oil aerosol concentrations are not uniform in space or time. Concentrations are highest immediately after release and near the generator, and decline with distance and time since release (Driver et al. 1993). Most fog oil aerosol droplets quickly evaporate or diffuse into the atmosphere; aerosol clouds dissipate within 5 to 30 minutes (Driver et al. 1993, Getz et al. 1996). Ideally, fog oil obscurant smoke testing and training conditions fall into a rather narrow range of atmospheric conditions. Much fog oil smoke release is done under conditions of relatively low wind and minimal amounts of atmospheric turbulence to facilitate effective cloud formation and dispersion. 
Estimates of atmospheric concentrations are available from both field and modeling studies (e.g., Liljegren 1988, Policastro et al. 1989, Driver et al. 1993). The most comprehensive models currently available (those that include the most environmental variables) predict that a release of $80 \mathrm{gal} / \mathrm{hr}$ during a 2-hour exercise (i.e., worst-case scenario or 1.6 times the expected fog oil utilization rate/hr) will yield aerosol concentrations of 64 and $56 \mathrm{mg} / \mathrm{m}^{3}$ at locations $100 \mathrm{~m}$ and $200 \mathrm{~m}$ downwind, respectively (Driver et al. 1993). Under the same release conditions, concentrations are estimated to be less than $13 \mathrm{mg} / \mathrm{m}^{3}$ at distances greater than $1 \mathrm{~km}$. Unfortunately, precise estimates of air concentrations are problematic because generators are often mobile and atmospheric conditions are variable.

Once a fog oil plume is released into the atmosphere, particle dissipation and dispersion will be affected by local terrain and weather. Wind speed and variability in wind direction will enhance cloud dispersion. In areas having variable terrain, fog oil aerosols will tend to accumulate in coves or valleys that are sheltered from wind or exhibit temperature inversions. With lower wind velocities and lessened turbulence, deposition close to the source of generation can be expected to be greater than that under higher wind conditions.

Fog oil smoke concentrations in red-cockaded woodpecker nest cavities have been measured by Guelta and Checkai (2001) and Driver et al. (2002b) under laboratory and simulated field fog oil smoke release conditions. In those studies fog oil smoke concentration within the cavity ranged from $61 \%$ to $94 \%$ of the concentrations outside the cavity with a stabilized average concentration of approximately $75 \%$.

\section{Deposition of Fog Oil Obscurant Smoke in the Environment}

Fog oil aerosol deposition is strongly influenced by droplet aerodynamics, local meteorological conditions, and initial aerosol concentrations (Driver et al. 1993). Modeling studies predict and field measurements indicate that the amount of fog oil deposited on surfaces is extremely small (Driver et al. 1993, Liljegren et al. 1988, Policastro et al. 1989). Fog oil smoke aerosol deposited at the end of a typical fog oil training exercise is estimated to range between 2,000 and $3,080 \mathrm{mg} / \mathrm{m}^{2}$ at a distance of $100 \mathrm{~m}$ downwind of the generator. Average surface deposition is estimated to be less than $243 \mathrm{mg} / \mathrm{m}^{2}$ and $101 \mathrm{mg} / \mathrm{m}^{2}$ at distances $500 \mathrm{~m}$ and $1 \mathrm{~km}$ downwind, respectively. At greater distances, deposition rates drop markedly.

These estimates assume that all of the fog oil droplets will deposit within a 1-km by $1-\mathrm{km}$ area, when the actual deposition area may be larger. Consequently, these estimates represent maximums. Actual rates of deposition are likely to be much lower. This is substantiated by empirical data that show very low rates of fog oil 
deposition (Liss-Suter and Villaume 1978, Cataldo et al. 1989, Liljegren et al. 1988, Policastro et al. 1989). For example, at distances 20, 40, 80, and $160 \mathrm{~m}$ from the generator, deposits have mean concentrations less than $1 \mathrm{ppm}$ when measured at ground level in a forested area (McMurry et al. 1997)

Rates of fog oil smoke deposition are low due to the small droplet size, which typically ranges between $0.6 \mu \mathrm{m}$ and $3 \mu \mathrm{m}$ in diameter (Cataldo et al. 1989, Driver et al. 1993). Particles of this size have settling velocities between 0.001 and $0.03 \mathrm{~cm} / \mathrm{s}$ (0.04 - $1 \mathrm{~m} / \mathrm{hr}$ ), allowing them to remain airborne for long periods of time or until they evaporate (Aiken and Roberts 1979, Driver et al. 1993). However, some settling and physical deterioration of the fog oil smoke cloud is fostered by agglomeration of droplets (Katz et al. 1980).

Deposition rates are also influenced by local meteorological conditions. For example, as the wind speed increases beyond $6 \mathrm{mph}$ (10 kph), deposition on foliar surfaces increases markedly (Cataldo et al. 1989). Higher deposition rates are also expected during temperature inversions, because aerosol dispersion is hindered. Aerosol droplet size and aerodynamic behavior is not affected by relative humidity (Driver et al. 1993). Apparently, condensation of water vapor on fog oil aerosol particles is limited by the hydrophobic nature of fog oil.

If fog oil aerosols settle, they deposit on environmental surfaces such as soils, vegetation, and animals. On plant surfaces, mass loading and deposition velocities are 1.5 to 2 times higher for sparse foliage (e.g., ponderosa pine [Pinus ponderosa] and short needle pine [Pinus echinata]), than for dense foliage (e.g., bush bean [Phaseolus vulgaris] and tall fescue [Festuca elator]; Cataldo et al. 1989). This difference probably reflects the greater relative surface area of plants with sparse foliage. When the amount of fog oil smoke aerosol deposited on plant surfaces has been measured in wind tunnel experiments, average air concentrations of $737 \mathrm{mg} / \mathrm{m}^{3}$ over a period of 2 hours resulted in foliar deposits of 300 to $3,000 \mathrm{mg} / \mathrm{m}^{2}$; Cataldo et al. 1989). However, these surface concentrations are likely to be higher than field deposition rates, given that the airborne concentrations were much higher than those expected during training exercises. To that effect, in field trials conducted by Liljegren et al. (1988) no measurable levels of fog oil residue were found on either horizontal or vertical surfaces. Moreover, in a separate field trial, Brubaker et al. (1992) reported concentrations of $<11 \mathrm{ppm}$ on soil and vegetation surfaces in areas of frequent smoke generation.

\section{Depuration of Fog Oil Obscurant Smoke Residues}

Fog oil deposits are rapidly removed from environmental surfaces by various biotic and abiotic processes that collectively weather and break down residues (Bausum 
and Taylor 1986, Driver et al. 1993). The initial rapid rates of depuration that are observed are apparently largely the result of evaporation. For example, at temperatures between $0^{\circ} \mathrm{C}$ and $40^{\circ} \mathrm{C}$ residues are estimated to decline by approximately $30 \%$ to $40 \%$ after 1 hour, and by $80 \%$ to $90 \%$ after 1 week (Driver et al. 1993). Over longer periods, rates of depuration slow as the remaining residues have lower vaporization rates and degradation becomes the primary process of depuration. The most effective weathering processes on fog oil smoke deposits are dew formation, precipitation, evaporation, microbial degradation, and adsorption to surfaces (Driver et al. 1993). Photolysis, or the effects of sunlight on fog oil smoke constituents, is also presumed to be a degradation factor (Posten et al. 1988). Generally, depuration rates increase as surface area and temperature increase. For example, fog oil residue degradation is more rapid on soils with greater porosity (Cataldo et al. 1989). Empirical evidence has shown that depuration of SGF No. 2 from soils can reach $500 \mathrm{~g} / \mathrm{m}^{2} / \mathrm{month}$ during the first few months following application (Raymond et al. 1976). Overall, the depuration rate of fog oil residues from plant and soil surfaces is high due to rapid volatilization from relatively large foliar and other surface areas (Cataldo et al. 1989, Driver et al. 1993).

\section{Environmental Fate and Degradation}

The fate of fog oil smoke residues depends on numerous physical and chemical processes including mass transport, phase transformation, and chemical, photochemical, and biological degradation. Mass transport (e.g., via precipitation) and phase transformation (e.g., via evaporation) processes allow fog oil smoke residues to move between environmental media (e.g., soil, water, air). Yet, extensive redistribution and resuspension of residues is unlikely given the adhesive nature of fog oil. Mass transport could be enhanced if deposition occurred on exposed soils that are prone to wind or water erosion (Driver et al. 1993).

The fate of fog oil residues also depends, in part, on the surface on which it has deposited. In general, fog oil smoke aerosol droplets will persist, absorb, degrade, or evaporate from the surface where it has deposited. If fog oil smoke deposits on water, its components may dissolve, aggregate, sorb to particulates, and/or degrade. Fog oil smoke residues will either be adsorbed by, or persist on plant surfaces, gradually evaporating or degrading. Evaporation of fog oil residues from plant surfaces has been found to be rapid owing to large surface areas (Cataldo et al. 1989). On soil, fog oil deposits will tend to sorb to soil particles, evaporate, and/or undergo degradation (Driver et al. 1993). Hydrocarbons composing fog oil smoke residue are biodegradable and would attenuate over time (Driver et al. 1993). 


\section{Chemical Transformation}

Fog oil smoke constituents may undergo chemical transformations through abiotic and biotic processes (e.g., photolysis, hydrolysis, oxidation, or reduction). This results in either detoxification or creation of secondary toxins, which may be more toxic than the original hydrocarbon constituents. For example, photolytic reactions caused by exposure to sunlight (ultraviolet radiation) can increase the toxicity of certain hydrocarbons in fuel oils, and may also result in the production of chemicals such as aromatic ketones, which have toxic properties different from the original fog oil (Poston et al. 1986). Unfortunately, the production of secondary compounds has not been quantified for fog oil or fog oil smoke. However, as currently specified (MILSPEC 1998) and manufactured, fog oil contains no toxic or carcinogenic constituents. In addition, due to the generation process, fog oil smoke is or can be considered already a secondary compound of fog oil (i.e., SFG No. 2). In general, the only observed transformation of fog oil is the evaporation/volatilization of the lower molecular weight $\left(<\mathrm{C}^{10}\right)$ hydrocarbons (3D/I 1996).

\section{Ecosystem Characterization}

In this section characterizes/summarizes the spatial and temporal distribution of the ecosystem components of concern, as well as elements of life history. What follows is a summary of available information on aspects of red-cockaded woodpecker biology and natural history in relation to their habitat and relevant to potential stressor interaction.

\section{Reproduction: Cooperative Behavior/Nesting Cavities}

The red-cockaded woodpecker has a cooperative breeding system and lives in family groups called clans (Walters 1990, Walters et al. 1988a, Walters et al. 1992). Clans may contain two to nine birds, and are typically composed of a breeding pair and male offspring ("helpers") from previous seasons. In some instances, females may serve as "helpers" (Conner et al. 2001). This cooperative brood rearing strategy has apparently evolved as an approach to increasing survival and ultimately populations through increased clutch size, reduced brood loss, or both (Conner et al. 2001).

Nesting and roosting cavities are commonly excavated in mature pines that have been infected by red heart fungus (Phellinus pini; Jackson 1977, Jackson et al. 1979, Conner and Locke 1982, DeLotelle and Epting 1988, Rudolph and Conner 1991). Although, excavation time averages 6.3 years in longleaf pines (Conner and Rudolph 1995), cavities are used repeatedly and may be occupied by family groups 
for decades (Jackson 1994). Cavities are usually constructed just below the lowest branches, typically at a height of 10 to $13 \mathrm{~m}$ above ground. The horizontal diameter of the cavity entrance tunnel averages $7.1 \pm 1.9 \mathrm{~cm}$ (Jackson 1978). The entrance tunnel angles slightly upward and extends approximately 6 to $9 \mathrm{~cm}$ before connecting with the interior chamber. The interior chamber extends downward 17 to $18 \mathrm{~cm}$ and has a diameter of 9 to $10 \mathrm{~cm}$. Nesting cavities generally open to the west (Ligon 1970, Jackson 1994, Conner and Rudolph 1995).

The loss of cavity trees has been attributed as a primary and continuing cause of decline in red-cockaded woodpeckers (USFWS 2003). To counter the loss (Conner et al. 1991) and scarcity of natural cavities and the conditions that support them, artificial cavities have been developed (Copeyon 1990, Copeyon et al. 1991, Allen 1991, Taylor and Hooper 1991) to mimic, replace, and supplement natural cavities. Although details differ, the different cavity construction methods and approaches are similar enough to natural cavities that their effectiveness in promoting production is recognized. For example, after a $90 \%$ loss of cavity trees attributable to Hurricane Hugo in 1989, the judicious use of artificial cavities has been attributed with preserving population in the Francis Marion National Forest, SC, and contributing to subsequent population growth (Watson et al. 1995). Similarly, increases in redcockaded woodpeckers at Fort Stewart, GA (Table 1, page 11) have been attributed in part to an aggressive artificial cavity management approach.

\section{Breeding/Incubation/Hatching/Parental Care}

Breeding occurs from April through July (Figure 6; see also Jackson 1994). Clutch size ranges from 2 to 5 eggs, but typically 3 to 4 eggs are laid. Females incubate the eggs during the day, with the breeding male usually brooding during the night (Jackson 1994). Therefore, males would appear to have a greater chance of being exposed to fog oil smoke clouds during the nesting season, since training sessions occur almost exclusively during the day. Egg laying typically begins in April with hatching in 10 to 11 days. Fledging occurs at 26 to 29 days and most young fledge by the end of June (Ligon 1970; Figure 6). Most commonly, only a single clutch is laid per season; however, if a clutch or brood is lost early in the season, another may be initiated (LaBranch et al. 1994). Young are altricial at hatching (i.e., blind, immobile, lacking down, and unable to feed themselves). Young are fed by both parents and by helpers. Fledging success, which is defined as the number of fledged young per breeding attempt, is relatively high, ranging from 1.4 to 1.7 among populations (USFWS 2003).

Although reproductive maturity is attained at 1 year, males frequently remain in their natal group for 1 or more years, helping to care for young during the next breeding season (Walters et al. 1988a, Walters et al. 1992). Males may disperse dur- 
ing their first year if roosting cavities are unavailable or if a mate is located. Females normally disperse during their first winter, infrequently remaining as helpers. Mean dispersal distances of fledgling females and males, has been reported as $4.7 \mathrm{~km}$ and $5.4 \mathrm{~km}$, respectively (Walters et al. 1988b). Within a population, not all groups produce nestlings every year. As an average, approximately $10 \%$ of groups do not nest in a given year (USFWS 2003). Red-cockaded woodpeckers are known to have lived at least 12 years in the wild, and captive birds have lived as long as 13 years (Jackson 1994).



Figure 6. Annual cycle of breeding and molt for the red-cockaded woodpecker.

Thick lines represent the most characteristic dates/period for each activity, whereas thin lines represent overall range of dates of when behaviors/activities may occur. Inner line $=$ molt, middle line = rearing young, outer line = egg laying and incubation.

\section{Habitat Use Daily Time Budget/Feeding Behavior}

Red-cockaded woodpecker clans forage up to $2 \mathrm{~km}$ from their cavity trees, but generally forage within $0.8 \mathrm{~km}$ (Jackson 1994). Home range size is dependent on habitat quality, such that poor habitats require larger territories (Jackson 1994). For example, home ranges are often larger than 80 ha (Nesbitt et al. 1978, 1983, Hooper et al.1982, DeLotelle et al. 1983, Bradshaw 1990, Jackson 1990), but may exceed 400 ha in very poor habitat (Jackson 1994). Only portions of the home range are actually used on a daily basis. 
At night red-cockaded woodpeckers roost in cavity trees, but emerge at sunrise (10 minutes before to 20 to 30 minutes after), and return shortly before sunset ( 15 to 40 minutes before). Most of the day is spent foraging or maintaining territorial boundaries. Foraging is generally limited to large pines, but varies with available habitat and season (Ramey 1980). Males tend to forage along the branches and upper-trunk of trees, whereas females more commonly forage on the lower trunk (Porter 1985). The red-cockaded woodpecker forages by probing and peeling off pieces of loose bark from pines to reveal arthropod prey (e.g., wood roaches, beetle larvae, spiders, ants, etc.; Harlow and Lennartz 1977, Hanula and Franzreb 1995, Hess 1997). The red-cockaded woodpecker also consumes some vegetable material (approximately $14 \%$ of diet) including: pine seeds (Pinus spp.), wild cherry (Prunus spp.), pokeweed (Phytolacca Americana), grape (Vitis spp.), magnolia (Magnolia spp.) poison ivy (Rhus toxicodendron), blueberry (Vaccinium spp.) and blackgum (Nyssa sylvatica); Beal et al. 1916, Baker 1971, Hanula et al. 2000b).

\section{Additional Behavioral Attributes}

In general, it appears that birds do not avoid oil-contaminated foods or habitat (Holmes and Cronshaw 1977). This would seem to indicate that birds would be comparatively nondiscriminating in their selection of food items potentially exposed to fog oil aerosol. Beyond that, red-cockaded woodpeckers possess certain behavioral characteristics that may influence the likelihood and magnitude of their exposure to fog oil aerosols and residues. For example, the species is tolerant of (or habituates to) smoke from forest fires, anthropogenic noise, and physical disturbances such as generator vehicles, soldier movements, wheeled or tracked vehicles, helicopters, and simulated and real artillery and small arms fire (Delaney et al. 2002, Hayden et al. 2002). Therefore, it appears likely that individuals would not be inclined to actively avoid fog oil smoke clouds or the activities associated with exercises. The species' sociality (i.e., group foraging and nesting) is not expected to affect the magnitude or probability of exposures for any one woodpecker, but it may lead to simultaneous exposure in several individuals.

\section{Climactic Conditions}

The red-cockaded woodpecker occurs in the Piedmont and Coastal Plain physiographic provinces of the southeastern United States. This region has long growing seasons (240 to 330 days), hot summers, mild winters, high humidity, and abundant annual precipitation (Martin and Boyce 1993). Mean daily temperatures are between $0^{\circ} \mathrm{C}$ and $18^{\circ} \mathrm{C}$ in the coldest month and greater than $22^{\circ} \mathrm{C}$ in the warmest month. Although monthly means suggest that precipitation is evenly distributed throughout the year, annual variation in rainfall is extremely important in determining availability of water during the growing season. In general, spring and fall 
tend to be drier seasons than winter, when precipitation is a consequence of frontal storms, and summer when precipitation is a consequence of convective storms (Martin and Boyce 1993). Under the natural regime fires occur regularly (lightning strikes ignite summer fires every 3 to 5 years) in the pyroclimax forests inhabited by the red-cockaded woodpecker.

\section{Role of the Ecosystem in Affecting Stressor Fate and Distribution}

The fate and distribution of fog oil smoke aerosol in the environment is affected by climate and weather conditions. For example, the warm summers and relatively mild winters found in the red-cockaded woodpeckers' historic range may enhance evaporation of fog oil aerosols, and thereby potentially limit deposition rates. Local climatic conditions can also be particularly important in determining depuration rates, which will affect rates of exposure. The southeast receives abundant rainfall, which will enhance depuration of fog oil from environmental surfaces by providing conditions appropriate for microbial degradation and weathering. Rainfall may also transport residues from the surface of vegetation to soils. Any accumulated residues on groundcover vegetation would also be removed by periodic fires. Rapid depuration of fog oil smoke residues would decrease the probability that red-cockaded woodpeckers suffer from ingestion and secondary contact exposure.

\section{Exposure Analyses}

Exposure is influenced by a set of numerous and often stochastic interactions between the stressor and ecosystem of concern. For example, the duration, frequency, timing, location, and scale of training exercises using fog oil obscurant smoke all influence the likelihood and magnitude of exposure. Equally important in affecting exposure are characteristics of the red-cockaded woodpecker such as life stage, behavioral attributes, activity patterns, and sensitivity. Exposure analysis focuses on the spatial and temporal distributions of the stressor and the ecological components of concern, as exposure is primarily determined by co-occurrences in these distributions.

Exposure to fog oil obscurant smoke aerosols is limited to military training events when fog oil smoke generation is employed. Employment of fog oil smoke generation in or as part of training exercises does not necessarily occur in each training exercise or at every, or even most, red-cockaded woodpecker habitat sites. Furthermore, although fog oil obscurant smoke generation is permitted (in accordance with standard training guidelines) in close proximity to supplemental recruitment clusters, it is not allowed within a buffer zone (200 ft) of delineated, marked active clusters, primary recruitment clusters, and/or cavity trees (U.S. Army 1996b, Hayden 
1997a). Concurrently, within marked cavity tree buffer zones, all military training is limited to activity of a transient (less than 2 hours occupation) nature. Given the potential broad area of coverage of fog oil obscurant smoke dispersal and the rela-

tively widespread distribution of clusters and cavity trees on Army installations, it is impractical, if not impossible to prevent fog oil obscurant smoke, generated outside the buffer, from dispersing into buffer zones. However, Army red-cockaded woodpecker management guidelines only allow fog oil and other obscurant smoke infiltration into buffer zones at a "haze level" of obscurance. Army red-cockaded woodpecker management protocols, guidance, and installation Integrated Natural Resources Management Plans prepared in accordance with Federal military lands and natural resources management and conservation requirements (Sikes Act, U.S. Army 1995) do not allow for the generation of fog oil obscurant (or other smoke) within designated buffer zones (U.S. Army 1996b).

With this background, red-cockaded woodpeckers may still potentially be exposed to some level of fog oil smoke and fog oil smoke residues via several pathways (Figure 5 , page 32). Because thorough examination of every possible pathway is neither practical nor possible, concentrating the exposure analysis on the worst-case scenarios helps develop a focused risk assessment. Furthermore, if these worst-case scenarios are found to pose no significant risk of exposure, then scenarios that are less probable or presumably less harmful can be assumed to be innocuous (pose no significant risk).

This exposure analysis will focus on those specific scenarios judged to have the greatest probability of actually occurring, and thus have the greatest potential to impact red-cockaded woodpecker survival, reproduction, and habitats. Specifically, this analysis examines: (1) the acute exposure of adult birds to fog oil aerosols at locations near the generator for an extended period ( $<100 \mathrm{~m}$ for $\geq 2 \mathrm{hrs}$ ), (2) the acute exposure of eggs/nestlings to fog oil smoke aerosol within the nesting cavity, and (3) the exposure of soils, vegetation, and prey items to fog oil smoke residues.

The red-cockaded woodpecker may be exposed to fog oil and/or fog oil smoke through three primary routes: inhalation, ingestion, and dermal contact/absorption. Our analysis of exposure will be structured around these three routes.

\section{Inhalation Exposure}

Terrestrial vertebrates have functionally comparable respiratory systems that allow for gas exchange. There are however differences among vertebrate groups. For example, the mammalian lung allows for more of a tidal flow of oxygen in and out of the blind ending bronchial tubes. In avian species the elimination of blind ending tubes within the avian lung and their replacement by branching parabronchi and 
air capillaries, coupled with the development of air sacs, allows birds to continuously suffuse air through the branching airways of the lung. The blood-gas barrier in birds is much thinner to allow greater efficiency in the transfer of gases and to support generally higher metabolic rates. These processes allow for a higher efficiency of gas exchange in birds and are a characteristic of the group.

\section{Adult and Fledgling Exposure}

The exposure pathways for inhalation consist of exposure to a fog oil smoke plume in flight, exposure to the plume while at rest or when perched, or exposure when in the nest cavity. During flight, respiration rates are greater than those at rest, which would increase the rate of exposure for the birds in flight. In flight, exposure would vary with location of flight area in relation to the smoke plume. Flight directly into the plume seems likely due to the bird's tolerance to smoke from forest fires (Conner et al. 2001). Birds have been seen traveling through smoke plumes. Flight through home ranges during military training exercises is also likely, although apparently no more likely than during other periods (Hayden et al. 2002). In part because of the adherence to Army red-cockaded woodpecker management guidelines (U.S. Army 1996b), fog oil smoke concentration and dispersion is less through forested stands that the red-cockaded woodpecker normally uses. Exposure at rest also depends on location. Resting inside the cavity would give the birds, particularly fledglings, lower exposure levels compared to resting outside the cavity. American robins are similar in size $(22 \mathrm{~cm}$ and 70 to $90 \mathrm{~g})$ to the red-cockaded woodpecker (USEPA 1993). Overall inhalation rates for adult American robins are considered to be $.041 \mathrm{~m}^{3} /$ day (3D/I 1997, USEPA 1993).

\section{Nestling Exposure}

Exposure of nestlings to aerosolized fog oil is through one route, penetration into the nest cavity. Nestlings spend their time at the bottom of their nest cavities (Figure 6, page 32), as do adults during egg laying, incubation, and brooding periods (Jackson 1994). Guelta and Checkai (2001) have reported on the amount of fog oil smoke entering natural and artificial cavities (such as used on military installations and throughout the red-cockaded woodpecker range to supplement natural cavities) under laboratory conditions. The amount of penetration depends in part on the orientation of the cavity to the fog oil smoke release. In cavities at 0,90 and 180 degrees to the release point, fog oil smoke that entered the cavity varied from approximately $61 \%$ to $94 \%$ of the outside concentration. These data indicate that fog oil obscurant smoke will enter red-cockaded woodpecker nest cavities and can be viewed as maximum levels expected. Under field conditions of fog oil smoke release, wind velocity, distance from the source, and the elevated location of the cavity in relation to the release point can be expected to reduce the amount of fog oil smoke 
entering the cavity. Under simulated field fog oil smoke release conditions, Driver et al. (2002b) reported that the maximum fog oil smoke aerosol concentration in nest cavities was $73 \%$ to $75 \%$ of the outside concentration. Also under simulated field fog oil smoke release conditions, the concentration of fog oil smoke in nest cavities required 30 to 50 minutes to reach $90 \%$ of the stable concentration in the cavity. Apparently, it takes some time to reach maximum concentration in nest cavities. Additionally, no differences in fog oil aerosol concentrations were detected between natural and artificially constructed cavities (Copeyon 1990, Copeyon et al. 1991, Allen 1991, Taylor and Hooper 1991).

With fog oil smoke concentrations in both natural and artificial nest cavities at less than ambient concentrations outside of nest cavities, the potential for nestling exposure to fog oil smoke aerosols is somewhat reduced.

\section{Ingestion Exposure}

\section{Adult and Fledgling Exposure}

Ingestion exposure is possible via two routes: consumption of contaminated prey or water and during preening. Exposure during preening depends on fog oil aerosol deposition on red-cockaded woodpecker plumage, which requires that birds remain within a fog oil smoke cloud for sufficient period and that fog oil aerosols deposit on their feathers. Given the relatively rapid evaporation rates of residues (Driver et al. 1993), preening would have to occur shortly after deposition. Driver et al. (2002a) have reported that actual levels of fog oil aerosol deposition on feathers is in the nanogram range, so the opportunity for fog oil smoke ingestion from preening seems minimal.

Exposure during consumption is possible as a result of direct deposition of fog oil smoke residues on arthropods or other prey or subsequent transfer of fog oil smoke residues on arthropods from the surfaces that the prey come into contact with, drinking water, or through bioaccumulation and transfer of fog oil constituents in the food chain (i.e., arthropods). Red-cockaded woodpeckers forage to a large degree on the boles and branches of pines. During foraging, red-cockaded woodpeckers typically remove or pry away loose bark with their bill or feet to reveal insect and other arthropod larvae, pupae, and adults (Bent 1992, Jackson 1994). Given the extremely high proportion of arthropods in the diet of nestlings (Hanula et al. $2000 \mathrm{~b}$ ) foraging on trees by adults is probably almost exclusive during that part of the life cycle. Some arthropods (e.g., ants, Psocoptera, spiders) are resident species associated with pine bark, while other important arthropods either crawl up or fly to their pine bark habitat from the forest floor detritus or other vegetation (Hanula and Franzreb 1998). Whether living on pine trees or moving there from other habi- 
tats, arthropods in all life stages tend to remain hidden and therefore are less likely to be exposed to fog oil smoke aerosols. When considering insect diets, the digestive efficiency of birds is approximately 70\% (Levey and Karasov 1989). Thus, not all fog oil smoke residues associated with arthropod prey would be available to or metabolized by red-cockaded woodpeckers.

Free water demand by red-cockaded woodpeckers is seemingly low and moisture needs are apparently satisfied by that obtained from arthropod and fruit foods (USFWS 2003).

\section{Nestling Exposure}

Pathways for exposure through ingestion for nestlings are the same as for adults and fledglings. However, ingestion exposure due to preening activities would be practically nonexistent because of the comparative lack or scarcity of feathers during the nestling stage. Fledging does not occur until approximately 26 days or more after hatching (Ligon 1971, USFWS 2003). Retrices (flight feathers) are typically not fully emerged from their sheaths at fledging and fledglings may remain partially dependant on their parents for 2 to 5 months after hatching (Jackson 1983, 1994). Exposure is possible through ingestion of fog oil smoke residues on arthropod and other food items coupled with theoretical bioaccumulation in the food chain. Ingestion exposure would almost exclusively be through ingestion of insects since little plant material is offered to nestlings (Hanula et al. 2000b, Hanula and Engstrom 2000).

\section{Contact Exposure}

Contact exposure of all life stages of red-cockaded woodpeckers could occur with direct exposure of feathers or dermal or other body surfaces (e.g., mouth, eye, nasal) with fog oil smoke aerosols or residues.

\section{Adult and Fledgling Exposure}

Excessive exposure of feathers to petroleum compounds can cause a loss of thermoregulatory ability and result in death (Bourne 1968). This phenomenon is almost exclusively limited to aquatic and marine birds (Rocke 1999). In red-cockaded woodpeckers, thermoregulatory ability begins about 4 days after hatching and is well developed by days 13 to 15 (Jackson 1994).

For adults and fledgling red-cockaded woodpeckers, given the comparatively small area of eyes, bill, legs, and feet, opportunity for direct dermal contact with fog oil smoke appears to be minimal. However, ocular surfaces would be exposed during 
flight through fog oil smoke plumes and feet could come into contact with fog oil smoke residues that may be present on tree trunks and branches.

Red-cockaded woodpeckers show a preference for larger live pines as foraging areas (Hooper and Lennartz 1981, Porter and Labisky 1986, Bowman et al. 1997) but dying and recently dead pines can be important also (Ligon 1968, Hooper and Lennartz 1981, Bowman et al. 1997). Additionally, males more commonly forage on dead branches on the crowns of trees, while females more commonly forage on the trunk (Ligon 1970, Hooper and Lennartz 1981, Engstrom and Sanders 1997, Hardesty et al. 1997). Differences in potential fog oil smoke residue contact exposure to male and female red-cockaded woodpeckers as well as between old, young, live, or dead pines is unknown but probably inconsequential.

\section{Nestling Exposure}

For unfeathered or sparsely feathered nestlings, the potential for dermal contact exposure with fog oil smoke aerosols exists if fog oil smoke enters nesting cavities. However, brooding of the hatchlings is nearly constant for the first 4 days after hatching, decreases in duration and frequency until about day 10, and may continue at night until just prior to fledging (Jackson 1994). Thus, adults would physically shield hatchlings from deposition of fog oil obscurant smoke for a substantial part of their early life. Additionally, while the young remain in the bottom of the nest cavity until about 15 days after hatching, during the last 3 to 5 days the nestlings will begin clinging to and climbing the nest cavity walls (Jackson 1994). Although fog oil smoke aerosol may enter nest cavities, the amount actually contacting exposed nestlings is reduced from outside concentrations (Guelta and Checkai 2001, Driver 2002b). In addition, any potential nestling dermal exposure would be limited to approximately the first 2 weeks after hatching since erupted feathers cover much of the body surface by 16 days after hatching (USFWS 2003). The eyes of nestlings do not open until about 10 days after hatching (Jackson 1994) therefore ocular contact exposure cannot occur before that time.

Driver et al. (2002b) reported average fog oil smoke aerosol deposition on the floor of

the exposure chamber as $5.9 \mathrm{ng} / \mathrm{cm}^{2}$. Assuming a $25 \%$ reduction in the amount of fog oil smoke deposition on a nest cavity floor based on a similar reduction in fog oil smoke aerosol concentration in the atmosphere in a nest cavity (Guelta and Checkai 2001, Driver 2002b), deposition on nestlings can be estimated at $4.4 \mathrm{ng} / \mathrm{cm}^{2}$. 


\section{Egg Exposure}

The avian embryo is contained in a virtual closed system from the time of laying until it is hatched, which for the red-cockaded woodpecker lasts 10 to 13 days (Jackson 1994). Both parents incubate with incubation usually beginning after the second egg is laid (a clutch generally contains 2 to 4 eggs) with the eggs therefore hatching at different intervals (Ligon 1970). Not all eggs hatch, and some nestlings, generally the youngest, die in the nest (USFWS 2003). Because incubation is a more or less continuous activity, there is little likelihood of substantial exposure while the parents are incubating. Additionally, Army red-cockaded woodpecker management guidelines (U.S. Army 1996b) prohibit any fog oil smoke generation within $200 \mathrm{ft}$ of known cavity trees.

Driver et al. (2002b) measured fog oil deposition on eggs of northern bobwhite (Colinus virginianus) in red-cockaded woodpecker nest cavities under simulated field fog oil smoke release conditions. After 30 minutes of exposure to fog oil smoke at over $300 \mathrm{mg} / \mathrm{m}^{3}$, the amount deposited to egg surfaces was extremely small (i.e., average $70.6 \mathrm{ng} / \mathrm{egg}$ ), and in over $90 \%$ of samples was found to be undetectable.

\section{Other Behavioral Factors}

When characterizing exposure it is important to consider how the stressor may affect the behavior of the ecological components of concern, thereby influencing the magnitude or likelihood of exposure. For example, increased preening is common in oil-soaked birds. If fog oil smoke aerosol settles on avian feathers and induces increased preening behavior, individuals may experience elevated rates of ingestion exposure. Another example of how fog oil smoke may indirectly influence exposure is if insects exposed and/or contaminated by fog oil smoke have an increased probability of being consumed by red-cockaded woodpeckers. On the other hand, it is also possible that contaminated insects may be consumed with less frequency, due to reduced palatability or mortality induced by fog oil smoke and the consequent reduced availability.

For the red-cockaded woodpecker there is no information to suggest that behaviorally the species is inordinately susceptible to fog oil smoke aerosol exposure.

\section{Exposure Profile}

The exposure profile presented in Table 8 is a summary and compilation of identified fog oil smoke exposure levels for the red-cockaded woodpecker and its habitat. The profile identifies and takes into account red-cockaded woodpecker habitat at- 
tributes and component exposure pathways that contribute to or are integral to redcockaded woodpecker ecology. The profile also identifies exposure pathways for redcockaded woodpecker life stages.

Exposure to fog oil smoke residues through direct or indirect soil, water, vegetation/leaf, bark, and insect food pathways appears minimal. When compared with concentrations of fog oil components in soil samples collected at reference and control sites, concentrations of fog oil components detected in soil, water, vegetation/leaf, bark, and insect samples collected at military fog oil smoke exposed sites were either non-existent, lower, and/or not of concern (3D/I 1996). For the redcockaded woodpecker the most important exposure pathways are those that may bring fog oil smoke aerosols into direct contact with the individual, specifically dermal, ingestion, and inhalation routes.

The exposure levels presented were derived from the identified sources. As indicated previously, information and data on ecological impacts and effects of fog oil smoke is limited. Nonetheless, the summary presented represents an interpretation of available information. Incorporating information from the exposure analysis, the exposure profile quantifies the magnitude and spatial and temporal patterns of exposure for the scenarios developed during the problem formulation stage (Figure 5, page 32) and serves as input to the risk characterization (Norton et al. 1993).

Table 8. Fog oil smoke aerosol exposure profile.

\begin{tabular}{|c|c|c|c|}
\hline Parameter & Contact & Ingestion & Inhalation \\
\hline Soil $^{A}$ & $308 \mathrm{mg} / \mathrm{m}^{2}$ & NA & NA \\
\hline Ground vegetation $^{\mathrm{A}}$ & $2772 \mathrm{mg} / \mathrm{m}^{2}$ & NA & NA \\
\hline $\begin{array}{l}\text { Tree boles, } \\
\text { horizontal perches }^{\mathrm{A}}\end{array}$ & $770 \mathrm{ng} / \mathrm{m}^{2}$ & NA & NA \\
\hline Arthropods $^{\mathrm{A}}$ & $154 \mathrm{ng} / \mathrm{m}^{2}$ & $>154 \mathrm{ng} / \mathrm{m}^{2}$ & $>154 \mathrm{ng} / \mathrm{m}^{2}$ \\
\hline $\mathrm{Egg}^{\mathrm{B}}$ & 71 ng/egg & NA & 71 ng/egg \\
\hline Hatchling & $4.4 \mathrm{ng} / \mathrm{cm}^{2 \mathrm{C}}$ & $96 \mathrm{mg} / \mathrm{kg}^{\mathrm{E}}$ & $450 \mathrm{mg} / \mathrm{m}^{3 \mathrm{~B}}$ \\
\hline Fledgling & $1.3 \mathrm{ng} / \mathrm{g}^{\mathrm{E}}$ & $96 \mathrm{mg} / \mathrm{kg}^{\mathrm{E}}$ & $450 \mathrm{mg} / \mathrm{m}^{3 \mathrm{~B}}$ \\
\hline Adult & $1.3 \mathrm{ng} / \mathrm{g}^{\mathrm{E}}$ & $96 \mathrm{mg} / \mathrm{kg}^{\mathrm{D}}$ & $400 \mathrm{mg} / \mathrm{m}^{3 \mathrm{D}}$ \\
\hline \multicolumn{4}{|c|}{$\begin{array}{l}{ }^{A} \text { Derived from Getz et al. } 1996 . \\
{ }^{B} \text { Driver et al. 2002b. } \\
{ }^{C} \text { Derived from Driver et al. 2002b. } \\
{ }^{D} \text { Driver et al. 2002a. } \\
{ }^{E} \text { Derived from Driver et al. } 2002 a .\end{array}$} \\
\hline
\end{tabular}




\section{Stressor-Response Profile}

In the evaluation of ecological risk the relationships between the stressor and ecosystem or organism and their responses must be understood. In the case at hand, the issue is the exposure of red-cockaded woodpeckers and their habitats to military fog oil smoke obscurants and any resultant responses, impacts, and/or effects. As indicated previously, data and information on avian responses (i.e., physiological, biological, ecological) due to exposure to fog oil and fog oil smoke aerosol obscurants is somewhat limited. Nonetheless, as derived from surrogate species studies for the red-cockaded woodpecker and fog oil smoke obscurant exposure, response levels and parameters can be estimated or identified (Table 9).

Table 9. Response levels of red-cockaded woodpeckers and red-cockaded woodpecker surrogates to exposure to fog oil or fog oil smoke aerosol.

\begin{tabular}{|c|c|c|c|}
\hline Lethal concentration $_{50}\left(\mathrm{LC}_{50}\right)^{\mathrm{A}}$ & \multicolumn{3}{|l|}{ Not known } \\
\hline Lethal dose ${ }_{50}\left(L_{50}\right)^{B}$ & \multicolumn{3}{|l|}{ Not known } \\
\hline Effective concentration $_{50}\left(\mathrm{EC}_{50}\right)^{\mathrm{C}}$ & \multicolumn{3}{|l|}{ Not known } \\
\hline \multirow{2}{*}{$\begin{array}{l}\text { Lowest Observed Adverse Effect Level } \\
(\text { LOAEL })^{D}\end{array}$} & \multicolumn{3}{|c|}{ See Table 10} \\
\hline & Contact & Ingestion & Inhalation \\
\hline \multicolumn{4}{|c|}{ No Observed Adverse Effect Level (NOAEL) ${ }^{\mathrm{E}, \mathrm{F}}$} \\
\hline Egg & 71 ng/egg & -- & -- \\
\hline Hatchling & $4.4 \mathrm{ng} / \mathrm{cm}^{2}$ & $96 \mathrm{mg} / \mathrm{kg}$ & $450 \mathrm{mg} / \mathrm{m}^{3}$ \\
\hline Fledgling & $4.4 \mathrm{ng} / \mathrm{cm}^{2}$ & $96 \mathrm{mg} / \mathrm{kg}$ & $450 \mathrm{mg} / \mathrm{m}^{3}$ \\
\hline Adult & $1.3 \mathrm{mg} / \mathrm{g}$ & $96 \mathrm{mg} / \mathrm{kg}$ & $400 \mathrm{mg} / \mathrm{m}^{3}$ \\
\hline \multicolumn{4}{|l|}{ Toxicity Reference Values $^{G}$} \\
\hline adult (chronic) & $0.13 \mathrm{~g} / \mathrm{kg}$ & $0.014 \mathrm{~g} / \mathrm{kg}$ & $0.000625 \mathrm{~g} / \mathrm{m}^{3}$ \\
\hline adult (acute) & $1.4 \mathrm{~g} / \mathrm{kg}$ & $1.10 \mathrm{~g} / \mathrm{kg}$ & $3.75 \mathrm{~g} / \mathrm{m}^{3}$ \\
\hline \multicolumn{4}{|c|}{$\begin{array}{l}\text { A Concentration of a substance that is estimated to be lethal to } 50 \% \text { of the test organisms over a specific } \\
\text { period of time. } \\
B \text { Dose of a substance that causes mortality in } 50 \% \text { of the organisms tested over a specific period of time. } \\
\text { C The concentration of a substance that is estimated to cause a toxic effect in } 50 \% \text { of the test organisms. } \\
\text { D The lowest dose (or concentration) in a toxicity test or biological field survey that causes a statistically } \\
\text { significant adverse effect. }\end{array}$} \\
\hline
\end{tabular}


A method of describing or quantifying toxicity is through consideration of the lowest levels or concentration where effects are observed (LOAELs) ${ }^{*}$ and/or those levels or concentrations where no adverse effect or modification was observed (NOAELs) ${ }^{\dagger}$. Another means of describing or profiling exposure assessment and toxicity is the use of toxicity reference values or TRVs. TRVs are numerical expressions of exposure-response relationships (USEPA 1997a) derived from available toxicity data for a particular stressor, with considerations of uncertainty included, and can be used to generate an estimated NOAEL (3D/I 1997). The TRVs shown in Table 9 were derived from fog oil smoke exposure investigations relative to the American robin. Because of general similarities and comparability to the red-winged blackbird (3D/I 1997, USEPA 1993), the American robin can also be considered a suitable surrogate for the red-cockaded woodpecker. While the NOAELs, and TRVs shown in Table 9 were derived in different studies, they nonetheless appear to be in reasonable agreement with each other.

\section{Evaluation of Relevant Effects Data}

Data and information on the effects and impacts of fog oil smoke obscurant on redcockaded woodpecker surrogates are presented in Tables 7 (page 26) and 9. Because NOAEL and LOAEL values typically are obtained or estimated by hypothesis testing, the actual proportion of the test organisms showing an adverse response depends on the sample size, variability of response, and the exposure and/or dose interval. For this reason, it has been recommended that the more conservative NOAELs be used to determine exposure levels that are unlikely to adversely affect receptor populations (i.e., red-cockaded woodpeckers; USEPA 1997a). If NOAELs are unavailable a standard practice is to multiply the LOAEL by 0.1 and apply or use that value as a NOAEL. This practical convention originates from a review of data indicating that all of the chemicals included in that review that had LOAEL/NOAEL ratios of 10 or less (Dourson and Stara 1983, USEPA 1997a). Applying this approach in reverse, LOAEL values for the red-cockaded woodpecker are presented in Table 10.

\footnotetext{
* Lowest observed adverse effect level (LOAEL). The lowest level of a stressor evaluated in a test that causes statistically significant differences from the controls (Suter et al. 2001).

$\dagger$ No observed adverse effect level (NOAEL). The highest level of a stressor evaluated in a test that does not cause statistically significant differences from the controls (Suter et al. 2001).
} 
Table 10. Calculated lowest adverse effect levels of fog oil smoke aerosol on the red-cockaded woodpecker (derived from Table 9).

\begin{tabular}{|l|l|l|l|}
\hline & Contact & Ingestion & Inhalation \\
\hline Egg & $710 \mathrm{ng} / \mathrm{egg}$ & -- & -- \\
\hline Hatchling & $44 \mathrm{ng} / \mathrm{cm}^{2}$ & $.96 \mathrm{~g} / \mathrm{kg}$ & $4.5 \mathrm{~g} / \mathrm{m}^{3}$ \\
\hline Fledgling & $44 \mathrm{ng} / \mathrm{cm}^{2}$ & $.96 \mathrm{~g} / \mathrm{kg}$ & $4.5 \mathrm{~g} / \mathrm{m}^{3}$ \\
\hline Adult & $13 \mathrm{mg} / \mathrm{g}$ & $.96 \mathrm{~g} / \mathrm{kg}$ & $4.0 \mathrm{~g} / \mathrm{m}^{3}$ \\
\hline
\end{tabular}

The NOAELS presented in Table 9 were generally derived from single-exposure or relatively short-term (i.e., acute) studies. Although data and information from longer-term (i.e., chronic) studies are preferred, the data and information used in this ecological risk assessment are those that are available.

\section{Ecological Response Analyses}

The intent of ecological response analysis is to identify and quantify the stressorresponse relationship and to evaluate the evidence for causality. To be meaningful, the cause and effect relationship and/or relationships between the contaminant/stressor (i.e., fog oil smoke obscurant) and the receptor/endpoint (i.e., redcockaded woodpecker) must be established.

As reiterated throughout this ecological risk assessment, the information available relative to impacts and effects of fog oil smoke obscurant on avian species is derived from fog oil smoke exposure studies of surrogate red-winged blackbirds and house sparrows (Driver et al 2002a, 2002b, 2004), which, based on physical, physiological, behavioral, and other parameters (e.g., size, environmental sensitivity, altricial development), are deemed comparable to the red-cockaded woodpecker. In those investigations, red-cockaded woodpecker surrogates, eggs, and nesting cavities were exposed to $50 \mathrm{mg} / \mathrm{m}^{3}$ and $100 \mathrm{mg} / \mathrm{m}^{3}$ of fog oil smoke, which is typical of observed military training field concentrations. Surrogates, eggs, and nesting cavities were also exposed to fog oil smoke concentrations of from $300 \mathrm{mg} / \mathrm{m}^{3}$ to $400 \mathrm{mg} / \mathrm{m}^{3}$ and $450 \mathrm{mg} / \mathrm{m}^{3}$, which are levels present only in proximity to a source generating fog oil obscurant smoke.

These studies reported:

- no mortality attributable to exposure to aerosolized fog oil;

- no behavioral indications (e.g. fluffed feathers, increased feeding) of adverse effects of exposure to aerosolized fog oil; 
- no signs of respiratory stress (e.g., respiratory rate) due to exposure to aerosolized fog oil;

- no significant negative physiological indications or clinical toxicity (e.g., muscular atrophy, depleted body fat, changes in weight of internal organs [e.g., spleen]) attributable to exposure to aerosolized fog oil;

- no gross histopathological lesions (e.g., lymphoid nodules, inflammation) or toxic indications of exposure to aerosolized fog oil;

- no observed long-term organ dysfunction due to exposure to aerosolized fog oil;

- no immunomodulation or immunosuppression due to exposure to aerosolized fog oil;

- no reduction in hatching success due to exposure to aerosolized fog oil;

- no reduction in fledgling success due to exposure to aerosolized fog oil; and

- no reduction in fledging survival due to exposure to aerosolized fog oil (Table 5, page 16). 


\section{Risk Characterization}

Risk characterization is the final phase of ecological risk assessment. During this phase, the likelihood of adverse effects occurring as a result of exposure to a stressor is evaluated (Norton et al. 1993, USEPA 1998, Suter et al. 2001). Risk characterization contains two major steps: risk estimation and risk description in terms of the assessment endpoints. Risk characterization integrates data and information on stressor-exposure and receptor-response relationships and results in an estimate(s) of the likelihood and/or severity of possible adverse effects of exposure. Risk characterization also can include an "analysis" of uncertainty and the presentation of conclusions.

\section{Risk Estimation}

\section{Risk Estimation Approaches}

A number of approaches have been identified to characterize and/or estimate risk (USEPA 1998, Simini et al. 2000, Suter et al. 2001). Major ecological risk estimation and/or characterization approaches can be classified broadly as the (1) hazard quotient, (2) probabilistic, and (3) lines of evidence methods.

The hazard quotient risk assessment approach uses estimates or measurements of presumed or estimated concentrations to known or extrapolated levels of toxicant or other stressors (Simini et al. 2000). Hazard quotients generally are derived by dividing measured or estimated (e.g., modeled) exposure level (i.e., the estimated/measured exposure concentration) by the concentration corresponding to an acceptable level of risk or the toxicological endpoint concentration (e.g., LOAEL, NOAEL, or other level ; USEPA 1997a). The hazard quotient method typically is employed to estimate the possibility of an adverse effect from a single exposure to a specific receptor at a given site. The hazard quotient method results in a single number or point estimate. That number, which is the ratio or quotient of the expo-

\footnotetext{
* When using dose instead of site concentrations, the estimated/measured exposure concentration is the dose corresponding to an acceptable level of risk and the toxicological endpoint is a TRV.
} 
sure value to the effect value, provides a relative estimate of risk. Generally, ratios of estimated/measured exposure concentrations to toxicological endpoint concentrations greater than 1.0 are considered indicative of potential risk.

The probabilistic risk assessment approach, rather than using a single point(s) as in the hazard quotient method, uses statistical distributions of data to model distributions of concentrations, exposure, effects, or other parameters (e.g., hazard quotients; USEPA 1997b). Ecological risk can then be quantified by the overlap between dose and response distributions with greater overlap indicating greater ecological effect. With the advent of enhanced computational software capabilities, probabilistic risk assessment applications are more easily approached. However, the theoretical distributions generated are models in and of themselves and not necessarily a totally complete reflection of actual conditions. Certainly the assumed distributions can be considered to increase or introduce elements of uncertainty.

The lines of evidence approach (USEPA 1998) can be described as relating multiple or different sources of data and information to estimate ecological risk. Different and diverse data and information can be appraised and integrated so that a weight of evidence evaluation (Suter et al. 1993, Simini et al. 2000) can be made. In this instance, rather than modeling possible effects or risk as is the case with strictly hazard quotient and probabilistic approaches, available data from all sources are evaluated and used to estimate the likelihood of significant effects occurring that are attributable to the stressor. This is the approach used in this ecological risk assessment.

\section{Integration of Exposure and Ecological Characterizations and Exposure-Stressor Response}

Red-cockaded woodpecker populations are present on nine Army installations, ranging broadly across the southeastern part of the country from North Carolina to Louisiana (Table 1, page 11). Red-cockaded woodpecker populations on Army installations have been identified as important to species recovery and ultimate removal from Endangered Species Act protection. The species is nonmigratory and inhabits mature open pine forests. This habitat type (i.e., mainly pyroclimax longleaf pine) has been reduced to only a small percentage of its original pre-settlement extent. Thus, the overriding threat to the species and the greatest impediment to its recovery is the lack of suitable habitat.

Red-cockaded woodpeckers live in family groups and have a cooperative breeding system where non-breeding birds (i.e., "helpers") assist with brood rearing. Breeding and brood rearing occurs from April through July with nesting occurring in natural or artificial cavities at suitable sites. Red-cockaded woodpeckers are pri- 
marily insectivorous, generally foraging on branches and trunks of large pines, usually within $0.8 \mathrm{~km}$ of their cavity trees. Daytime is spent foraging (for self or broods) or maintaining home range and territorial boundaries. At night, birds roost in cavities. Red-cockaded woodpeckers are tolerant of smoke from prescribed and natural fires, as well as human-induced noise and disturbance such as that produced by or resulting from Army training activities (e.g., fog oil smoke generator and tracked vehicles, small arms fire, aircraft; Delaney et al. 2002, Hayden et al. 2002).

Currently produced and utilized parent fog oil is best characterized and described as a refined mineral oil with no carcinogenic constituents or potentially carcinogenic effects. Fog oil smoke obscurant is an aerosol mist (droplets nominally 0.9 to $1.9 \mu \mathrm{m}$ in size), produced by heating fog oil in a movable-mobile (e.g., vehicle-mounted) chamber and ejecting it in Army and other military training and testing scenarios. The resulting concentration of fog oil smoke aerosols in the atmosphere is dynamic and varies with local atmospheric, terrain, and training or testing protocols. Typical and representative field concentrations of fog oil smoke are approximately 50 to $100 \mathrm{mg} / \mathrm{m}^{3}$. Generated fog oil smoke clouds are variable in size, with a reasonable estimated average size being $1000 \mathrm{~m}$ by $1000 \mathrm{~m}$. The vertical extent of fog oil smoke clouds is also variable, with higher concentrations being closer to ground level. Fog oil smoke aerosol deposition and deposition rates decline with distance from the generation source. Fog oil smoke residues degrade over time via natural biotic and abotic processes. Additionally, fog oil smoke aerosols evaporate, diffuse, and otherwise dissipate rapidly (i.e., <30 minutes) at normal temperatures.

Fog oil utilization and resultant fog oil smoke generation is variable. As a generalization, on a given Army installation, training exercises involving fog oil smoke obscurant are conducted sporadically, six to eight times a year. Those training exercises typically last a week or less and during that period fog oil smoke is generated about four times, most often less than 1 hour for each event. A fog oil smoke generator typically uses approximately 50 gallons of fog oil, during a typical 1-hour training event. Fog oil smoke obscurant is deployed and used by the Army worldwide. However, there are only eight Army installations where red-cockaded woodpecker occurrence and potential fog oil obscurant smoke training or testing coincide. Four of those installations have major primary core red-cockaded woodpecker populations with the others having "secondary" but nonetheless important support populations.

Little data and information are available on the impacts and effects of fog oil smoke on the naturally occurring biologic components of ecosystems, including wildlife. Fog oil exposure and potential toxicity is not necessarily comparable to or the same 
as fog oil obscurant smoke exposure and potential toxicity. Physical and chemical changes may take place in fog oil during smoke generation and subsequent to release to the atmosphere. The available data and information indicate that at least under typical generation and release conditions, fog oil smoke has little if any identifiable impact or effect on vegetation, soil or other microbes, and invertebrates. In three separate focused fog oil smoke obscurant exposure studies of multiple surrogate species for the red-cockaded woodpecker in simulated field conditions, and with fog oil smoke exposures of up to $450 \mathrm{mg} / \mathrm{m}^{3}$, researchers observed no mortality; no reduced adult, fledgling, or hatchling success, and survival; and no negative behavioral, physiological, immuninological, or other effects attributable to fog oil smoke exposure (Driver et. al 2002a, 2002b, 2004). In a related predictive assessment and investigation involving the American robin, no acute or identifiable chronic toxicological effects attributable to fog oil smoke exposure from Army fog oil smoke training and testing events were anticipated (3D/I 1997). Further, bioaccumulation of fog oil smoke residues has not been demonstrated or established (3D/I 1996).

\section{Risk Description}

\section{Characterization of Ecological Effects}

To characterize the ecological effects, the relationship between the stressor and the assessment and measurement endpoints is analyzed. To be at risk from an environmental stressor, environmental components and the environmental stressor must coexist, be available to, and/or come in contact with each other. This coexistence, availability, or contact can have either spatial or temporal components, or both.

For the red-cockaded woodpecker, ecological effects of greatest concern are those that may affect populations. Community-level effects are also a concern. In part because of the Endangered Species Act and the implementation requirements in-

cumbent on Federal agencies (e.g., 50 CFR 401 et seq.), individual effects can also be important.

\section{Nature of Effects}

The potential effects of fog oil obscurant smoke on the red-cockaded woodpecker can be broadly categorized as those related to short-term (i.e., acute) exposure, longterm (i.e., chronic) exposure, toxicity, behavior, reproductive success, physiological processes, bioaccumulation, and habitat. 
In this ecological risk assessment, no short-term or acute effects attributable to fog oil obscurant smoke exposure at representative and elevated concentrations, as related to the red-cockaded woodpecker, could be identified or experimentally demonstrated (Table 7, page 26).

Long-term or chronic effects of exposure to smoke, smoke residue, and smoke transformation products could take years or even decades to exhibit obvious symptoms in ecological systems (NRC 1997). Long-term risks might be related to changes such as decreased fertility, decreased survivability, increased vulnerability, decreased fitness, and behavioral alteration, as well as interrelated changes in habitat or its associated components. The available information and data on short-term exposure to fog oil obscurant smoke is inadequate to provide a complete evaluation of long-term, chronic effects at this time. However, the lack of identifiable short-term effects gives an indication of a lack of long-term effects.

\section{Intensity of Effects}

The intensity or relative strength (e.g., duration, severity) of a response to exposure to an environmental stressor can provide important information or at least indications of the potential effects of the stressor on particular measurement endpoints and ultimately on established assessment endpoints.

In this ecological risk assessment, identifiable and significant effects related to a broad range of parameters including deposition (e.g., eggs, nest cavities), toxicity (e.g., inhalation, ingestion, dermal, soil microbes, vegetation, arthropods), behavior (e.g., food consumption, posture), reproductive success (e.g., hatching, fledging), survival, and bioaccumulation, attributable to fog oil obscurant smoke exposure at representative and elevated concentrations could not be identified or experimentally demonstrated (Table 7, page 26). Further, no data or information indicating negative effects of fog oil obscurant smoke on the red-cockaded woodpecker or its habitat are known.

\section{Spatial Scale}

Throughout their range (Figure 3, page 20) red-cockaded woodpeckers are potentially exposed to fog oil smoke obscurant at approximately 16 relatively discrete locations (USFWS 2003). These locations correspond with Army, Marine Corps, Navy, Air Force, and National Guard installations. While it is not necessary or practical for purposes of this ecological risk assessment to identify every individual site where fog oil obscurant smoke use may occur, it is believed that fog oil obscurant smoke usage occurs only at Army installations (Table 1, page 11), U.S. Marine Corps 
Base Camp Lejeune, NC; and Camp Blanding, FL; which is administered by the Florida Department of Military Affairs. ${ }^{*}$

At those military installations where fog oil obscurant smoke training and use occurs, smoke generation is done on designated training ranges under controlled and simulated battlefield conditions. These training ranges, depending on location, may or may not be in congruence with red-cockaded woodpecker habitat. Certainly all red-cockaded woodpecker habitat on military installations where fog oil obscurant smoke is employed is not subject to fog oil obscurant smoke exposure.

\section{Temporal Scale}

Military fog oil obscurant smoke training and use can take place at all times of the year and at all hours. From a practical as well as an operational standpoint, fog oil obscurant smoke training almost always takes place during daytime hours because smoke obscuring qualities are not necessary after night fall. Military fog oil obscurant smoke training exercises typically last a maximum of 90 minutes (U.S. Army 1996a), with the resultant smoke cloud dissipation dependent on local climactic conditions, primarily those related to wind.

If red-cockaded woodpeckers (i.e., adults, fledged young) flew into the smoke plume, it would be expected that total exposure time would be minimal with a theoretical and unrealistic maximum exposure being equal to the duration of the specific training event. The same potential maximum time can be expected for other ecological components (e.g., soil, vegetation, arthropods). Eggs and young birds in the nest cavity are also potentially exposed to fog oil obscurant smoke during training events. While the rate of air exchange in the nest cavity is unknown, fog oil smoke concentrations in nest cavities have been shown to be considerably reduced from outside ambient concentrations (Guelta and Checkai 2001, Driver et al. 2002b).

Disturbance related to human and military training activity, which is generally associated with fog oil smoke obscurant training events (e.g., noise, military maneuver), has not been shown to negatively impact red-cockaded woodpecker populations (Hayden et al. 2002, Delaney et al. 2002).

\footnotetext{
* There is some potential for oil smoke obscurant smoke use at Eglin Air Force Base, FL, as part of Army Reserve or National Guard training.
} 


\section{Potential for Recovery}

A goal of recovery for the red-cockaded woodpecker is "delisting" or no longer being classified as endangered. An interim recovery goal for the species can be considered "downlisting" to a less precarious threatened status. Five factors are identified (16 USC 1533(a)(1)) which must be eliminated before delisting can occur. These five factors include: (1) the present or threatened destruction, modification, or curtailment of its habitat or range; (2) overutilization for commercial, recreational, scientific, or educational purposes, (3) disease or predation; (4) the inadequacy of existing regulatory mechanisms; or, (5) other natural or manmade factors affecting its continued existence.

For the red-cockaded woodpecker, delisting will occur when each of the following criteria (summarized) is met (USFWS 2003):

Criterion 1 - there are 10 populations of red-cockaded woodpeckers that each contain at least 350 potential breeding groups, and 1 population that contains at least 1000 potential breeding groups from among 13 designated primary core populations;

Criterion 2 - there are 9 populations of red-cockaded woodpeckers that each contain at least 250 potential breeding groups from among 10 designated secondary core populations;

Criterion 3 - there are at least 250 potential breeding groups distributed among designated essential support populations;

Criterion 4 - there are 3 designated populations which are stable or increasing and each containing at least 100 breeding groups; and,

Criterion 5 - for each population, responsible management agencies shall provide a habitat management plan and a plan for continued population monitoring.

For the red-cockaded woodpecker, downlisting will occur when each of the following criteria (summarized) is met (USFWS 2003):

Criterion 1 - the Central Florida Panhandle Primary Core Population is stable or increasing and contains at least 350 potential breeding groups;

Criterion 2 - there is at least one stable or increasing population containing at least 250 potential breeding groups in each of the Sandhills, Mid-Atlantic Coastal 
Plain, South Atlantic Coastal Plain, West Gulf Coastal Plain, Upper West Gulf Coastal Plain, and Upper East Gulf Coastal Plain recovery units;

Criterion 3 - there is at least one stable or increasing population containing at least 100 potential breeding groups in each of the Mid-Atlantic Coastal Plain, Sandhills, South Atlantic Coastal Plain, and East Gulf Coastal Plain;

Criterion 4 - there is at least one stable or increasing population containing at least 70 potential breeding groups in each of the Cumberlands/Ridge and Valley, Ouachita Mountains, Piedmont, and Sandhills recovery units and also the Northeast North Carolina/Southeast Virginia Essential Support Population is stable or increasing and contains at least 70 potential breeding groups;

Criterion 5 - there are at least four populations each containing at least 40 potential breeding groups on State and/or Federal lands in the South/Central Florida Recovery Unit; and,

Criterion 6 - there are habitat management plans in place in each of the above populations identifying management actions sufficient to increase the populations to recovery levels.

The primary actions needed to accomplish ultimate delisting and interim downlisting are: (1) application of prescribed burning to cluster and foraging habitat; (2) protection and development of large, mature pines throughout the red-cockaded woodpecker range; (3) protection of existing cavities and provisioning of artificial cavities; (4) provision of sufficient recruitment clusters in suitable chosen locations; and, (5) restoration of sufficient quantity and quality of habitat (USFWS 2003).

On military installations, red-cockaded woodpecker populations are generally increasing, in part due to active habitat management (USFWS 2003). Adequate regulatory mechanisms exist (Endangered Species Act, U.S. Army 1995, U.S. Army 1996b); and overutilization for any purpose does not take place. Although broadly speaking, fog oil obscurant smoke exposure, as with any chemical exposure, could conceivably be postulated as a factor in causing or pre-disposing disease, there is no data or information to suggest that that is the case. Similarly, the manmade factor of fog oil obscurant smoke use for military training purposes cannot at this time be construed as a threat to the species existence.

\section{Military Mission}

Fog oil obscurant smoke training under field and simulated battlefield conditions allows soldiers to gain experience with fog oil smoke use and exposure and develop 
skills to fulfill the combat mission of the Army. Military installations must maintain the utility of existing training lands for a number of reasons, first and foremost being the continued maintenance and further development of military capability. Directly related to this is the fact that with changing technology, evolving world situations, and closure of military installations, existing military training and testing lands can be expected to be used more and more intensively. In assessing the ecological risks of fog oil obscurant smoke effects on the red-cockaded woodpecker, some information must be assumed. These factual assumptions include: (1) to ensure the readiness of the country for war conditions, Army field training with fog oil obscurant smoke will continue; (2) lands that are used for fog oil obscurant smoke field training exercises are inhabited by plants and animals, one of which may be the red-cockaded woodpecker; and (3) the Army and other armed services will fulfill their obligations under the Constitution, 10 USC, the Endangered Species Act, and related requirements.

\section{Uncertainty}

\section{General}

Risk estimation is uncertain by definition. At each step of the risk assessment process there is an element of uncertainty and explicit consideration of uncertainty is appropriate (USEPA 1998, Suter et al. 1993). Uncertainty may be due to quantitative or qualitative considerations or both. The final estimate of risk represents the consideration of individual bits of information, each with its own uncertainty (Suter et al. 2001). Another source of uncertainty is the general difficulty in quantifying the magnitude and/or duration of an ecological stress on the ecological receptor, and associated receptor response. In addition to limitations in specific site and/or species understanding (Efroymson and Suter 2001), there can be uncertainties associated with potential cumulative effects (Foran and Ferenc 1999, USEPA 2003) of multiple stressors or exposures.

In part to address unknowns and lack of absolute assuredness, a risk assessment should make conservative assumptions about potential exposures and effects. Therefore, predictive risk assessments tend to overestimate the real or actual risk. It is extremely important to recognize that risk assessments are best considered as indicators of potentials for negative or adverse effects. Risk assessments are not to be used as strict predictors of such effects.

An overarching uncertainty associated with ecological risk assessment in general is the typically limited amount of data and information available to characterize the exposure and potential or actual ecological effects. This limitation leads to the re- 
sultant effect of ecological risk being estimated rather than being measured (Bartell et al. 1992). This does not necessarily negate the results of ecological risk assessment, but it does point to inherent limitations in our scientific knowledge and predictive abilities. As a method of addressing limitations in data and improving ecological predictive abilities, modeling approaches of varying degrees of sophistication are used more and more often (Pastorok et al. 2002). In this ecological risk assessment, graphic models have been presented to depict and describe the interactions and interrelationships of the red-cockaded woodpecker, its ecology, and the use of fog oil smoke obscurant (Figure 4 [page 31] and Figure 5 [page 32]).

\section{Red-cockaded Woodpecker and Fog Oil Obscurant Smoke Interaction Uncertainty}

There are at least three broad categories of uncertainty in this ecological risk assessment. These include those related to fog oil obscurant smoke, the general setting and environment, including specific red-cockaded woodpecker habitat, and the red-cockaded woodpecker itself. (A fourth category of uncertainty might be considered to be the combined and/or resulting interaction of these components). For example, since every field fog oil smoke release essentially has a unique set of environmental and other circumstances and conditions, there is a degree of uncertainty about the actual amount and rate of fog oil obscurant smoke exposure in the field.

Some of the uncertainty related to fog oil obscurant smoke is that related to potential toxic effects. Other than the studies of Driver et al. (2002a, 2002b, 2004) for avian species, there are little or no data and information on wildlife health effects on other vertebrates. However, as indicated previously, Driver et al. (2002a, 2002b, 2004) reported no negative effects attributable to avian exposure to concentrations of fog oil smoke at much higher levels than reasonably expected to result from military training uses (Table 6, page 19). Additionally, overt toxic effects of fog oil obscurant smoke on red-cockaded woodpecker ecosystem components (e.g., vegetation, food) have not been demonstrated, and although long-term effects are not known, there is no indication of their existence. Consequently, uncertainty associated with or attributable to fog oil smoke exposure at typical and effective field concentration levels can be considered comparatively minimal.

In overview, the environment and habitat of the red-cockaded woodpecker is composed of mature southern open pine forests and thus can be described as being rather homogenous. While there are some regional, local, and site differences and variation, red-cockaded woodpecker habitat and ecosystem components are fairly well known and can be considered at least functionally uniform (Conner et al. 2001). Red-cockaded woodpecker habitats and ecosystems on Army installations are comparatively similar (Hayden 1997a). Consequently, uncertainty associated with or 
attributable to the red-cockaded woodpecker ecosystem or habitat, particularly on military lands, can be considered modest.

As a species, the red-cockaded woodpecker has been well studied (see Jackson 1994, USFWS 2003). While there are regional, local, and site variations in red-cockaded woodpecker numbers, productivity, and survival, any differences are related to habitat quantity and quality rather than to any particular or potential anthropogenic environmental stressor (USFWS 2003). In fact, even in the presence of disturbance related to military training (Delaney et al. 2002, Hayden et al. 2002), red-cockaded woodpecker populations on Army and other armed services' installations are generally increasing (USFWS 2003) and can be described as healthy. Consequently, for purposes of this ecological risk assessment, uncertainty related to the species can be considered minimal.

The confluence of fog oil obscurant smoke exposure, various red-cockaded woodpecker habitats and ecosystem components, and the species itself, is a complex of action, reaction, and interaction, most of which occurs at scales too large or too small (or too long or too short) to measure and/or interpret with current readily applied methodologies. A number of studies addressing anthropogenic and militaryspecific land management and soldier training activities have been reported (Jackson and Parris 1995, Doresky et al. 2001, Delaney et al. 2002, Hayden et al. 2002). None of these investigations have indicated a significant negative alteration of measured red-cockaded woodpecker biological parameters (e.g., survival, productivity, mortality, etc.).

Part of the red-cockaded woodpecker range and habitat is included in regions subject to severe weather events such as hurricanes. Hurricanes are known to cause severe damage to red-cockaded woodpecker habitat (e.g., cavity trees) and could lead to local population extirpation (Watson et al. 1995). Previously, the Army has developed a model (i.e., PVAvES, Population Viability of Avian Endangered Species) to help assess population viability status of threatened or endangered and other avian species (Melton et al. 2001). Using this model, it has been speculated that on some military installations subject to hurricane events, their effects may have considerable influence on local red-cockaded woodpecker population recovery and may substantially increase the likelihood of local population extinction (Melton et al. 2001:27). In an application of the PVAvES model to disturbance related to military training activity, Hayden et al. (2002:60) discussed results that suggested that if a substantial proportion (i.e., $>50 \%$ ) of red-cockaded woodpecker habitat on a mili- 
tary training installation were subject to high disturbance activity, this could have a negative effect on the viability of that red-cockaded woodpecker population and such a condition might increase that population's probability of extirpation.*

The fog oil obscurant smoke exposure levels generated by Driver et al. (2002a, $2002 \mathrm{~b}, 2004$ ), up to $450 \mathrm{mg} / \mathrm{m}^{3}$, are far in excess of concentrations anticipated under field application conditions (Table 4, page 15). Using the results presented regarding the mean number of fledglings per clutch in Table 11, the authors considered, as a "worst case scenario" the results for the control $\left(0 \mathrm{mg} / \mathrm{m}^{3}\right) \mathrm{vs}$. the high aerosol concentration $\left(450 \mathrm{mg} / \mathrm{m}^{3}\right)$ experimental treatments, which was the only comparison for this variable that showed a change in outcome (i.e., decline in performance in the direction of a possible toxic treatment effect). An observed effect that was in the direction of a negative influence of red-cockaded woodpecker fecundity was purposely chosen. Keep in mind however, that the treatment effect on this variable was not, in fact, statistically significant.

Table 11. Hatching and fledging success of House Sparrow clutches exposed to fog oil aerosols (from Driver et al. 2002b).

\begin{tabular}{|c|c|c|c|c|}
\hline \multirow[b]{2}{*}{ Parameter } & \multirow[b]{2}{*}{ Control } & \multicolumn{3}{|c|}{ Fog Oil $\left(\mathrm{mg} / \mathrm{m}^{3}\right)$} \\
\hline & & 0 & 100 & 450 \\
\hline Number of clutches & 16 & 13 & 13 & 12 \\
\hline Mean number of eggs/clutch & 3.2 & 2.9 & 3.1 & 2.8 \\
\hline Mean number nestlings/clutch & 2.0 & 1.4 & 1.7 & 1.1 \\
\hline Mean number fledglings/clutch & 1.8 & 1.2 & 1.5 & 1.0 \\
\hline Percent hatched ${ }^{\mathrm{A}}$ & 59.0 & 52.8 & 56.6 & 51.7 \\
\hline Percent fledged $^{\mathrm{B}}$ & 50.5 & 46.5 & 41.2 & 46.3 \\
\hline
\end{tabular}

Again using the PVAvES model, and applying this "treatment effect" to data from and existing red-cockaded woodpecker population, ${ }^{\dagger}$ estimates of potential effect on local population viability were made. Estimates were calculated for the probability

\footnotetext{
* In part because of the availability of population data, both Melton et al. (2001) and Hayden et al. (2002) were addressing potential Red-cockaded Woodpecker responses at Fort Stewart, GA.

† Statistics derived from data collected on the Fort Stewart, GA, Red-cockaded Woodpecker population, on a total sample of 103 individual females observed breeding at least once between 1995 and 1999 were used.
} 
that the red-cockaded woodpecker population would fall into the IUCN extinction risk class "critically endangered," (i.e., classed as having a probability of extinction within 10 years $\geq 50 \%$; IUCN 1994). These probabilities were essentially $0 \%$ for all cases. The results of this modeling exercise suggest that in applying the effects of the such high fog oil smoke treatment on fecundity of house sparrows observed by Driver et al. (2002b) to red-cockaded woodpeckers, even if the entire red-cockaded woodpecker population were exposed every year and at the same incubation stage to such doses of fog oil smoke, it would not lead to extirpation of the population. Similarly, the results suggest that the risks to the population attributable to fog oil smoke exposure are no greater than natural weather events or military soldier training activities that have been taking place on armed forces installations for decades. We do however need to recognize that the PVAvES model, is simply that - a model. As such, there are other uncertainties associated with it, including a predictive approach based on Monte Carlo or probabilistic analysis (see USEPA 1997b).

With that being said, and as a reminder, a purpose of this discussion is simply to point out that among other things, given the limitations of information, data, knowledge, and/or interpretation, uncertainties can and do exist in estimating ecological risk. With some species, some stressors, some sites, some ecological conditions, and some ecological endpoints, the ecological risk may be little to none. With rare species (e.g., red-cockaded woodpecker) and uncommon stressors (e.g., military fog oil smoke) non-existent or incomplete data and information obviously present limitations. For this ecological risk assessment, the uncertainties involved are comparable to other similar ecological analysis and are not of such a magnitude to cause undue concern.

\section{Interpretation of Ecological Effects}

The "lines of evidence" approach used here provides an outline framework for characterizing the risk to the red-cockaded woodpecker from military fog oil smoke exposure. It is not, nor is it presented as a rigorous proof or examination of ecological effects or a lack thereof (Fox 1991, Menzie et al. 1996). Rather, it is intended to provide a logical, informed, and reasonable representation of pertinent data and information (i.e., lines of evidence) as they are known and understood. These lines of evidence were derived from different sources and by different techniques and methods including models, technical reports, scientific literature, laboratory experiment, and observed and reported field effects.

Toward that end, the ecological interpretation of military fog oil smoke exposure on the red-cockaded woodpecker is presented in Table 12. In this ecological risk assessment, the nature and intensity of observed effects, particularly with the tempo- 
ral and spatial scale of potential fog oil smoke release and red-cockaded woodpecker and red-cockaded woodpecker habitat exposure, and considering individual organism effects, species recovery, and military mission (i.e., fog oil smoke training), indicate little to no risk - either to individual red-cockaded woodpeckers, their populations, or their habitat. Furthermore, the use and ecological effects of military fog oil obscurant smoke, as it is currently employed, appears to pose no risk to redcockaded woodpecker species recovery.

Table 12. Summary of weight of evidence analysis for exposure of red-cockaded woodpeckers and their habitat to military fog oil smoke obscurant.

\begin{tabular}{|c|c|c|c|c|c|c|}
\hline \multirow[b]{2}{*}{ Endpoints } & \multirow{2}{*}{$\begin{array}{l}\text { Fog Oil } \\
\text { Smoke } \\
\text { Present }\end{array}$} & \multicolumn{3}{|c|}{ Fog Oil Smoke Toxicity } & \multirow{2}{*}{$\begin{array}{l}\text { Observed/ } \\
\text { Reported } \\
\text { Effects }\end{array}$} & \multirow{2}{*}{$\begin{array}{l}\text { Possible } \\
\text { Conclusions }\end{array}$} \\
\hline & & Inhalation & Ingestion & Dermal & & \\
\hline Nest cavities & + & NA & NA & NA & $\begin{array}{l}\text { Fog oil smoke } \\
\text { enters }\end{array}$ & $\begin{array}{l}\text { Fog oil smoke concentration } 25 \% \\
\text { less than outside nest cavity }\end{array}$ \\
\hline Egg hatchability & NA & NA & NA & + & None observed & Fog oil deposit on eggs minimal \\
\hline Nestling survival & NA & + & + & + & None observed & $\begin{array}{l}\text { Nestling survival unaffected by } \\
\text { exposure }\end{array}$ \\
\hline Fledgling survival & NA & + & + & + & None observed & $\begin{array}{l}\text { Fledgling survival unaffected by } \\
\text { exposure as nestling }\end{array}$ \\
\hline Adult acute effects & NA & + & + & + & None observed & Adults suffer no acute effects \\
\hline Adult chronic effects & NA & + & + & + & None observed & Adults suffer no chronic effects \\
\hline Arthropods & NA & + & + & + & None reported & Little or no ecological effect \\
\hline $\begin{array}{l}\text { Soil, microbes, } \\
\text { vegetation }\end{array}$ & NA & + & + & + & None reported & Little or no ecological effect \\
\hline \multicolumn{7}{|c|}{$\begin{array}{l}+ \text { indicates the evidence is consistent with known, observed, and reported endpoint effects. } \\
\text { - would indicate the evidence is inconsistent with known, observed, and reported endpoint effects. } \\
+/- \text { would indicate the evidence is inconclusive or ambiguous to interpret with known, observed, and re- } \\
\text { ported endpoint effects. }\end{array}$} \\
\hline
\end{tabular}




\section{Summary}

This ecological risk assessment addresses the potential effects and impacts on the red-cockaded woodpecker of the continued deployment and use of fog oil smoke obscurant, for Army and other military training and testing purposes.

This ecological risk assessment further recognizes that no effects or impacts to individuals or populations of red-cockaded woodpeckers or their habitats resulting from past or present fog oil obscurant smoke use have been observed.

It is recognized that natural and normal ecological variation, as well as those variations attributable to anthropogenic influences, make it difficult to detail and attribute stressor-related perturbations (i.e., by fog oil obscurant smoke). Introducing additional anthropogenic influences and potential stresses, such as coincident military activity (Hayden et al. 2002, Delaney et al. 2002) make the prediction and identification of individual ecological effects even more difficult.

In this ecological risk assessment the most appropriate and relevant data and information have been considered. In total, the stressor (fog oil smoke) and receptor (red-cockaded woodpecker and its ecologic habitat components) response data and information available does not show or indicate any signs of direct or indirect stress, impact, or effects to red-cockaded woodpecker individuals, communities, populations, or habitat due to the use of fog oil obscurant smoke in military training and testing exercises and protocols. This conclusion is supported by species ecology information (e.g., Jackson 1994, USFWS 2003), ecological modeling (Melton et al. 2001), laboratory and other exposure data (e.g., Getz et al. 1996, Driver et al. 1993, 2002a, 2002b, 2004), and other relevant avian-fog oil smoke ecological risk assessment analysis (e.g., 3D/I 1997). 


\section{References}

3D/International Inc., Environmental Group. 1996. Environmental fate of fog oil at Fort McClellan, Alabama. Report submitted to U.S. Army Corps of Engineers, Kansas City, MO.

3D/International Inc., Environmental Group. 1997. Ecological risk assessment: effect of fog oil obscurant on selected amphibians, reptiles, and birds at Fort Leonard Wood, Missouri. Report submitted to U.S. Army Corps of Engineers, Kansas City, MO.

Aiken, J.L., and C.L. Roberts. 1979. Final Environmental Impact Statement; Establishment of the U.S. Army Chemical School. U.S. Army Training and Doctrine Command.

Albers, P.H. 1977. Effects of external application of fuel oil on hatchability of Mallard eggs. Pp 158-163 in D.A. Wolfe ed. Fate and effects of petroleum hydrocarbons in marine ecosystems and organisms. Pergamon Press, New York, NY.

Allen, D.H. 1991. Constructing artificial Red-cockaded Woodpecker cavities. USDA Forest Service General Technical Report SE-73.

Anderson, F.R., and R.M. Daniels. 1973. NEPA in the courts: a legal analysis of the National Environmental Policy Act. Resources for the Future, Baltimore, MD.

Austin, M.E. 1965. Land resources regions and major land resource areas of the United States. Agriculture Handbook 296. Soil Conservation Service, U.S. Department of Agriculture, Washington, DC

Bailey, R.G. 1995. Description of the ecoregions of the United States. 2d ed. Rev. Misc. Publ. 1391. USDA Forest Service, Washington, DC.

Bailey, R.G. 1998. Ecoregions map of North America: explanatory note. Misc. Publ. 1548. USDA Forest Service, Washington, DC.

Baker, W.W. 1971. Observations on the food habits of the Red-cockaded Woodpecker. Pp. 100-107 in R. L. Thomson, ed. The ecology and management of the red-cockaded woodpecker. U.S. Department of the Interior, Tall Timbers Research Station, Tallahassee, FL.

Baker, W.W. 1995. The distribution and status of the Red-cockaded Woodpecker (Picoides borealis) in Georgia. Pp. 465-469 in D.L. Kulhavy, R.G. Hooper, and R. Costa, eds. Redcockaded Woodpecker: Recovery, Ecology and Management. Center for Applied Studies in Forestry, Stephen F. Austin State Univ., Nacogdoches, TX.

Barnthouse, L., and J. Brown. 1994. Issue paper on conceptual model development. In Ecological risk assessment issue papers. EPA 630/R-94/009. 
Bartell, S.M., R.H. Gardner, and R.V. O’Neill. 1992. Ecological risk estimation. Lewis Publishers, Boca Raton, FL.

Bausum, H.T., and G.W. Taylor. 1986. A literature survey and data base assessment: microbial fate of diesel fuel and fog oils. ADA167799. U.S. Army Materiel Bioengineering Research and Development Laboratory, Ft. Detrick, MD.

Beal, F. E. L., W. L. McAtee, and E. R. Kalmbach. 1916. Red-cockaded Woodpecker. Pp. 34-35 in Common birds of southeastern United States in relation to agriculture. U.S. Dep. Agr. Farmer's Bull. 755.

Beletsky, L.D. 1996. The Red-winged Blackbird: the biology of a strongly polygamous songbird. Academic Press, Harcourt Brace and Co., London, UK.

Bent, A.C. 1992. Life histories of North American woodpeckers. Indiana University Press, Indianapolis, IN.

Bingham, E., A.W. Horton, and R. Tye. 1965. The carcinogenic potency of certain oils. Arch. Environ. Health 10:449-451.

Bourne, W.R.P. 1968. Oil pollution and bird populations. Pp. 99-121 in J.D. McCarthy and D.R. Arthur, eds. The biological effects of oil pollution on littoral communities. Field Studies 2(suppl.).

Bowman, R.D., L. Leonard, L.M. Richman, and K.L. Backus. 1997. Demography of the Redcockaded Woodpecker at the Avon Park Air Force Range. Report Number F08602-96D0015. Archbold Biological Station, Lake Placid, FL.

Bradshaw, D.S. 1990. Habitat quality and seasonal foraging patterns of the Red-cockaded Woodpecker (Picoides borealis) in southeastern Virginia. M.A. thesis, Coll. William and Mary, Williamsburg, VA.

Brubaker, K.L., D.H. Rosenblatt, and C.T. Snyder. 1992. Environmental effects of fog oil and CS usage at the Combat Maneuver Training Center, Hohenfels, Germany. ANL/ESD/TM-38. Argonne National Laboratory, Argonne, Il.

Calabrese, E.J., and L.A. Baldwin. 1993. Performing ecological risk assessments. Lewis Publishers, Chelsea, MI.

Cataldo, D.A., P. Van Voris, M.W. Ligotke, R.J. Fellows, B.D. McVeety, S.W. Li, H. Bolton, Jr., and J.K. Frederickson. 1989. Transport, transformations, fate and terrestrial ecological effects of fog oil obscurant smokes. PNL-6799. Pacific Northwest Laboratory. U.S. Army Medical Research and Development Command, Fort Detrick, MD.

Cely, J.E., and D.P. Ferral. 1995. Status and distribution of the Red-cockaded Woodpecker in South Carolina. Pp 470-476 in D.L. Kulhavy, R.G. Hooper, and R. Costa, eds. Redcockaded Woodpecker: recovery, ecology and management. Center for Applied Studies in Forestry, Stephen F. Austin State Univ., Nacogdoches, TX.

Comprehensive Environmental Response, Compensation, and Liability Act. 42 U.S.C. 9601- 9675. U.S. Code, Title 42, "The Public Health and Welfare," Chapter 103. 
Conner, R.N. 1995. Red-cockaded Woodpecker cavity trees: an introduction. Pp.335-337 in Kulhavy, D. L., R. G. Hooper, and R. Costa, eds. Red-cockaded Woodpecker: recovery, ecology, and management. Center for Applied Studies in Forestry, Stephen F. Austin State University, Nacogdoches, TX. .

Conner, R.N. and B.A. Locke. 1982. Fungi and Red-cockaded Woodpecker cavity trees. Wilson Bull. 94: 64-70.

Conner, R.N., and D.C. Rudolph. 1989. Red-cockaded Woodpecker colony status and trends on the Angelina, Davy Crockett, and Sabine National Forest. U. S. Forest Service, Southern Forestry Experiment Station Research Paper 50-250.

Conner, R.N., and D.C. Rudolph. 1991. Forest habitat loss, and Red-cockaded Woodpecker populations. Wilson Bull. 103: 446-457.

Conner, R.N., and D.C. Rudolph. 1995. Excavation dynamics and use patterns of Red-cockaded Woodpecker cavities: relationships with cooperative breeding. Pp 342-352 in Kulhavy, D. L., R. G. Hooper, and R. Costa, eds. Red-cockaded Woodpecker: recovery, ecology, and management. Center for Applied Studies in Forestry, Stephen F. Austin State University, Nacogdoches, TX.

Conner, R.N., D.C. Rudolph, D.L. Kulhavy, and A.E. Snow. 1991. Causes of mortality of Redcockaded Woodpecker cavity trees. Jour.Wildl. Mgmt. 55: 531-537.

Conner, R.N., D.C. Rudolph, and J.R. Walters. 2001. The Red-cockaded Woodpecker: surviving in a fire-maintained ecosystem. Univ. of Texas Press, Austin TX.

Copeyon, C.K. 1990. A technique for constructing cavities for the Red-cockaded Woodpecker. Wildl. Soc. Bull.18:303-311.

Copeyon, C.K., J.R. Walters, and J.H. Carter III. 1991. Induction of Red-cockaded Woodpecker group formation by artificial cavity construction. Jour. Wildl. Mgmt. 55:549-556.

Costa, D.L., and M.O. Amdur. 1979. Respiratory responses of guinea pigs to oil mists. Jour. American Industrial Hygiene Assoc. 40:673-679.

Costa, R. and R. Escano. 1989. Red-cockaded Woodpecker: status and management in the southern region in 1986. U.S. Forest Service Technical Publication. R8-TP12.

Cura, J.J., W. Heiger-Bernays, T.S. Bridges, and D.W. Moore. 1999. Ecological and human health risk assessment guidance for aquatic environments. ERDC TR DOER-4. U.S. Army Corps of Engineers, Washington, DC.

Delaney, D.K., L.L. Pater, R.J. Dooling, B. Lohr, B.F. Brittan-Powell, L.L. Swindell, T.A. Beaty, L.D. Carlile, E.W. Spadgenske, B.A. MacAllister, and R.H. Melton. 2002. Assessment of training noise impacts on the Red-cockaded Woodpecker: 1998-2000. ERDC/CERL TR02-32. U.S. Army Construction Engineering Laboratory, Champaign, IL.

DeLotelle, R. S., and R. J. Epting. 1988. Selection of old trees for cavity excavation by Redcockaded Woodpeckers. Wildl. Soc. Bull. 16:48-52. 
DeLotelle, R. S., J. R. Newman, and A. E. Jerauld. 1983. Habitat use by Red-cockaded Woodpeckers in central Florida. Pp. 59-67 in D. A. Wood, ed. Red-cockaded Woodpecker symposium II. Florida Game and Fresh Water Fish Commission, Tallahassee, FL.

Doresky, J., K. Morgan, L. Ragsdale, and J. Townsend. 2001. Effects of military activity on reproductive success of Red-cockaded Woodpeckers. Jour. Field Ornithol. 72(2):305-311.

Driver, C.J., M.W. Ligotke, J.L. Downs, B.L. Tiller, E.B. Moore, Jr., and D.A. Cataldo. 1993. Environmental and health effects review of obscurant fog oil. ERDEC-CR-071. Pacific Northwest Laboratory, Richland, WA.

Driver, C., M. Ligotke, H. Galloway-Gorby, G. Dennis, K. Reinbold, and H. Balbach. 2002a. Acute inhalation toxicity of fog oil smoke in the Red-winged Blackbird, a size-specific inhalation surrogate for the Red-cockaded Woodpecker. ERDC/CERL TR-02-6. U.S. Army Construction Engineering Research Laboratory, Champaign, IL.

Driver, C., J Oilero, Y.F. Su, R. Fulton, G. Dennis, B. Tiller, H. Balbach, and K. Reinbold. 2002 b. Effects of fog oil smoke on the hatchability and fledgling survival of the House Sparrow (Passer domesticus), a nestling surrogate for the Red-cockaded Woodpecker. ERDC/CERL TR-02-34. U.S. Army Construction Engineering Research Laboratory, Champaign, IL.

Driver, C., A. Jarrell, J. Ollero, B. Tiller, R. Fulton, G. Dennis, H. Balbach, and K. Reinbold. 2004. Effects of fog oil smoke on immune response in the House Sparrow (Passer domesticus) and Red-winged Blackbird (Agelaius phoeniceus). ERDC/CERL TR-04-13. U.S. Army Construction Engineering Research Laboratory, Champaign, IL.

Dourson, M.L., and J.F. Stara. 1983. Regulatory history and experimental support of uncertainty (safety) factors. Reg. Toxicol. Pharmacol. 3:224-238.

Efroymson, R.A., W.H. Rose, S. Nemeth, and G.W. Suter II. 2000. Ecological risk assessment framework for low-altitude overflights by fixed-wing and rotary-wing military aircraft. ORNL/TM-2000/289 ES-5048. Oak Ridge National Laboratory, Oak Ridge, TN.

Efroymson, R.A., and G.W. Suter II. 2001. Ecological risk assessment framework for low-altitude aircraft overflights: II Estimating effects on wildlife. Risk Analysis 21(2).263-274.

Efroymson, R.A., W.H. Hargrove, M.J. Peterson, D.S. Jones, W.H. Rose, L.L. Pater, K.A. Reinbold, and G.W. Suter. 2001. Demonstration of the military ecological risk assessment framework (MERAF): Apache Longbow - Hellfire Missile test at Yuma Proving Ground. ORNL-2001/211. Oak Ridge National Laboratory, Oak Ridge, TN.

Endangered Species Act. 16 USC 1531-1544. 50 CFR 401 et seq.

Engstrom, R.T., and F.J. Sanders. 1997. Red-cockaded Woodpecker foraging ecology in an old growth longleaf pine forest. Wilson Bull. 109:203-217.

Executive Order 13186. January 10, 2001. Responsibilities of Federal Agencies To Protect Migratory Birds. FR 66(11):3853-3856.

Federal Insecticide, Fungicide, and Rodenticide Act. 7 USC 136-136y. 40 CFR 165. 
Frost, C. 1993. Four centuries of changing landscape patterns in the longleaf pine ecosystem. Pp 17-37 in S. M. Hermann, ed. The longleaf pine ecosystem: ecology, restoration, and management. Proceedings of the 18th Tall Timbers Fire Ecology Conference, Tall Timbers Research Station, Tallahassee, FL.

Foran, J.A., and S.A. Ferenc, eds. 1999. Multiple stressors in ecological risk and impact assessment. Soc. Env. Toxicol. And Chem., SETAC Press, Pensacola, FL.

Fox, G. 1991. Practical causal inference for ecoepidemiologists. Jour. Toxicol. Environ. Health 33:359-373.

Geraci, J. R., and T. G. Smith. 1977. Consequences of oil fouling on marine mammals. in E. C. Malins, ed. Effects of petroleum on Arctic and subarctic marine environments and organisms. Vol II. Biological Effects. Academic Press, New York, NY.

Getz, L.L., K.A. Reinbold, D.J. Tazik, T. J. Hayden, and D.M. Cassels. 1996. Preliminary assessment of the potential impact of fog oil smoke on selected threatened and endangered species. USACERL Technical Report 96/38. USACERL, Champaign, IL.

Grau, C.R., T. Roudybush, J. Dobbs, and J. Wathen. 1977. Altered yolk structure and reduced hatchability of eggs from birds fed single doses of petroleum oils. Science 195:377-390.

Grose, E.C., M. J. K. Selgrade, K. Dean, G. E. Hatch, and R. J. Jasket. 1985. Pulmonary and systemic effects of acute and subchronic exposure to smoke obscurant SFG-2. Report 600/D-85/201 U.S. Environmental Protection Agency, Washington, D.C.

Grose, E.C., M.K. Selgrade, and D.W. Davies. 1986. Inhalation toxicology of fog oil smoke. Final Report. ADA176109. U.S. Environmental Protection Agency, Washington, D.C.

Guelta, M.A., and R.T. Checkai. 2001. Methodology for measurement of fog oil smoke penetration into a Red-cockaded Woodpecker nest cavity. ECBR-TR-21. U.S. Army Soldier and Biological Chemicals Command, Aberdeen Proving Ground, MD.

Hanula, J.L., and R.T. Engstrom. 2000. Comparison of Red-cockaded Woodpecker (Picoides borealis) nestling diet in old growth and old-field longleaf pine (Pinus palustris) habitats. American Midland Naturalist 144:370-376.

Hanula, J. L., and K. E. Franzreb. 1995. Arthropod prey of nestling Red-cockaded Woodpeckers in the upper coastal plain of South Carolina. Wilson Bull. 107:485-495.

Hanula, J.L., and K.E. Franzreb. 1998. Source, distribution, and abundance of macroarthropods on the bark of longleaf pine: potential prey for the Red-cockaded Woodpecker. Forest Ecology and Management 102:89-102.

Hanula, J.L., K.E. Franzreb, and W.D. Pepper. 2000a. Longleaf pine characteristics associated with arthropods available for Red-cockaded Woodpeckers. Jour. of Wildl. Mgmt. 64(1):6070 .

Hanula, J.L., D. Lipscomb, K.E. Franzreb, and S.C. Loeb. 2000b. Diet of nestling Red-cockaded Woodpeckers at three locations. Journal of Field Ornithology 71(1):126-134. 
Hardesty. J.L., R.J. Smith, C.J. Petrick, W.B. Hagedorn, and H.F. Percival. 1995. Status and distribution of the fourth largest population of Red-cockaded Woodpeckers: preliminary results from Eglin AFB, Florida. Pp. 494-502 in Kulhavy, D. L., R. G. Hooper, and R. Costa, eds. Red-cockaded Woodpecker: recovery, ecology, and management. Center for Applied Studies in Forestry, Stephen F. Austin State University, Nacogdoches, TX.

Hardesty, J.L., K.E. Gault, and F.P. Percival. 1997. Ecological correlates of Red-cockaded Woodpecker (Picoides borealis) foraging preference, habitat use, and home range size in northwest Florida (Eglin Air Force Base). Final Report Research Work Order 99, Florida Cooperative Fish and Wildlife Research Unit, Univ. of Florida, Gainesville, FL.

Harlow, R.F., and M.R. Lennartz. 1977. Foods of nestling Red-cockaded Woodpeckers in coastal South Carolina. Auk 94:376-377.

Harlow, R.F., and M.R. Lennartz. 1983. Interspecific competition for Red-cockaded Woodpecker cavities during the nesting season in South Carolina. Pp. 41-43 in D. A. Wood, ed. Redcockaded Woodpecker symposium II. Fla. Game Fresh Water Fish Commission, Tallahassee, FL.

Hartung, R. 1967. Energy metabolism in oil-covered ducks. Jour. of Wildl. Mgmt. 30:564-570.

Hartung, R., and G.S. Hunt. 1966. Toxicity of some oils to waterfowl. Jour. Wildl. Mgmt. 31:564570.

Hayden, T.J. 1997a. Biological assessment of the effects of the proposed revision of the 1994 Management guidelines for the Red-cockaded Woodpecker on Army installations. Special Report 97/48. U.S. Army Construction Engineering Research Laboratory, Champaign, IL.

Hayden, T. J. 1997b. Environmental assessment of the effects of the proposed revision of the 1994 Management guidelines for the Red-cockaded Woodpecker on Army installations. Special Report 97/49. U.S. Army Construction Engineering Research Laboratory, Champaign, IL.

Hayden, T.J., R.H. Melton, B. Willis, L.B. Martin III, and T. Beaty. 2002. Assessment of the effects of maneuver training activities on Red-cockaded Woodpecker populations on Fort Stewart, GA. ERDC/CERL TR-02-17. U.S. Army Construction Engineering Research Laboratory, Champaign, IL.

Hazard Communication Standard (29 CFR 1910.1200).

Hess, C. A. 1997. Stomach flushing: sampling the diet of the Red-cockaded Woodpecker. Wilson Bull. 109:535-539.

Hermann, S. M. 1993. The longleaf pine ecosystem: ecology, restoration, and management. Proceedings of the 18th Tall Timbers Fire Ecology Conference, Tall Timbers Research Station, Tallahassee, FL.

Hoffman, D.J. 1990. Embryotoxicity and teratogenicity of environmental contaminants to bird eggs. Reviews of Environmental Contamination and Toxicology 115:39-89. 
Holmes, W.N., and J. Cronshaw. 1977. Biological effects of petroleum on marine birds. Pp. 359398 in D.C. Malins, ed. Effects of petroleum on arctic and subarctic marine environments and organisms. Vol II: Biological effects. Academic Press, New York, NY.

Hooper, R.G., and M.R. Lennartz. 1981. Foraging behavior of the Red-cockaded Woodpecker in South Carolina. Auk 98:321-334.

Hooper, R.G., and M.R. Lennartz. 1995. Short-term response of a high density Red-cockaded Woodpecker population to a loss of foraging habitat. Pp 283-289 in Kulhavy, D. L., R. G. Hooper, and R. Costa, eds. Red-cockaded Woodpecker: recovery, ecology, and management. Center for Applied Studies in Forestry, Stephen F. Austin State University, Nacogdoches, TX.

Hooper, R.G., A.F. Robinson, and J.A. Jackson. 1980. The Red-cockaded Woodpecker: notes on life history and management. USDA Forest Service, General Report SA-GR9.

Hooper, R.G., L. J. Niles, R. F. Harlow, and G. W. Wood. 1982. Home ranges of Red-cockaded Woodpeckers in coastal South Carolina. Auk 99:675-682.

Hovis, J.A., and R.F. Labisky. 1985. Vegetative associations of Red-cockaded Woodpecker colonies in Florida. Wildl. Soc. Bull. 13:307-314.

IUCN Species Survival Commission. 1994. IUCN Red List Catagories. International Union for Conservation of Nature and Natural Resources, Gland, Switzerland.

Jackson, J.A. 1977. Red-cockaded Woodpeckers and pine red heart disease. Auk 94: 160-163.

Jackson, J.A. 1978. Competition for cavities and Red-cockaded Woodpecker management. Pp. 103-112 in S.A. Temple, ed. Endangered birds: management techniques for threatened species. University of Wisconsin Press, Madison, WI.

Jackson, J.A. 1983. Morphological and behavioral development of post-fledged red-cockaded woodpeckers. Pp. 30-37 in D.A. Wood, ed. Red-cockaded Woodpecker symposium II. Florida game and Freshwater Fish Commission, Tallahassee, FL.

Jackson, J. A. 1990. Intercolony movements of Red-cockaded Woodpeckers in South Carolina. Jour. Field Ornithology 61:149-155.

Jackson, J. A. 1994. Red-cockaded Woodpecker (Picoides borealis). The birds of North America, Number 85. A. Poole and F. Gill, eds. The Academy of Natural Sciences, Philadelphia, Pennsylvania; American Ornithologists' Union, Washington, D.C.

Jackson, J.A., and S.D. Parris. 1995. The ecology of Red-cockaded Woodpeckers associated with construction and use of a multi-purpose range complex at Fort Polk, Louisiana. Pp 277282 in Kulhavy, D. L., R. G. Hooper, and R. Costa, eds. Red-cockaded Woodpecker: recovery, ecology, and management. Center for Applied Studies in Forestry, Stephen F. Austin State University, Nacogdoches, TX.

Jackson, J. A., W. W. Baker, V. Carter, T. Cherry, and M. L. Hopkins. 1979. Recovery plan for the Red-cockaded Woodpecker. U.S. Fish Wildl. Serv., Atlanta, GA. 
James, F. C. 1995. The status of the Red-cockaded Woodpecker in 1990 and the prospect for recovery. Pp 349-351 in Kulhavy, D. L., R. G. Hooper, and R. Costa, eds. Red-cockaded Woodpecker: recovery, ecology, and management. Center for Applied Studies in Forestry, Stephen F. Austin State University, Nacogdoches, TX.

James, F. C., C. A. Hess, and D. Kufrin. 1997. Species-centered environmental analysis: indirect effects of fire history on Red-cockaded Woodpeckers. Ecological Applications 7:118-129.

James, F. C., C. A. Hess, and B.C. Kicklignter. 2001. Ecosystem management and the niche gestalt of the Red-cockaded Woodpecker in long-leaf pine forests. Ecological Applications 11:854-870

Jepsen, J.R., S. Stoyanov, M. Unger, J. Clausen, and H.E. Christensen. 1977. Cutting fluids and their effects on the skin of mice. Acta. Pathol. Microbiol. Scand. Sect. A. 85:731-738.

Katz, S., A. Snelson, R. Butler, R. Farlow, R. Welker, and S. Mainer. 1980. Physical and chemical characterization of military smokes, Part 2: Fog oils and oil fogs. Final Report. DAMD1778-C-8085. ADA093205. U.S. Army Medical Bioengineering Research and Development Laboratory, Fort Detrick, MD.

Kopischke, E. D. 1972. The effect of 2,4-D and diesel fuel on egg hatchability. Jour. Wildl. Mgmt. 36:1353-1356.

Kulhavy, D. L., R. G. Hooper, and R. Costa, eds. 1995. Red-cockaded Woodpecker: recovery, ecology, and management. Center for Applied Studies in Forestry, Stephen F. Austin State University, Nacogdoches, Texas, USA.

LaBranche, M.S., J.R. Walters, and K.S. Laves. 1994. Double brooding in Red-cockaded Woodpeckers. Wilson Bull. 106:403-408.

LaPoint, T.W., M. Simini, J.D. Florian, Jr., T.K. Warren, K.R. Dixon, R.S. Mellott, R.S. Wentsel, and R.T. Checkai. 1995. Procedural guidelines for ecological risk assessments at U.S. Army sites. Vol. II - Research and biomonitoring methods for the characterization of ecological effects. ERDEC-TR-221. Edgewood Research, Development and Engineering Center, U.S. Army Chemical and Biological Defense Command, Aberdeen Proving Ground, MD.

Lennartz, M. R., and V. G. Henry. 1985. Endangered species recovery plan. Red-cockaded Woodpecker Picoides borealis. U. S. Fish Wildl. Serv., Atlanta, GA.

Lennartz, M.R., H.A. Knight, J.P. McClure, and V.A. Rudis. 1983a. Status of Red-cockaded Woodpecker nesting habitat in the south. Pp. 13-19 in D.A. Wood, ed. Red-cockaded Woodpecker symposium II. Florida Game and Freshwater Fish Commission, Tallahassee, FL.

Lennartz, M.R., P. H. Geissler, R. F. Harlow, R. C. Long, K. M. Chitwood, and J. A. Jackson. 1983b. Status of the Red-cockaded Woodpecker on federal lands in the south. Pp. 7-12 in D. A. Wood, ed. Red-cockaded Woodpecker symposium II. Florida Game Fresh Water Fish Commission, Tallahassee, FL. 
Levey, D.J. and W.H. Karasov. 1989. Digestive responses of temperate birds switched to fruit or insect diets. Auk 106:675-686.

Ligon, J.D. 1968. Sexual differences in foraging behavior in two species of Dendrocopus woodpeckers. Auk 85:203-215.

Ligon, J. D. 1970. Behavior and breeding biology of the Red-cockaded Woodpecker. Auk 87: 255278.

Ligon, J.D. 1971. Some factors influencing numbers of the Red-cockaded Woodpecker. Pp. 30-43 in R.L. Thompson, ed. The ecology and management of the Red-cockaded Woodpecker. U.S. Dept. Interior, Tall Timbers Research Station, Tallahassee, FL.

Ligon, J.D., P.B. Stacey, R.N. Conner, C.E. Bock, and C.S. Adkisson. 1986. Report of the American Ornithologists' Union Committee for the Conservation of the Red-cockaded Woodpecker. Auk. 103: 848-855.

Ligon, J.D., W.W. Baker, R. N. Conner, J.A. Jackson, F.C. James, D.C. Rudolph, P.B. Stacey, and J.R. Walters. 1991. The conservation crisis - the Red-cockaded Woodpecker: on the road to oblivion? Auk 108:200-213.

Lilegren, J.C., W.E. Dunn, and G. E. Devaull. 1988. Field study of fog oil smokes. U.S. Army Research and Development Command, Fort Detrick, MD. ADA205334.

Lilegren, J.C., W.E. Dunn, and G. E. Devaull. 1989. The Atterbury-87 field study of smoke dispersion and a new stochastic dispersion model. Final Report. U.S. Army Research and Development Command, Fort Detrick, MD. ADA212983.

Liss-Suter, D., and J.E. Villaume. 1978. Environmental aspects of diesel fuels and fog oils SFG No. 1 and SGF No. 2 and smoke screens generated from them. A literature reviewproblem definition studies on selected toxic chemicals, Vol 8, ADA056021. Franklin Institute Research Laboratories.

Lushbaugh, C.C., J.W. Green, and C.E. Redemann. 1950. Effects of prolonged inhalation of oil fogs on experimental animals. Archive Industrial Hygiene and Occupational Medicine 1:237-247.

McEwan, E. H., N. Aitchison, and P. E. Whitehead. 1974. Energy metabolism of oiled muskrats. Canadian Journal of Zoology. 52: 1057-1062.

McMurry, S. T., T. W. LaPoint, and K. D. Reynolds. 1997. Fog oil deposition during a training exercise on Fort McClellan, Al. Unpublished report to USCERL.

Macko, S.A., and S.M. King. 1980. Weathered oil: effect on hatchability of heron and gull eggs. Bulletin of Environmental Contamination and Toxicology 25:316-320.

Martin, W. H., and S. C. Boyce. 1993. Introduction: the southeastern setting. Pages 1-46 in W. H. Martin, S. C. Boyce, and A. C. Echternacht, eds. Biodiversity of the southeastern United States: lowland terrestrial communities. John Wiley, New York, NY. 
Masters, R.E., J.E. Skeen, and J. Whitehead. 1995. Preliminary fire history of McCurtain County Wilderness Area and implications for Red-cockaded Woodpecker management. Pp. 290302 in D.L. Kulhavy, R. G. Hooper, and R. Costa, eds. Red-cockaded Woodpecker: recovery, ecology, and management. Center for Applied Studies in Forestry, Stephen F. Austin State University, Nacogdoches, TX.

Mayhew, D. A., S. H. Smith, G. L. Doyle, J. C. Kreuger, and K. A. Mellon. 1985. Dermal, eye, and oral toxicologic evaluations of brass powder, fog oil, diesel fuel and their mixtures. ADA172-198, U.S. Army Medical Research and Development Command, Fort Detrick, Frederick, MD.

Means, D. B., and G. Grow. 1985. The endangered longleaf community. In ENFO Report. Winter Park: Florida Conservation Foundation, pp. 1-12.

Melton, R. H., L. A. Jetté, T. J. Hayden, and T. A. Beaty. 2001. Population viability of avian endangered species: the PVAvES program. U.S. Army Construction Engineering Research Laboratory Technical Report ERDC/CERL TR-01-7.

Menzie, C., M.H. Henning, J. Cura, K. Finkelstein, J. Gentile, J. Maughan, D. Mitchell, S. Petron, B. Potocki, S. Svirsky, and P. Tyler. 1996. Special report on the Massachusetts weight-ofevidence workgroup: a weight of evidence approach for evaluating ecological risks. Human Ecol. Risk Assess 2:277-304.

Migratory Bird Treat Act. 16 USC 703-712.

Military Specification (MILSPEC). 1998. Performance Specification - Fog Oil. MIL-PRF-1270E. U.S. Army Tank - Automotive and Armaments Command, Warren, MI.

Muhly, R.L. 1983. Programmatic life cycle environmental assessment for smoke/obscurants: fog oil, diesel fuels and polyethylene glycol (PEG 200). Chemical Research and Development Center (CRDC), Aberdeen Proving Ground, MD.

National Contingency Plan. 42 USC 9605.

National Environmental Policy Act. 42 USC 4321 et seq. 40 CFR 1500-1508.

National Research Council. 1997. Toxicity of military smokes and obscurants. Vol. 1. Fog-oil smoke. National Academy Press, Washington, D.C.

Nesbitt, S. A., D. T. Gilbert, and D. B. Barbour. 1978. Red-cockaded Woodpecker fall movements in a Florida flatwoods community. Auk 95: 145-151.

Nesbitt, S. A., A. E. Jerauld, and B. A. Harris. 1983. Red-cockaded Woodpecker summer range sizes in southwest Florida. Pp., 68-71 in D.A. Wood, ed. Red-cockaded Woodpecker symposium II. Florida Game and Fresh Water Fish Commission, Tallahassee, FL.

Norton, S. B., D. J. Rodier, J. H. Gentile, W. H. Van der Schalie, W. P. Wood, and M. W. Slimak. 1993. A framework for ecological risk assessment at the EPA. in Conference on the risk assessment paradigm after ten years. 
Outcalt, K.W., and R.M. Sheffield. 1996. The longleaf pine forest: trends and current conditions. SRS-RB-9. U.S. Forest Service Resource Bulletin.

Palmer, W.G. 1990. Exposure standard for fog oil. Technical Report 9010. U.S. Army Medical Bioengineering Research and Development Laboratory, Fort Detrick, Maryland.

Pastorok, R.A., S.M. Bartell, S. Ferson, and L.R. Ginzberg, eds. 2002. Ecological modeling in risk assessment. Lewis Publishers, Boca Raton, FL.

Peakall, D.B., J. Tremblay, W.B. Kinter, and D.S. Miller. 1981. Endocrine dysfunction in seabirds caused by ingested oil. Environ. Res. 24:6-14.

Peakall, D.B. D.J. Hallett, J.R. Bend, G.L. Fourman, and D.S. Miller. 1982. Toxicity of Prudehoe Bay crude oil and its aromatic fractions to nestling herring gulls. Environ. Res. 27:206215.

Phalen, R.F. 1984. Inhalation studies: foundation and techniques. CRC Press, Inc., Boca Raton, FL.

Platt, W. J., G. W. Evans, and S. L. Rathbun. 1988a. The population dynamics of a long-lived conifer (Pinus palustris). American Naturalist 131:491-525.

Platt, W. J., G. W. Evans, and M. M. Davis. 1988b. Effects of fire season on flowering of forbs and shrubs in longleaf pine forests. Oecologia 76:353-363.

Policastro, J.J., D.M. Maloney, W.E. Dunn, J.C. Liljegren, and G.E. DeVaull. 1989. Evaluation of atmospheric dispersion models for fog-oil smoke dispersion. U.S. Army Medical Research and Development Command, Fort Detrick, MD.

Porter, M. L. 1985. Foraging behavior of Red-cockaded Woodpeckers: an evaluation of research methodologies. Jour. Wildl. Mgmt. 49: 505-507.

Porter, M. L., and R. F. Labisky. 1986. Home range and foraging habitat of Red-cockaded Woodpeckers in northern Florida. Jour.Wildl. Mgmt. 50:239-247.

Poston, T.M., K.M. McFadden, R.M. Bean, M.L. Clark, B.L. Thomas, B.W. Killand, L.A. Prohammer, and D.R. Kalkwarf. 1986. Acute toxicity of smoke screen materials to aquatic organisms, white phosphorus-felt, red phosphorus-butyl rubber and SGF No. 2 fog oil. ADA 16790. Supported by U.S. Army Medical Research and Development Command, Fort Detrick, MD. Pacific Northwest Laboratory.

Poston, T.M., R.M. Bean, D.R. Kalkwarf, B.L. Thomas, M.L. Clark, and B.W. Killand. 1988. Photooxidation products of smoke generator fuel (SGF) No. 2 fog oil and toxicity to Hyallela azteca. Environmental Toxicology \& Chemistry 7:753-762.

Ralph, C.J., and J.M. Scott, eds. 1981. Estimating numbers of terrestrial birds. Stud. Avian Biol. 6.

Rand, G.M., and S.R. Petrocelli. 1985. Aquatic toxicology. Methods and applications. McGraw Hill. New York, NY. 
Ramey, P. 1980. Seasonal, sexual, and geographical variation in the foraging ecology of Redcockaded Woodpeckers. M.S. thesis, Mississippi State University, Jackson, MS.

Raymond, R.L., J.O. Hudson, and V.W. Jamison. 1976. Oil degradation in soils. Appl. Environ. Microbiol. 33:675-680.

Robbins, L.E., and R.L. Myers. 1992. Seasonal effects of prescribed burning in Florida: a review. Tall Timbers Research Station, Miscellaneous Publication No. 8, Tallahassee, FL.

Rocke, T.E., T.M. Yuill, and R.D. Hinsdill. 1984. Oil and related toxicant effects on mallard immune defenses. Environ. Res. 33:343-352.

Rocke, T. 1999. Oil. Pp. 309-315 in E.A. Ciganovich, ed. Field manual of wildlife diseases. Information and Technology Report 1999-01. U.S. Geological Survey, Washington, DC.

Roush, G.C., J.W. Meigs, J.A. Kelly, J.T. Flannery, and H. Burdo. 1980. Sinonasal cancer and occupation: A case-control study. Am. Jour. Epidemiol. 111:183-193.

Rudolph, D.C. and R.N. Conner. 1991. Cavity tree selection by Red-cockaded Woodpeckers in relation to tree age. Wilson Bull. 103:458-467.

Sample, B.E., T.L. Ashwood, B.A. Carrico, L.A. Kszos, N.S. Nazerias, T.L. Phipps, W.K. Roy, M.G. Ryon, E.M. Schilling, M. Smith, A.J. Stewart, G.W. Suter, L.F. Wicker, and K.A. Reinbold. 1997. Methods for field studies of effects of military smokes, obscurants, and riot-control agents on threatened and endangered species. Vol. 2: methods for assessing ecological risks. Technical Report 97/140. U.S. Army Construction Engineering Research Laboratory, Champaign, IL.

Schafer, E.W. 1972. The acute oral toxicity of 369 pesticidal and pharmaceutical and other chemicals to wild birds. Toxicology and Applied Pharmacology 21:315-330.

Schafer, E.E., Jr., R.B. Brunton, N.F. Lockyer, and J.W. DeGrazio. 1973. Comparative toxicity of seventeen pesticides to the Quelea, House Sparrow, and Red-winged Blackbird.

Toxicology and Applied Pharmacology 26:154-161.

Schafer, E.E., Jr., W.A. Bowles, and J. Hurlbut. 1983. The acute toxicity, repellency, and hazard potential of 998 chemicals to one or more species of wild and domestic birds. Arch. Environm. Contam. Toxicol. 12:355-382.

Schaffer, M.L. 1981. Minimum population sizes for species conservation. Bioscience 31:131-134.

Schaffer, M.L. 1987. Mimimum viable populations: coping with uncertainty. Pp. 69-86 in M.E. Soule, ed. Viable populations for conservation. Cambridge University Press, Cambridge, U.K.

Selgrade, M.K., G.E. Hatch, E.C. Grose, J.W. Illing, A.G. Stead, F.J. Miller, and J.A. Graham. 1987. Pulmonary effects due to short-term exposure to oil fog. Journal of Toxicology Environmental Health 21:173-185. 
Selgrade, M.K., G.E. Hatch, E.C. Grose, A.G. Stead, F.J. Miller, and J.A. Graham. 1990. Pulmonary effects due to subchronic exposure to oil fog. Toxicol. Indust. Health 6(1):123143.

Shinn, J.H., S.A. Martins, P.A. Cedarwall, and L.B. Gratt. 1985. Smokes and obscurants: a health and environmental effects data base assessment. A first order, environmental screening and ranking of Army smokes and obscurants. Phase I Report. U.S. Army Medical Research and Development Command, Fort Detrick, MD.

Shoshkes, M., W.G. Banfield, Jr., and S.J. Rosenbaum. 1950. Distribution, effect, and fate of oil aerosol particles retained in the lungs of mice. Arch. Ind. Hyg. Occup. Med. 1:20-35.

Sikes Act. 16 U.S.C. $670 a$ - et seq.

Simberloff, D. 1993. Species-area and fragmentation effects on old growth forests: prospects for long-leaf pine communities. Pp. 1-14 in S. M. Hermann, ed. The longleaf pine ecosystem: ecology, restoration, and management. Proceedings of the 18th Tall Timbers Fire Ecology Conference, Tall Timbers Research Station, Tallahassee, Fl.

Simini, M., R.T. Checkai, and M.E. Maly. 2000. Tri-service remedial project manager's handbook for ecological risk assessment. SFIM-AEC-ER-CR-200015. U.S. Army Environmental Center, Aberdeen Proving Ground, MD.

Smith, L. H., M. L. Daugherty, and J. G. Pruett. 1987. The toxicity of diesel fuels, and JP-8 aviation fuels in mammals and environmental species. Oak Ridge National Laboratory, Oak Ridge, TN.

Superfund Amendments and Reauthorization Act of 1986. The Superfund Amendments and Reauthorization Act (SARA) amended the Comprehensive Environmental Response, Compensation, and Liability Act (CERCLA) on October 17, 1986.

Suter, G.W. 1990. Endpoints for regional ecological risk assessments. Environmental Management. 14:9-23.

Suter, G.W., L.W. Barnthouse, S.M. Bartell, T. Mill, D. Mackay, and S. Paterson. 1993. Ecological risk assessment. Lewis Publishers, Boca Raton, FL.

Suter, G.W. II, K.A. Reinbold, W.H. Rose, M.K. Chawla. 2001. Military ecological risk assessment framework (MERAF) for assessment of risks of military training and testing to natural resources. U.S. Army Construction Engineering Research Laboratory, Champaign, IL.

Taylor, W.E., and R.G. Hooper. 1991. A modification of Copeyon's drilling technique for making artificial Red-cockaded Woodpecker cavities. USDA Forest Service General Technical Report SE-72.

Thompson, R. L., ed. 1971. The ecology and management of the Red-cockaded Woodpecker. U. S. Department of the Interior, Tall Timbers Research Station, Tallahassee, FL.

Toxic Substances Control Act. 15 USC 2601-2654. 40 CFR 761. 
Trivelpiece, W.Z., R.G. Butler, D.S. Miller, and D.B. Miller. 1984. Reduced survival of chicks of oil-dosed adult Leach's Storm-petrels. Condor 86:81-82.

U.S. Army. 1995. U.S. Army Regulation 200-3, Natural Resources - Land, Forest and Wildlife Management. Headquarters, U.S. Army, Washington, D.C., 28 February 1995.

U.S. Army. 1996a. Field Manual (FM) 3-50, Smoke Operations. Headquarters, Department of the Army, 11 September 1996.

U.S. Army. 1996b. 1996 Management guidelines for the Red-cockaded Woodpecker on Army installations. HQ Department of the Army, Washington, D.C. 30 October 1996.

U.S. Army. 1988. Army Regulation 200-2. Environmental Effects of Army Actions.

U.S. Environmental Protection Agency. 1992. Framework for ecological risk assessment. EPA/630/R-92/001. Risk Assessment Forum, Washington, D.C.

U.S. Environmental Protection Agency. 1993. Wildlife exposure handbook, Vol. 1. EPA 540/1-89002. Office of Research and Development, Washington, DC.

U.S. Environmental Protection Agency. 1997a. Ecological risk assessment guidance for superfund: process for designing and conducting ecological risk assessments. Interim Final, EPA 540-R-97-006. OSWER 9285.7-25; PB97-963211. Washington, DC.

U.S. Environmental Protection Agency. 1997b. Guiding principles for Monte Carlo analysis. EPA/630/R-97/001. Risk Assessment Forum, Washington, D.C.

U.S. Environmental Protection Agency. 1998. Guidelines for ecological risk assessment. EPA/630/R095/02F. Risk Assessment Forum, Washington, D.C.

U.S. Environmental Protection Agency. 1999. Issuance of final guidance: ecological risk assessment and risk management principles for superfund. OSWER Directive 9825.728P. Washington, D.C.

U.S. Environmental Protection Agency. 2003. Framework for cumulative risk assessment. EPA/630/P-02/001F. Risk Assessment Forum, Washington, D.C.

U.S. Forest Service. 1995. Final Environmental Impact Statement For the Management of the Red-cockaded Woodpecker and its Habitat on National Forests in the Southern Region. Management Bulletin R8-MB 73. USDA Forest Service, Atlanta GA.

U.S. Fish and Wildlife Service. 2003. Recovery Plan For the Red-cockaded Woodpecker (Picoides borealis): Second Revision. U.S. Fish and Wildlife Service, Atlanta, GA.

Verner, J. 1985. Assessment of counting techniques. Curr. Ornithol. 2:247-302.

Wagner, W.O., P.G. Wright, and H.E. Stokinger. 1964. Inhalation toxicology of oil mists. I. Chronic effects of white mineral oil. Journal of the American Industrial Hygiene Association 25:158-168. 
Walters, J.R. 1990. Red-cockaded woodpecker: A “primitive” cooperative breeder. Pp. 67-102 in P.B. Stacey and W. D. Koenig, eds. Cooperative breeding in birds: long term studies of ecology and behavior. Cambridge University Press, Cambridge, UK.

Walters, J.R. 1991. Application of ecological principles to the management of endangered species: the case of the Red-cockaded Woodpecker. Annual Review of Ecology and Systematics 22:505-523.

Walters, J.R., P.D. Doerr, and J.H. Carter III. 1988a. The cooperative breeding system of the Redcockaded Woodpecker. Ethology 78:275-305.

Walters, J.R., S.K. Hansen, J.H. Carter III, and P. D. Manor. 1988b. Long-distance dispersal of an adult Red-cockaded Woodpecker. Wilson Bulletin 100:496-499.

Walters, J.R., P.D. Doerr, and J.H. Carter III. 1992. Delayed dispersal and reproduction as a lifehistory tactic in cooperative breeders: Fitness calculations from Red-cockaded Woodpeckers. American Naturalist. 139:623-643.

Walters, J.R., S.J. Daniels, J.H. Carter, P.D. Doerr, K. Brust, and J.M. Mitchell. 2000a. Foraging habitat resources, preferences and fitness of Red-cockaded Woodpeckers in the North Carolina sandhills. Fort Bragg Project Final Report. Virginia Polytechnic Institute and State University, Blacksburg, VA., and North Carolina State University, Raleigh, NC.

Walters, J.R., S.J. Daniels, J.H. Carter, and P.D. Doerr. 2000b. Population viability analysis for Red-cockaded Woodpeckers using an individual based model. Ecological Applications 12:249-260.

Ware, S., C. Frost, and P.D. Doerr. 1993. Southern mixed hardwood forest: the former longleaf pine forest. Pages 447-493 in W. H. Martin, S. C. Boyce, and A. C. Echternacht, eds. Biodiversity of the southeastern United States: lowland terrestrial communities. John Wiley, New York, NY.

Watson, J.C., R.G. Hooper, D.L. Carlson, W.E. Taylor, and T.C. Milling. 1995. Restoration of the Red-cockaded Woodpecker population on the Francis Marion National Forest; three years post-Hugo. Pp. 172-182 in Kulhavy, D. L., R. G. Hooper, and R. Costa, eds. Red-cockaded Woodpecker: recovery, ecology, and management. Center for Applied Studies in Forestry, Stephen F. Austin State University, Nacogdoches, TX.

Wentsel, R.S., T.W. LaPoint, M.Simini, R.T. Checkai, D. Ludwig, and L. Brewer. 1994. Procedural guidelines for ecological risk assessments at U.S. Army sites. Vol. 1. ERDEC-TR-221. Edgewood Research, Development and Engineering Center, U.S. Army Chemical and Biological Defense Command, Aberdeen Proving Ground, MD.

White, D.H., K.A. King, and N.C. Coon. 1979. Effects of No. 2 fuel oil on hatchability of marine and estuarine bird eggs. Bulletin of Environmental Contamination and Toxicology 21:7-10.

Wood, D.A., ed. 1983. Red-cockaded Woodpecker symposium II. Florida Game and Freshwater Fish Commission, Tallahassee, FL.

Yanders, A.F., E.W. Novak, and W.R. Lower. 1985. Mutagenic testing of obscurant smokes. Environ. Mutagen. 7(3):60. 




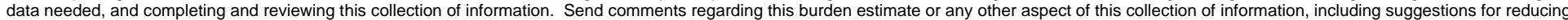

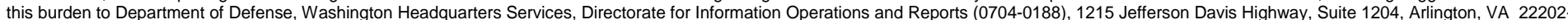


4302. Respondents should be aware that notwithstanding any other provision of law, no person shall be subi
rently valid OMB control number. PLEASE DO NOT RETURN YOUR FORM TO THE ABOVE ADDRESS.

\section{REPORT DATE (DD-MM-YYYY) 01-2005}

4. TITLE AND SUBTITLE

Ecological Risk Assessment of the Effects of Military Fog Oil Obscurant Smoke on the Redcockaded Woodpecker
3. DATES COVERED (From - To)

5a. CONTRACT NUMBER

5b. GRANT NUMBER

5c. PROGRAM ELEMENT NUMBER

5d. PROJECT NUMBER

SERDP

5e. TASK NUMBER

CS-766

5f. WORK UNIT NUMBER

CS-766

8. PERFORMING ORGANIZATION REPORT NUMBER

ERDC/CERL TR-05-4

U.S. Army Engineer Research and Development Center (ERDC)

Construction Engineering Research Laboratory (CERL)

PO Box 9005

Champaign, IL 61826-9005

\section{SPONSORING I MONITORING AGENCY NAME(S) AND ADDRESS(ES)}

Strategic Environmental Research and Development Program

901 N. Stuart St., Suite 303

Arlington, VA 22203-1821

10. SPONSOR/MONITOR'S ACRONYM(S)

Program Manager

11. SPONSOR/MONITOR'S REPORT NUMBER(S)

\section{DISTRIBUTION I AVAILABILITY STATEMENT}

Approved for public release; distribution is unlimited.

\section{SUPPLEMENTARY NOTES}

Copies are available from the National Technical Information Service, 5285 Port Royal Road, Springfield, VA 22161.

\section{ABSTRACT}

To satisfy its mission of wartime readiness, the U.S. Army relies on extensive troop training at military installations. These installations must comply with the mandates of Congressional directives and other regulations, including the Endangered Species Act (16 USC 1531-1544). Because the military is required to protect State and Federally listed threatened and endangered species on its lands, the Army and other military services must evaluate any activities that are potentially harmful to threatened and endangered species and their habitats. Toward that end, the Army has initiated studies to evaluate any potential impacts and effects of certain military-specific soldier training actions and activities on threatened and endangered species. Considerable study and management effort have been devoted to the red-cockaded woodpecker (Picoides borealis), in part because of its relatively widespread occurrence on installations. This report provides an assessment of the ecological risks that fog oil obscurant smoke training may pose to individual red-cockaded woodpeckers, red-cockaded woodpecker populations, and red-cockaded woodpecker habitat. The risks from military fog oil obscurants do not appear to be significant in field use.

\section{SUBJECT TERMS}

fog oil

smoke and obscurants

16. SECURITY CLASSIFICATION OF:

\section{a. REPORT}

Unclassified b. ABSTRACT

Unclassified red-cockaded woodpecker

threatened and endangered species c. THIS PAGE

Unclassified
17. LIMITATION OF ABSTRACT

SAR risk assessment military training
18. NUMBER OF PAGES

96 19a. NAME OF RESPONSIBLE PERSON Thomas Smith

19b. TELEPHONE NUMBER (include area code) (217) 352-6511 ext 5898 